\title{
Cochrane
}

Library

Cochrane Database of Systematic Reviews

\section{Continuation and maintenance treatments for depression in older people (Review)}

Wilkinson P, Izmeth Z

Wilkinson P, Izmeth Z.

Continuation and maintenance treatments for depression in older people.

Cochrane Database of Systematic Reviews 2016, Issue 9. Art. No.: CD006727. DOI: 10.1002/14651858.CD006727.pub3.

www.cochranelibrary.com 
TABLE OF CONTENTS

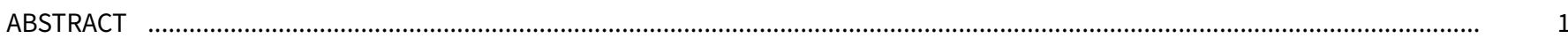

PLAIN LANGUAGE SUMMARY

SUMMARY OF FINDINGS

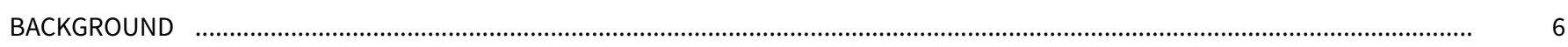

OBJECTIVES

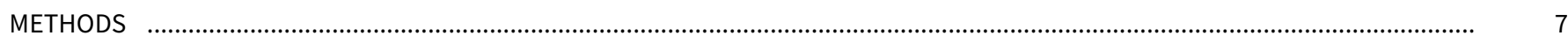

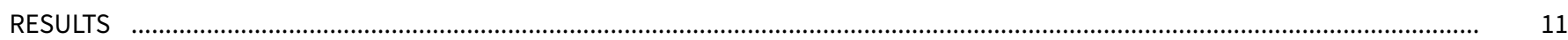

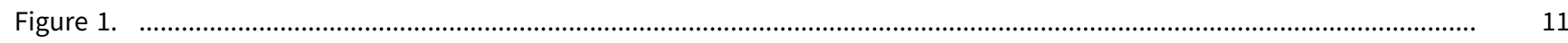

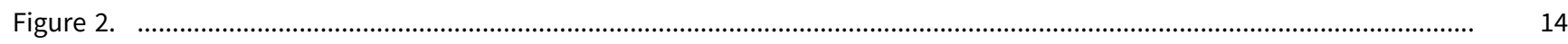

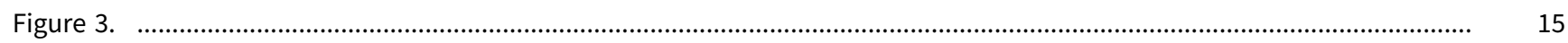

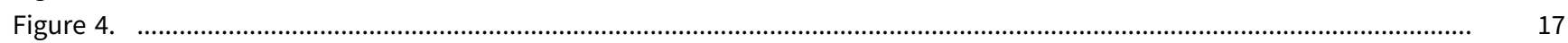

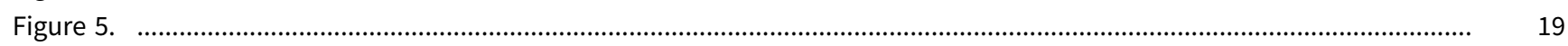

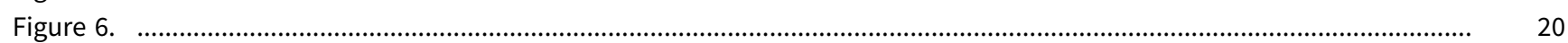

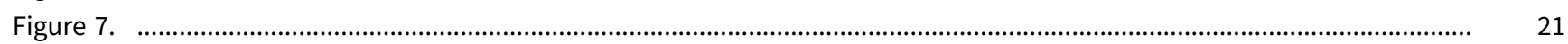

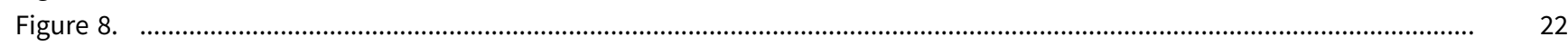

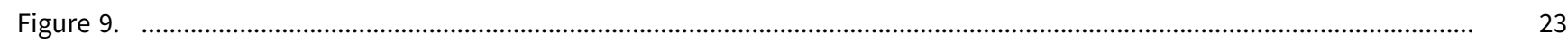

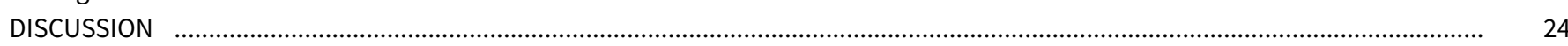

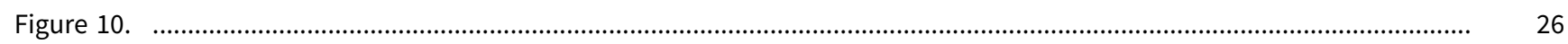

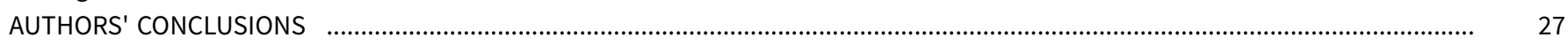

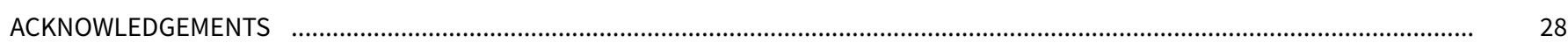

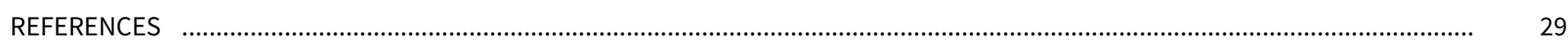

CHARACTERISTICS OF STUDIES

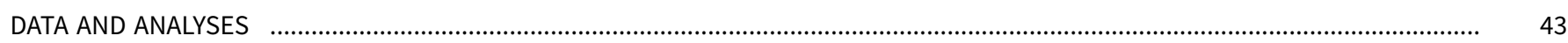

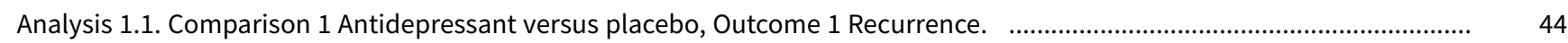

Analysis 1.2. Comparison 1 Antidepressant versus placebo, Outcome 2 Recurrence at 12 months (fixed-effect). ....................... 45

Analysis 1.3. Comparison 1 Antidepressant versus placebo, Outcome 3 Recurrence at 24 months (studies of tricyclic 45 antidepressants only).

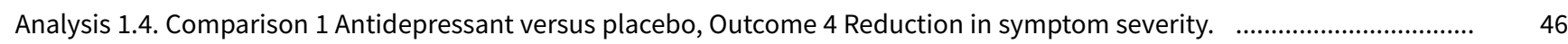

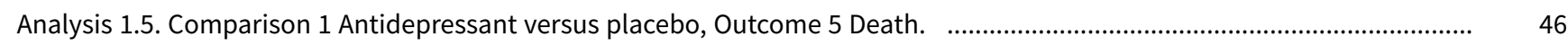

Analysis 1.6. Comparison 1 Antidepressant versus placebo, Outcome 6 Overall drop-out rates (excluding deaths). ...................

Analysis 1.7. Comparison 1 Antidepressant versus placebo, Outcome 7 Drop-outs due to adverse effects. ................................. 48

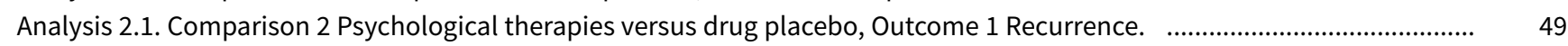

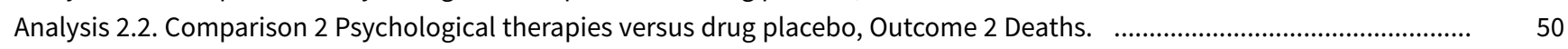

Analysis 2.3. Comparison 2 Psychological therapies versus drug placebo, Outcome 3 Overall drop-out rates (excluding 50 deaths).

Analysis 3.1. Comparison 3 Antidepressant/psychological therapies combination versus drug placebo, Outcome 1

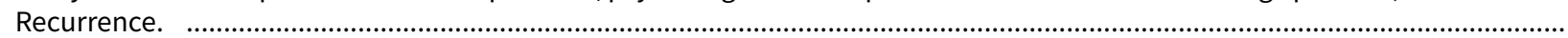

Analysis 3.2. Comparison 3 Antidepressant/psychological therapies combination versus drug placebo, Outcome 2 Death. ...... Analysis 3.3. Comparison 3 Antidepressant/psychological therapies combination versus drug placebo, Outcome 3 Overall dropout rates (excluding deaths).

Analysis 4.1. Comparison 4 Antidepressant versus psychological therapies, Outcome 1 Recurrence.

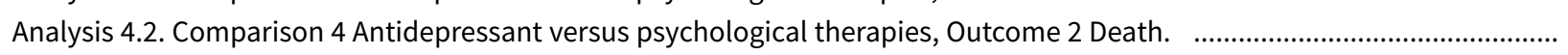

Analysis 4.3. Comparison 4 Antidepressant versus psychological therapies, Outcome 3 Overall drop-out rates (excluding deaths).

Analysis 5.1. Comparison 5 Antidepressant/psychological therapies combination versus antidepressant alone, Outcome 1 Recurrence.

Analysis 5.2. Comparison 5 Antidepressant/psychological therapies combination versus antidepressant alone, Outcome 2 Death.

Analysis 5.3. Comparison 5 Antidepressant/psychological therapies combination versus antidepressant alone, Outcome 3 Overall drop-out rates (excluding deaths).

Analysis 6.1. Comparison 6 Antidepressant/psychological therapies combination versus psychological therapies alone, Outcome 1 Recurrence. 
Analysis 6.2. Comparison 6 Antidepressant/psychological therapies combination versus psychological therapies alone, Outcome 2 Deaths.

Analysis 6.3. Comparison 6 Antidepressant/psychological therapies combination versus psychological therapies alone, Outcome 3 Overall drop-out rates (excluding deaths).

APPENDICES

FEEDBACK

WHAT'S NEW

HISTORY 
[Intervention Review]

\section{Continuation and maintenance treatments for depression in older people}

Philip Wilkinson'1,2, Zehanah Izmeth³

1Department of Psychiatry, University of Oxford, Warneford Hospital, Oxford, UK. 2Oxford Health NHS Foundation Trust, Fulbrook Centre, Churchill Hospital, Oxford, UK. ${ }^{3}$ Oxford University Hospitals NHS Foundation Trust, John Radcliffe Hospital, Oxford, UK

Contact: Philip Wilkinson, Department of Psychiatry, University of Oxford, Warneford Hospital, Oxford, OX3 7JX, UK. philip.wilkinson@psych.ox.ac.uk.

Editorial group: Cochrane Common Mental Disorders Group.

Publication status and date: New search for studies and content updated (no change to conclusions), published in Issue 9, 2016.

Citation: Wilkinson P, Izmeth Z. Continuation and maintenance treatments for depression in older people. Cochrane Database of Systematic Reviews 2016, Issue 9. Art. No.: CD006727. DOI: 10.1002/14651858.CD006727.pub3.

Copyright (c) 2016 The Cochrane Collaboration. Published by John Wiley \& Sons, Ltd.

\section{A B S T R A C T}

\section{Background}

Depressive illness is common in old age. Prevalence in the community of case level depression is around $15 \%$ and milder forms of depression are more common. It causes significant distress and disability. The number of people over the age of 60 years is expected to double by 2050 and so interventions for this often long-term and recurrent condition are increasingly important. The causes of late-life depression differ from depression in younger adults and so it is appropriate to study it separately.

This is an update of a Cochrane review first published in 2012.

\section{Objectives}

To examine the efficacy of antidepressants and psychological therapies in preventing the relapse and recurrence of depression in older people.

\section{Search methods}

We performed a search of the Cochrane Common Mental Disorders Group's specialised register (the CCMDCTR) to 13 July 2015. The CCMDCTR includes relevant randomised controlled trials (RCTs) from the following bibliographic databases: The Cochrane Library (all years), MEDLINE (1950 to date), EMBASE (1974 to date), and PsycINFO (1967 to date). We also conducted a cited reference search on 13 July 2015 of the Web of Science for citations of primary reports of included studies.

\section{Selection criteria}

Both review authors independently selected studies. We included RCTs involving people aged 60 years and over successfully treated for an episode of depression and randomised to receive continuation and maintenance treatment with antidepressants, psychological therapies, or a combination.

\section{Data collection and analysis}

Two review authors independently extracted data. The primary outcome for benefit was recurrence rate of depression (reaching a cut-off on any depression rating scale) at 12 months and the primary outcome for harm was drop-outs at 12 months. Secondary outcomes included relapse/recurrence rates at other time points, global impression of change, social functioning, and deaths. We performed meta-analysis using risk ratio (RR) for dichotomous outcomes and mean difference (MD) for continuous outcomes, with $95 \%$ confidence intervals (CI). 


\section{Main results}

This update identified no further trials. Seven studies from the previous review met the inclusion criteria (803 participants). Six compared antidepressant medication with placebo; two involved psychological therapies. There was marked heterogeneity between the studies.

Comparing antidepressants with placebo on the primary outcome for benefit, there was a statistically significant difference favouring antidepressants in reducing recurrence compared with placebo at 12 months with a GRADE rating of low for quality of evidence (three RCTs, $\mathrm{n}=247$, RR $0.67,95 \% \mathrm{Cl} 0.54$ to 0.82 ; number needed to treat for an additional beneficial outcome (NNTB) 5). Comparing antidepressants with placebo on the primary outcome for harms, there was no difference in drop-out rates at 12 months' follow-up, with a GRADE rating of low.

There was no significant difference between psychological treatment and antidepressant in recurrence rates at 12 months (one RCT, $\mathrm{n}=$ 53) or between combination treatment and antidepressant alone at 12 months.

\section{Authors' conclusions}

This updated Cochrane review supports the findings of the original 2012 review. The long-term benefits and harm of continuing antidepressant medication in the prevention of recurrence of depression in older people are not clear and no firm treatment recommendations can be made on the basis of this review. Continuing antidepressant medication for 12 months appears to be helpful with no increased harms; however, this was based on only three small studies, relatively few participants, use of a range of antidepressant classes, and clinically heterogeneous populations. Comparisons at other time points did not reach statistical significance.

Data on psychological therapies and combined treatments were too limited to draw any conclusions on benefits and harms.

The quality of the evidence used in reaching these conclusions was low and the review does not, therefore, offer clear guidance to clinicians and patients on best practice and matching interventions to particular patient characteristics.

Of note, we identified no new studies that evaluated pharmacological or psychological interventions in the continuation and maintenance treatment of depression in older people. We are aware of studies conducted since the previous review that included both older people and adults under the age of 65 years, but these fall outside of the remit of this review. We believe that there remains a need for studies solely recruiting older people, particularly the 'older old' with comorbid medical problems. However, these studies are likely to be challenging to conduct and may not, so far, have been prioritised by funders.

\section{PLAIN LANGUAGE SUMMARY}

\section{Long-term treatment for depression in older people}

This is an update of a Cochrane review first published in 2012.

\section{Why is this review important?}

Depression is a common problem among older people and causes considerable disability. Even after successful treatment, it frequently recurs.

The causes of depression in older people are more diverse than in younger adults and, as the number of older people is steadily increasing, it is important to study the effects of treatments specifically in older adults. Treatments commonly used are antidepressant drugs and psychological treatments (talking treatments).

\section{Who will be interested in this review?}

- People with depression, friends, families, and carers.

- General practitioners, psychiatrists, clinical psychologists, psychological therapists, and pharmacists.

- Professionals working in older-adult mental health services.

- Professionals working in Improving Access to Psychological Therapies services in the UK.

\section{What questions does this review aim to answer?}

In people aged 60 years and over who have recovered from depression while taking antidepressant medication:

- Is receiving continued antidepressant medicine, psychological treatment, or a combination of the two more effective in preventing recurrence of depression than receiving placebo (a pretend treatment) or any of the other treatments?

- Is receiving continued antidepressant medicine, psychological treatment, or a combination of the two more harmful than receiving placebo or any of the other treatments? 


\section{Which studies does the review include?}

We searched medical databases to find all relevant studies completed up to 13 July 2015. The studies had to compare antidepressant treatment, psychological treatment, or a combination of the two, with placebo or the other treatments for preventing recurrence of depression in people aged 60 years and over. We included seven studies, involving 803 people.

Six studies compared antidepressant medicine with placebo. Only two of the studies involved psychological treatments. The studies varied in how they were conducted, numbers of participants, and types of participants.

\section{What does the evidence from the review tell us?}

Remaining on antidepressant medicines for one year appears to reduce the risk of depression returning from $61 \%$ to $42 \%$ but the benefits at other time intervals could not be determined. Antidepressant treatment appeared to be no more harmful than placebo as measured by number of participants dropping out of trials. The benefits of psychological therapies were not clear, due to the small number of studies. The quality of evidence was low.

The majority of participants in the studies were women. Few were over 75 years of age. Most had received treatment for their original depressive illness as outpatients, indicating less severe depression.

Antidepressant medicines used were both older type antidepressants (called tricyclics) and newer type (called selective serotonin reuptake inhibitors). Psychological treatments were interpersonal therapy, which addresses obstacles in relationships, and cognitive behavioural therapy, which addresses inactivity and self-defeating thought patterns.

\section{What should happen next?}

This review provides limited evidence that continuing antidepressant medication for one year can reduce the risk of depression recurring with no additional harm. However, it cannot be used to make firm recommendations due to the limited number and small size of studies involved. Limitations in the design and reporting of these studies may also make the results unrepresentative. Similarly, no firm conclusions can be drawn about psychological treatments or combinations of antidepressant and psychological treatments in preventing recurrence.

Further, larger, trials are required to clarify any benefits of antidepressant and psychological treatments. These trials should include more people aged over 75 , and people with other problems typical of people treated in routine clinical services, such long-term physical illness and mild memory problems. 
SUMMARY OF FINDINGS

\section{Summary of findings for the main comparison. Antidepressant medication compared with placebo at 12 months' follow-up}

Antidepressant medication compared with placebo at 12 months' follow-up

Patient or population: older people in remission from depression

Setting: mixed

Intervention: antidepressant

Comparison: placebo

\begin{tabular}{|c|c|c|c|c|c|c|}
\hline \multirow[t]{2}{*}{ Outcomes } & \multicolumn{2}{|c|}{ Anticipated absolute effects* $(95 \% \mathrm{Cl})$} & \multirow{2}{*}{$\begin{array}{l}\text { Relative effect } \\
(95 \% \mathrm{Cl})\end{array}$} & \multirow{2}{*}{$\begin{array}{l}\text { No of partici- } \\
\text { pants } \\
\text { (studies) }\end{array}$} & \multirow{2}{*}{$\begin{array}{l}\text { Quality of the } \\
\text { evidence } \\
\text { (GRADE) }\end{array}$} & \multirow[t]{2}{*}{ Comments } \\
\hline & $\begin{array}{l}\text { Risk with place- } \\
\text { bo }\end{array}$ & $\begin{array}{l}\text { Risk with antidepres- } \\
\text { sant }\end{array}$ & & & & \\
\hline \multirow{4}{*}{$\begin{array}{l}\text { Recurrence at } \\
12 \text { months }\end{array}$} & \multicolumn{2}{|l|}{ Study population } & \multirow{4}{*}{$\begin{array}{l}\text { RR } 0.67 \\
\text { (0.55 to } 0.82)\end{array}$} & \multirow{4}{*}{$\begin{array}{l}247 \\
\text { (3 RCTs) }\end{array}$} & \multirow{4}{*}{$\begin{array}{l}\oplus \oplus \ominus \ominus \\
\text { Low }^{1}\end{array}$} & \multirow{4}{*}{$\begin{array}{l}2 \text { trials used TCAs (OADIG 1993; Reynolds } \\
\text { 1999a); } 1 \text { used an SSRI (Klysner 2002). Trials } \\
\text { varied in setting, mean age, cut-off for remis- } \\
\text { sion, and length of remission before randomi- } \\
\text { sation }\end{array}$} \\
\hline & 730 per 1000 & $\begin{array}{l}489 \text { per } 1000 \\
\text { (402 to } 599)\end{array}$ & & & & \\
\hline & \multicolumn{2}{|l|}{ Moderate } & & & & \\
\hline & 759 per 1000 & $\begin{array}{l}508 \text { per } 1000 \\
\text { (417 to } 622)\end{array}$ & & & & \\
\hline \multirow{4}{*}{$\begin{array}{l}\text { Overall drop- } \\
\text { out rates (ex- } \\
\text { cluding deaths) } \\
\text { at } 12 \text { months }\end{array}$} & \multicolumn{2}{|l|}{ Study population } & \multirow{4}{*}{$\begin{array}{l}\text { RR } 1.48 \\
\text { (0.75 to } 2.92 \text { ) }\end{array}$} & \multirow{4}{*}{$\begin{array}{l}121 \\
(1 \mathrm{RCT})\end{array}$} & \multirow{4}{*}{$\begin{array}{l}\oplus \oplus \odot \odot \\
\text { Low }^{2}\end{array}$} & \multirow{4}{*}{$\begin{array}{l}\text { Only } 1 \text { trial reporting drop-outs at } 12 \text { months } \\
\text { (Klysner 2002). Reynolds 1999b reported } \\
\text { drop-outs but not timing }\end{array}$} \\
\hline & 180 per 1000 & $\begin{array}{l}267 \text { per } 1000 \\
\text { (135 to } 527)\end{array}$ & & & & \\
\hline & \multicolumn{2}{|l|}{ Moderate } & & & & \\
\hline & 180 per 1000 & $\begin{array}{l}267 \text { per } 1000 \\
\text { (135 to } 526)\end{array}$ & & & & \\
\hline
\end{tabular}

*The risk in the intervention group (and its 95\% confidence interval) is based on the assumed risk in the comparison group and the relative effect of the intervention (and its $95 \% \mathrm{Cl}$ ).

CI: confidence interval; RCT: randomised controlled trial; RR: risk ratio; SSRI: selective serotonin reuptake inhibitor; TCA: tricyclic antidepressant.

GRADE Working Group grades of evidence

High quality: We are very confident that the true effect lies close to that of the estimate of the effect

Moderate quality: We are moderately confident in the effect estimate: The true effect is likely to be close to the estimate of the effect, but there is a possibility that it is substantially different 


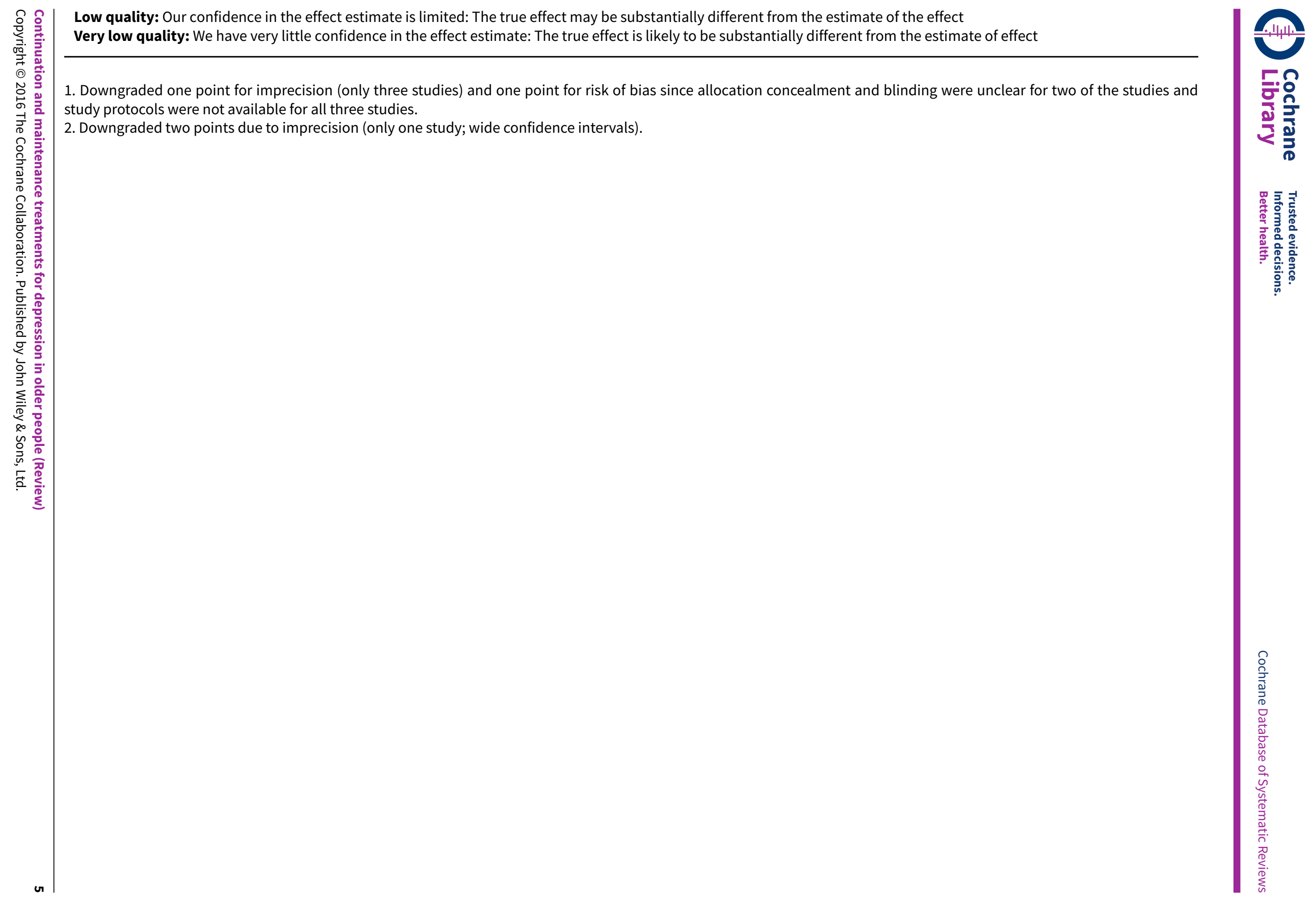




\section{B A C K G R O U N D}

\section{Description of the condition}

Depression is among the most common of psychiatric disorders. It remains common in old age, occurring more frequently than dementia. Several community studies have shown a prevalence in the population over 64 years of age of around $15 \%$ of case level depression (i.e. that which a psychiatrist would consider in need of treatment) (Evans 2003). Milder forms of depression are likely to be more common and still account for significant suffering. Very old people are particularly prone to developing depression (Blazer 2000).

Depression is important because it causes significant distress and is associated with a great deal of disability in older people. Chronic depression is associated with over five times the odds of worsening disability over three years (Lenze 2005). The number of people over the age of 60 years is expected to double by 2050 and so interventions for long-term and recurrent conditions such as depression will become more important in maintaining healthy functioning (WHO 2015).

The causes of late-life depression, especially in cases with onset after 50 years of age, are thought to differ from depression in younger adults. They include neuropsychological abnormalities such as executive dysfunction (Gansler 2015), and physical illnesses such as cardiovascular disease, diabetes, and stroke (Valkonova 2013). This makes it appropriate to study late-life depression separately from depression in younger adults. It also means that it would be useful to establish if there is a difference in treatment response between late-onset and early-onset illness.

\section{Description of the intervention}

A range of antidepressant medications are used to treat older people. They include older agents such as tricyclic antidepressants (TCAs) and monoamine oxidase inhibitors (MAOIs), as well as newer agents such as selective serotonin reuptake inhibitors (SSRIs), serotonin-noradrenaline reuptake inhibitors (SNRIs), noradrenergic and specific serotonergic antidepressants (NASSAs), and reversible inhibitors of monoamine oxidase A (RIMAs) (AbouSaleh 2010). TCAs include imipramine and amitriptyline; SSRIs include sertraline and citalopram; SNRIs include venlafaxine; NASSAs include mirtazapine; and RIMAs include moclobemide.

Several short-term psychological therapies are used to treat older people with depression, including behavioural therapy, cognitive behavioural therapy (CBT), interpersonal therapy (IPT), and psychodynamic therapy. Behavioural therapy uses an operant conditioning model to reintroduce positive reinforcement, to reduce the time spent on negative events, and to overcome avoidance through behavioural activation. CBT begins with behavioural activation but also tackles the thought patterns that maintain inactivity and depressed mood by using direct verbal challenging and behavioural experiments. Problem-solving therapy teaches a structured approach to tackling inactivity, lack of pleasurable activities, and dealing with psychosocial problems. Interpersonal psychotherapy focuses on the interplay between depression and interpersonal relationships. It uses patient education and a number of strategies such as role play and communication analysis to tackle obstacles in relationships (Wilkinson 2010). Mindfulness-based cognitive therapy combines teaching on the role of thought patterns in depression with training in meditation techniques (Segal 2002). Psychodynamic psychotherapy focusses on the person's life review, losses experienced, attitudes to ageing, and the relationship with the therapist (Garner 2008). Counselling, such as Rogerian personcentred therapy, is an unstructured psychological therapy with an emphasis on warmth, genuineness, and empathy in the therapeutic relationship (Zarit 1998).

There is a small number of trials that support the efficacy of psychological therapies as acute phase interventions with older people, but fewer than with younger people (NICE 2010). One Cochrane review found cognitive behavioural interventions to be superior to waiting list control in five trials, but the authors suggested caution in generalising this finding to clinical populations due to the small number of participants (Wilson 2008). A more recent trial with 204 participants in primary care showed benefits of combining CBT with treatment as usual (including antidepressants) as compared with treatment as usual and treatment as usual plus a talking control (Serfaty 2009).

\section{How the intervention might work}

Older adults with depression are frequently prescribed antidepressants (Percudani 2005), and the short-term response to treatment is generally good (Katona 2002). Antidepressant action is thought to result from regulation of the monoamine neurotransmitter changes that occur in depressive illness. The rationale for continuing antidepressant treatment after clinical recovery, therefore, is that it will sustain regulation of monoamine activity.

Individual CBT is as effective as antidepressants in reducing symptoms of depression and produces more enduring benefit than antidepressant treatment; it also appears to be better tolerated than antidepressants. Adding CBT to antidepressant treatment can also improve outcome in more severe depression and possibly in chronic depression (NICE 2010). People with residual symptoms of depression after treatment have a poorer prognosis and psychological therapies may have an important role in reducing relapse and recurrence rates in these people (Paykel 2005).

Interpersonal psychotherapy can be used as a short-term acute phase treatment of depression (usually up to 16 sessions) or as a maintenance treatment with sessions more widely spaced over a period of months. The use of maintenance treatment allows for a greater number of therapeutic foci to be addressed including the long-standing patterns of interpersonal behaviour that may contribute to recurrence (so-called interpersonal deficits) (Miller 2003).

Maintenance CBT involves helping the person to continue to identify and address the behavioural and cognitive patterns associated with depressive relapse (Wilkinson 2009). CBT can continue to have a positive effect after it is discontinued (Blackburn 1997), and, in younger adults, combining antidepressant medication and psychological therapies in the continuation phase produces better long-term results than antidepressants alone (Paykel 2005). Mindfulness-based cognitive therapy is an intervention partly derived from CBT that is used in the maintenance treatment of depression. It combines teaching in the cognitive model of depression with meditation-based exercises (Segal 2002) to help the individual to recognise when their mood 
is beginning to become low, and to develop the capacity to allow distressing mood, thoughts, and sensations to come and go without engaging with them.

Psychodynamic therapy for depression is based on a model of vulnerability arising from early life experiences and disrupted childhood attachment. The relationship with the therapist is of key importance in identifying and fostering insight into psychological defence mechanisms. Psychodynamic therapy with the older person may help to develop a long-term sense of contentment and acceptance of the losses and changes associated with ageing (Garner 2008).

As antidepressants and psychological therapies have different modes of action, combining them may produce greater benefits than either treatment alone. Psychological therapy may also include education on the benefits of antidepressant medication in order to foster treatment concordance.

\section{Why it is important to do this review}

This review adds to a programme of Cochrane reviews addressing the acute management of depression in older people with psychological therapies (Wilson 2008) and antidepressants (Mottram 2009).

The long-term prognosis of late-life depression is known to be poor, with around a quarter of people becoming depressed within two years of remission or recovery and a third experiencing one or more relapses after two years (Cole 1997). Therefore, it is important to identify treatments that will improve longer-term outcome (i.e. reduce rates of recurrence and relapse). In younger adults, continuing antidepressant medication after remission reduces the odds of relapse by $70 \%$ with effects lasting up to 36 months, as long as medication is continued (Geddes 2003).

Most previous reviews of trials with older adults have been narrative reviews and have focused on the acute treatment of depression (Areán 2007). None have included both antidepressant medication and psychological therapies. This review includes trials of antidepressant medication, psychological therapies, and combinations of the two in the continuation and maintenance phase treatment of depression in adults aged 60 years and over.

We anticipated that there would be few randomised controlled trials (RCTs) involving people aged 60 years and over. As many of these would be with small numbers of participants, a comprehensive review and meta-analysis was required. It was also likely that there would be high withdrawal rates through physical illness, adverse effects, and death and it was possible that drop-out rates would differ significantly between antidepressant treatment and psychological therapies. This review will help to identify the need for further studies.

\section{O B JE C T IVES}

To examine the efficacy of antidepressants and psychological therapies in preventing the relapse and recurrence of depression in older people.

\section{METHODS}

\section{Criteria for considering studies for this review}

\section{Types of studies}

The review included all randomised controlled trials (RCTs), published and unpublished, including cluster-randomised and cross-over trials.

\section{Types of participants}

Trial participants were aged 60 years or over, of either gender, who were in remission or who had recovered from a depressive episode diagnosed according to Diagnostic and Statistical Manual Criteria (DSM; APA 1994), International Classification of Diseases (ICD; WHO 1992), Research Diagnostic Criteria (RDC; Feighner 1972), Geriatric Mental State (GMS; Copeland 1976), or as defined by trialists. The review included participants treated in a range of settings (inpatients, outpatients, community, care homes) and people with comorbid physical illness. The review also included studies in which some participants were aged under 60 years provided that data from those aged 60 years and over were separately analysed. The review included trial participants with both lateonset depression (50 years or older) and early-onset (under 50 years). Trials were included in which all participants had already responded to acute treatment (i.e. all were in continuation and maintenance phases) and trials in which only some participants had already responded.

We excluded trials with participants experiencing bipolar disorder, dementia, and other severe mental disorders.

\section{Types of interventions}

\section{Experimental interventions}

Any antidepressant. There was no restriction on the dose of antidepressant treatment. All antidepressant drugs were eligible from the following classes.

- Tricyclic antidepressants (TCAs): amitriptyline, imipramine, trimipramine, doxepin, desipramine, protriptyline, nortriptyline, clomipramine, dothiepin, lofepramine.

- Selective serotonin reuptake inhibitors (SSRIs): zimelidine, fluvoxamine, fluoxetine, paroxetine, sertraline, citalopram, escitalopram.

- Serotonin-noradrenaline antidepressants (SNRIs): venlafaxine, milnacipram, duloxetine.

- Noradrenergic and specific serotonergic antidepressants (NASSAs): mirtazapine.

- Monoamine oxidase inhibitors (MAOIs): irreversible: phenelzine, tranylcypromine, isocarboxazid; reversible: brofaramine, moclobemide, tyrima.

- Other antidepressants: noradrenaline reuptake inhibitors (NARIs): reboxetine, atomoxetine; noradrenaline-dopamine reuptake inhibitors (NDRIs): amineptine, buproprion; serotonin antagonist and reuptake inhibitors (SARIs): trazodone; unclassified antidepressants: agomelatine, vilazodone; other heterocyclic antidepressants: mianserin, amoxapine, maprotiline.

Any psychological therapy. Any structured psychological therapy of any duration was eligible, including the following. 
- Behavioural therapy: activity scheduling, behaviour modification, psychoeducation.

- Cognitive behavioural therapy (CBT): problem-solving therapy, rational emotive therapy, self control.

- Third-wave CBTs: mindfulness, acceptance and commitment therapy, dialectical behaviour therapy.

- Integrative therapies: interpersonal therapy (IPT), cognitive analytical therapy.

- Psychodynamic therapies: brief psychological therapies, counter transference, psychoanalytic therapy.

- Humanistic therapies: existential therapy, experiential therapy.

We categorised counselling according to the psychological therapy approach used by counselling practitioners.

\section{Comparator interventions}

- Placebo

- Treatment as usual/waiting list control (provided these did not incorporate any of the excluded interventions).

- Antidepressants.

- Psychological therapies.

We excluded electroconvulsive therapy (ECT), antipsychotic medication, or lithium used as continuation or maintenance treatments.

We excluded psychological interventions, including systemic and family therapies, in which some recipients of therapy were not the index participant.

We excluded studies in which there was no randomisation to treatment in the continuation and maintenance phase, that is, those in which acute phase treatment was simply continued after remission.

For a list of main planned comparisons, see Data extraction and management.

\section{Types of outcome measures}

\section{Primary outcomes}

The primary outcome measure for benefit was recurrence rate of depression at 12 months' follow-up. We defined this as reaching a cut-off on depression rating scales such as the Beck Depression Inventory (Beck 1996), Hamilton Depression Rating Scale (HDRS; Hamilton 1960), Montgomery-Åsberg Depression Rating Scale (MADRS; Montgomery 1979), or any depression symptom rating scale used by study authors. We defined remission of a depressive illness as depressive symptoms dropping below case level and defined recovery as remission lasting for more than six months. Recurrence was return to case level symptoms during recovery (Frank 1991).

The primary outcome measure for harm was number of participants who had dropped out during the trial at 12 months as a proportion of the total number of randomised participants.

\section{Secondary outcomes}

Secondary outcomes for benefit were relapse and recurrence rates examined at six-monthly intervals over the follow-up period and at the point of final measurement (endpoint). We defined this as reaching a cut-off on depression rating scales such as the Beck Depression Inventory (Beck 1996), HDRS (Hamilton 1960), MADRS (Montgomery 1979), or any depression symptom rating scale used by study authors. We defined relapse as return to case level symptoms during remission and recurrence was return to case level symptoms during recovery (Frank 1991). We defined remission of a depressive illness as depressive symptoms dropping below case level and defined recovery as remission lasting for more than six months. We included long-term data after discontinuation of antidepressant medication if available.

Where data were available, we also included the following secondary outcomes.

- Global clinical impression by the clinician (Guy 1976).

- Global clinical impression by the participant.

- Social functioning measured using the Global Assessment of Function scores (Luborsky 1962), or another scale used by the authors.

- Quality of life measured using the 36-item Short Form (SF-36) (Ware 1993).

- Deaths.

\section{Acceptability}

Acceptability was measured through number of participants who dropped out due to drug-related adverse effects during the trial as a proportion of the total number of randomised participants (dropout rates due to drug-related adverse effects).

\section{Search methods for identification of studies}

The Cochrane Common Mental Disorders Group maintains a specialised register of randomized controlled trials, the CCMDCTR. This register contains over 40,000 reference records (reports of RCTs) for anxiety disorders, depression, bipolar disorder, eating disorders, self-harm and other mental disorders within the scope of this Group. The CCMDCTR is a partially studies based register with $>50 \%$ of reference records tagged to $c 12,500$ individually $\mathrm{PICO}$ coded study records. Reports of trials for inclusion in the register are collated from (weekly) generic searches of Medline (1950-), Embase (1974-) and PsycINFO (1967-), quarterly searches of the Cochrane Central Register of Controlled Trials (CENTRAL) and review specific searches of additional databases. Reports of trials are also sourced from international trial registries, drug companies, the handsearching of key journals, conference proceedings and other (non-Cochrane) systematic reviews and meta-analyses. Details of CCMD's core search strategies (used to identify RCTs) can be found on the Group's website with an example of the core Medline search displayed in Appendix 2.

\section{Electronic searches}

\section{Cochrane Common Mental Disorders Group's Specialised Register (CCMDCTR)}

The Group's Information Specialist cross-searched the CCMDCTRRefs and CCMDCTR-Studies registers (to 13 July 2015) using the following updated search strategy (precision maximizing):

\#1 depress*:ti,ab,kw,ky,emt,mh

\#2 ((relapse or recurr* or maintenance or continuation or prophyla*) and (recovered or remission or remit* or responder ${ }^{\star}$ or "responded to" or "recent* episode" or "recent* depress" or 
"previous* depress" ${ }^{\star}$ or "previous episode*" or (depress* near2 past))):ti,ab,kw,ky,emt,mh

\#3 ((continuation or maintenance) near2 (treatment* or *therap* or phase or antidepress ${ }^{\star}$ or medicat $\left.\left.{ }^{\star}\right)\right):$ ti,ab

\#4 "relapse prevention" or "time to relapse"

\#5 (aged or elder* or old or older or geriatric or "late* life" or institutional ${ }^{*}$ or "care home*"):ti

\#6 Aged:kw,ky,sh,emt

$\# 7$ (\#1 and (\#2 or \#3 or \#4) and (\#5 or \#6))

Key to search fields (Cochrane Register of Studies (CRS) platform): ti:title; ab:abstract; kw:keywords;ky:additional keywords; emt:EMTREE headings; $M H: M e S H$

The Group's Information Specialist also conducted a cited reference search on the Web of Science (WoS) at this time (13-Jul-2015) for citations of primary reports of included studies. Results were screened for eligibility and any additional RCTs added to the CCMDCTR search results.

Previous searches to June 2012 can be found in Appendix 1 .

\section{International trial registers}

The World Health Organization's International Clinical Trials Registry Platform (ICTRP) and ClinicalTrials.gov were also searched at this time (13-July-2015).

\section{Searching other resources}

\section{Handsearches}

We handsearched the following journals: International Journal of Geriatric Psychiatry,American Journal of Geriatric Psychiatry,Journal of the American Geriatrics Association, and International Psychogeriatrics. We screened relevant papers and major textbooks that covered late-life depression and its treatment. [Date]

\section{Personal communication}

We contacted the authors of significant papers and experts in the field for information on any unpublished studies.

\section{Bibliographies}

We examined references and bibliographies from relevant trials for further RCTs not identified.

\section{Grey literature}

We also searched grey literature, including conference abstracts of the International Psychogeriatrics Association.[Date]

\section{Data collection and analysis}

\section{Selection of studies}

Both review authors independently performed the selection of trials for inclusion in the review by reviewing the titles and abstracts culled by the search strategy. Where a title or abstract appeared to describe a trial eligible for inclusion, we obtained the full-text article to assess the relevance to this review based on the inclusion criteria. We attempted to resolve any disagreements by discussion. If agreement was not possible, we contacted the principle author of the study for further information to allow inclusion or exclusion.
We generated a Cohen Kappa statistic to show level of agreement between the review authors.

\section{Data extraction and management}

Both review authors independently extracted data using data extraction forms and evidence tables. We resolved differences by discussion. Both authors managed data entry into Review Manager (RevMan 2014). We analysed included trials for the following characteristics.

\section{Characteristics of the study participants}

- Age and any other recorded characteristics of participants.

- Location of participants.

- Methods used to define and diagnose study participants.

\section{Interventions used}

- Type and stated aim of psychological therapy.

- Type of antidepressant medication.

- Type of placebo/control/comparison.

\section{Measures}

- Assessment instruments.

- Assessment intervals.

\section{Outcomes}

Primary

- Relapse of depression.

- Recurrence of depressive disorder.

Secondary

- Global clinical impression by clinician.

- Global clinical impression by the participant.

- Social functioning.

- Quality of life.

\section{Acceptability:}

- Overall drop-out rate.

- Drop-out due to drug-related adverse effects.

- Drop-out due to death.

When aspects of methodology were unclear, or when the data were in a form unsuitable for meta-analysis and trials appeared to meet the eligibility criteria, we contacted the principal author for additional information.

\section{Planned comparisons}

- Antidepressants versus placebo.

- Psychological therapies versus placebo or treatment as usual/ waiting list.

- Antidepressants/psychological therapies combination versus drug placebo.

- Antidepressant versus psychological therapies.

- Antidepressant/psychological therapies combination versus antidepressants alone.

- Antidepressant/psychological therapies combination versus psychological therapies alone. 


\section{Assessment of risk of bias in included studies}

We assessed trial quality using the Cochrane tool for assessing risk of bias. This tool assesses the following domains: sequence generation, allocation concealment, blinding, handling of incomplete data, selective reporting, and other sources of bias. Both review authors independently assessed each paper before agreeing on 'Risk of bias' assessments in each domain. We contacted investigators for additional information in cases of incomplete recording.

We noted methods used for sequence generation and allocation concealment. We recorded methods for blinding participants, therapists, and assessors from treatment type along with evidence of effectiveness. In assessing incomplete outcome data, we assessed each main outcome at each time point for completeness including exclusions and attrition; we assessed methods for addressing incomplete data. To assess selective reporting, we compared stated outcomes with intended outcomes as stated in the methods sections and any available trial protocols.

We made judgements for each domain as high risk of bias, low risk of bias, or unclear risk of bias.

\section{Measures of treatment effect}

We calculated risk ratios (RR) and their 95\% confidence intervals $(\mathrm{Cl})$. When the overall results were significant, we calculated the number needed to treat for an additional beneficial outcome (NNTB) and additional harmful outcome (NNTH), as the inverse of the risk difference $(R D)$.

We presented mean differences (MD) for continuous data. Where necessary, we calculated standard deviations (SDs) from the study authors' Cls for MDs (Higgins 2011).

\section{Unit of analysis issues}

In trials in which participants were treated individually, the unit of analysis was the participants.

\section{Cluster-randomised trials}

In cluster-randomised trials, participants in the same treatment group cannot be regarded as independent and an analysis that ignores clustering is likely to underestimate the standard error (SE) of the estimate. If study authors had taken account of clustering and reported data adjusted for possible within-group correlation, we used the adjusted data in this review. If they did not report adjusted data, we contacted authors to obtain intra-class correlation coefficients.

\section{Studies with multiple treatment groups}

We analysed data from studies that compared more than two intervention groups using multiple pair-wise comparisons between all possible pairs of intervention groups while taking care not to include the same group of participants more than once in the same meta-analysis.

\section{Cross-over trials}

Cross-over trails evaluate the effect of experimental intervention compared with control intervention separately for each participant. Cross-over design is unlikely in continuation and maintenance trials in depression, especially trials of psychological therapies that have carry-over effects. As this review uses a point-in-time analysis comparing interventions at six monthly intervals from randomisation, data from cross-over trials could not be included.

\section{Dealing with missing data}

We obtained missing data from authors, if available.

We performed an intention-to-treat analysis in studies where more than $60 \%$ of people completed the study. We counted everyone allocated to the intervention, whether they completed the followup or not. We assumed that those who dropped out had a negative outcome, with the exception of death.

\section{Assessment of heterogeneity}

We used the $1^{2}$ statistic as a test of heterogeneity with results interpreted according to the following broad thresholds:

- $0 \%$ to $40 \%$ : may not be important;

- $30 \%$ to $60 \%$ : may represent moderate heterogeneity;

- $50 \%$ to $90 \%$ : may represent substantial heterogeneity;

- $75 \%$ to $100 \%$ : represents considerable heterogeneity.

\section{Assessment of reporting biases}

We entered data from included studies into a funnel graph in an attempt to identify the likelihood of significant publication bias.

\section{Data synthesis}

We calculated the RR using the random-effects model as this takes into account any differences between studies even if there is no statistically significant heterogeneity. We inspected data to see if an analysis using a fixed-effect model would make any substantive difference in outcomes that were not statistically significantly heterogeneous.

Where possible, we attempted to convert outcome measures to dichotomous data by identifying cut-off points on rating scales and dividing participants accordingly into 'depression relapse/ recurrence' or 'no relapse/recurrence of depression'. If the authors of a study had used a predefined cut-off point for determining clinical effectiveness, we used this, where appropriate. Otherwise, we assumed that if there had been a $50 \%$ reduction in a scalederived score, this was interpreted as being a clinically significant response.

We presented non-quantitative data descriptively.

\section{Subgroup analysis and investigation of heterogeneity}

We explored clinical heterogeneity, where possible, using the following subgroup analyses.

- Early-onset depressive disorder and late-onset depressive disorder in continuation and maintenance treatment.

- Response to treatment of participants (recovered) versus participants in remission.

\section{Sensitivity analysis}

We performed sensitivity analyses to see if the results were affected by methodological decisions made throughout the review process. We undertook the following analyses to test the impact of including studies at high risk of bias. 
- Removing studies at high risk of bias for allocation concealment.

- Removing studies at high risk of bias for blinding.

- Removing studies with a drop-out rate above $20 \%$.

\section{'Summary of findings' table}

We produced one 'Summary of findings' table for the two primary outcomes (recurrence and overall drop-outs) at 12 months' followup in the main comparison of interest, antidepressant versus placebo. There was no separation into high-risk and low-risk populations, as this was not possible using available data. We graded outcomes using the GRADE approach and produced the table using GRADEprofiler software (GRADEpro). We based the risk in the intervention group (and its $95 \% \mathrm{Cl}$ ) on the assumed risk in the comparison group and the relative effect of the intervention (and its $95 \% \mathrm{Cl}$ ).

\section{RES U LTS}

\section{Description of studies}

\section{Results of the search}

The updated search yielded 10 new records all of which we examined as full-text articles and excluded as not meeting inclusion criteria. Therefore, the number of included studies remained unchanged from the previous review at seven studies (Alexopoulos 2000; Gorwood 2007; Klysner 2002; OADIG 1993; Reynolds 1999a; Wilkinson 2009; Wilson 2003).

We produced an updated study flow diagram incorporating the studies included in the previous review (Figure 1).

Figure 1. Study flow diagram (including studies in previous review version).

7 studies included in previous
version of review (Wilkinson
and Izmeth 2012)

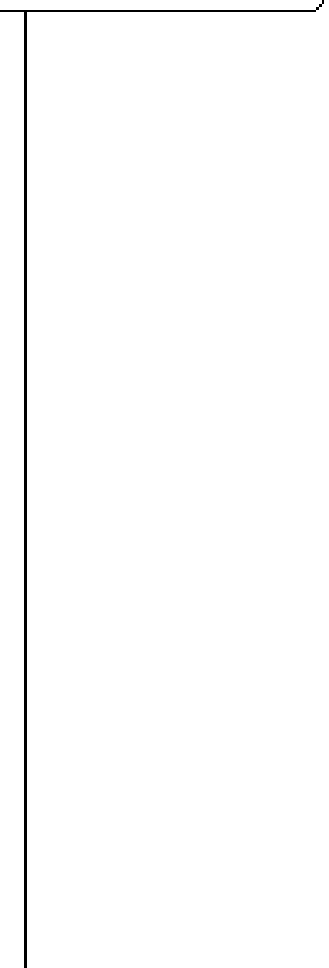

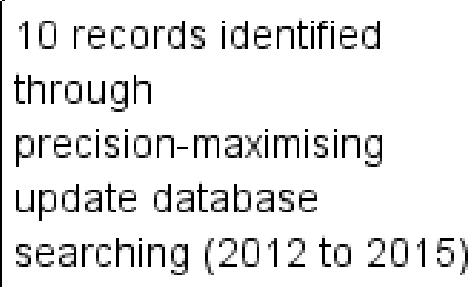




\section{Included studies}

The review included seven studies. See Characteristics of included studies table.

\section{Types of studies}

All seven included studies were of parallel design with participants allocated to therapeutic or control conditions. Four trials were multicentre (Gorwood 2007; OADIG 1993; Wilkinson 2009; Wilson 2003), and three were single centre (Alexopoulos 2000; Klysner 2002; Reynolds 1999a).

Five of the seven trials included two arms and compared antidepressant medication with drug placebo. Two used a TCA (Alexopoulos 2000; OADIG 1993), and three used an SSRI (Gorwood 2007; Klysner 2002; Wilson 2003). One trial included two arms and compared continuation of any acute phase antidepressant with a combination of antidepressant and group CBT (Wilkinson 2009). One trial included four arms and compared a TCA, drug placebo, IPT/drug placebo combination, and TCA/IPT combination (Reynolds 1999a).

Study size varied. One trial randomised 43 participants and another trial randomised 45 participants (Alexopoulos 2000; Wilkinson 2009). One trial randomised 69 participants (OADIG 1993), and three randomised between 107 and 121 participants (Klysner 2002; Reynolds 1999a; Wilson 2003). One trial randomised 305 participants (Gorwood 2007).

\section{Types of participants}

\section{Diagnoses and measures of depression severity}

Two trials required participants to have met DSM-IV criteria for major depression (Gorwood 2007; Klysner 2002). One trial used RDC (OADIG 1993), one used both DSM-IV and RDC (Alexopoulos 2000), one used Schedule for Affective Disorders and Schizophrenia - Lifetime Version (SADS-L) (Reynolds 1999a), one used ICD-10 criteria (Wilkinson 2009), and one used both Automated Geriatric Examination for Computer Assisted Taxonomy (AGECAT) and DSMIII (Wilson 2003).

Five of the trials also required participants to have scored above a cut-off on a depression rating scale. Three trials used the HDRS (Alexopoulos 2000; Reynolds 1999a; Wilson 2003) and two trials used the MADRS (Gorwood 2007; Klysner 2002).

Participants in all trials were in remission from depression before randomisation. All trials defined remission as scoring below a cutoff on a depression rating scale. Four trials used the MADRS with cut-offs of less than 13 (Gorwood 2007), less than 12 (Klysner 2002), less than 11 (OADIG 1993), and less than 10 (Wilkinson 2009). Two trials used the 17-item HDRS with a cut-off of less than 11 (Reynolds 1999a; Wilson 2003). One trial used the 24-item HDRS with a cutoff of less than 11 as well as the Cornell rating scale for depression with a cut-off of less than 7 (Alexopoulos 2000). Two of the trials also required participants no longer to meet the diagnostic criteria for depression used for entry to the study (Alexopoulos 2000; Wilkinson 2009). In all trials, participants were required to have been in a stable period of remission before randomisation. In the majority of trials, the period of remission was 16 weeks. In two trials, the required period of remission was shorter, that is, eight weeks (OADIG 1993) and four weeks (Wilson 2003). One trial required a period of remission of between eight weeks and one year (Wilkinson 2009).

\section{Recruitment source}

Four of the seven trials were based in psychiatry clinics in the USA and continental Europe (Alexopoulos 2000; Gorwood 2007; Klysner 2002; Reynolds 1999a). Authors described two of these clinics as research clinics (Klysner 2002; Reynolds 1999a). The other three trials were based in the UK National Health Service, recruiting people from primary and secondary care (OADIG 1993; Wilkinson 2009; Wilson 2003). Two of these included a proportion of participants who had received inpatient treatment (OADIG 1993; Wilkinson 2009), and one included some participants who had been recruited through a research community survey (Wilson 2003).

\section{Participant characteristics}

In keeping with the search strategy used, all participants were aged 60 years and over. Although the search had yielded many trials with adults of all ages that included a proportion of people aged 60 years and over, none of these analysed results separately from older participants and so we excluded all of them from the review. Three of the included trials recruited participants aged 65 years and over (Gorwood 2007; Klysner 2002; Wilson 2003); the remaining trials included participants aged 60 years and over. In six of the trials, the mean age was between 73 and 77 years; in the other trial, the mean was 67 years (Reynolds 1999a). In all trials, the majority of the participants were women. One trial stipulated that participants should have experienced at least one previous episode of major depression within the previous three years (Reynolds 1999a). One trial required participants to have experienced a depressive episode of at least four weeks' duration (Gorwood 2007).

\section{Exclusion criteria}

All trials except one (Wilkinson 2009) excluded people with severe or unstable physical illness. All except one (Klysner 2002) used a single measure of cognitive function to exclude people with cognitive impairment. However, the degree of cognitive impairment for exclusion varied considerably between studies. Of six studies using the Folstein Mini Mental State Examination, the lowest cut-off (representing the greatest degree of cognitive impairment) was 12 (Wilson 2003), and the highest cut-off (representing the smallest degree of cognitive impairment) was 27 (Reynolds 1999a). Two studies excluded people whose depressive episode had been treated with ECT (Gorwood 2007; Klysner 2002), and the two studies randomising to TCAs excluded people who were known to be unable to tolerate that class of antidepressant or who had contraindications to their use (OADIG 1993; Reynolds 1999a).

Three trials excluded people who had been treated for psychotic depression (Gorwood 2007; Reynolds 1999a; Wilson 2003). Three trials excluded people who had a history of any other psychiatric disorders, including bipolar disorder (Alexopoulos 2000; Gorwood 2007; Klysner 2002). One trial limited exclusion to bipolar disorder and dysthymia (Reynolds 1999a), and one to bipolar disorder alone (Wilkinson 2009). 


\section{Types of intervention}

\section{Antidepressant drugs and drug placebo interventions}

All trials except one (Wilkinson 2009) involved comparison of active antidepressant treatment with antidepressant placebo. Three of these trials used TCAs. One trial adjusted nortriptyline dose to achieve a plasma level of $60 \mathrm{ng} / \mathrm{mL}$ to $150 \mathrm{ng} / \mathrm{mL}$, while people randomised to placebo underwent titration from nortriptyline over a 10-week period; all participants continued to attend a medication clinic (Alexopoulos 2000). The second trial adjusted nortriptyline dose to achieve a plasma level of $80 \mathrm{ng} / \mathrm{mL}$ to $120 \mathrm{ng} / \mathrm{mL}$ with people randomised to placebo undergoing a six-week titration; all participants continued to attend a medication clinic (Reynolds 1999a). In the third trial using TCAs, all participants in the active treatment arm received dothiepin $75 \mathrm{mg}$ daily (OADIG 1993). None of the study authors specified titration arrangements for participants randomised to placebo.

The other three trials comparing active treatment with placebo antidepressant used SSRIs. Gorwood 2007 used escitalopram at 10 $\mathrm{mg}$ or $20 \mathrm{mg}$ daily, according to the dose required during active treatment. Participants randomised to receive placebo underwent direct switch from escitalopram $10 \mathrm{mg}$ daily or titration over one week from 20 mg daily. Klysner 2002 used citalopram at 20 mg, 30 $\mathrm{mg}$, or $40 \mathrm{mg}$ daily, according to the dose required during acute treatment; they did not specify titration procedures for participants randomised to placebo. Wilson 2003 used sertraline at a dose of 50 $\mathrm{mg}, 100 \mathrm{mg}$, or $150 \mathrm{mg}$ daily according to the dose used in the acute phase treatment except with participants who had required a dose of $200 \mathrm{mg}$ in the acute phase who had this reduced to $150 \mathrm{mg}$. They did not specify titration procedures for participants randomised to placebo.

Reynolds 1999a compared nortriptyline at a plasma level of $80 \mathrm{ng} / \mathrm{mL}$ to $120 \mathrm{ng} / \mathrm{mL}$ and medication clinic attendance with nortriptyline titrated for four weeks after randomisation to achieve a lower plasma level of $40 \mathrm{ng} / \mathrm{mL}$ to $60 \mathrm{ng} / \mathrm{mL}$ with medication clinic attendance. In Wilkinson 2009, all participants in both arms continued to receive whichever antidepressant had been used in their acute phase treatment.

\section{Types of psychological therapies}

Only two trials included psychological therapies. One trial used IPT (Reynolds 1999a). Treatment sessions were delivered on a monthly basis throughout the whole period of follow-up, that is, for three years or until recurrence or drop-out. Reference is made to use of a therapy manual. The other trial to involve a psychological therapies used eight sessions of group CBT over a fixed 12week period (Wilkinson 2009). This was a standardised therapy using a treatment manual and therapy homework, including usual cognitive behavioural techniques of activity scheduling, thought monitoring, and thought challenging.

\section{Process evaluation of psychotherapeutic evaluation}

Reynolds 1999a audiotaped IPT sessions and rated them for treatment integrity and compliance with the treatment manual. Although not explicitly stated, a reference indicated that a rating tool was used (Wagner 1992), although compliance ratings are not given. Wilkinson 2009 videotaped group CBT sessions and rated a $25 \%$ sample for therapy quality and adherence to the treatment manual using a modified version of the Cognitive Therapy Rating Scale (Blackburn 2001). All sessions achieved the predetermined level of therapy competence, apart from the sessions from the first group treated.

\section{Types of outcome measures}

\section{Primary outcomes}

Primary outcome measures were rates of recurrence of depression using predetermined cut-offs on different depression rating scales, diagnostic criteria, or clinical judgement. One study used the 17item HDRS requiring a score of 13 or more (Wilson 2003). Another study used the 24-item HDRS, requiring a score of 17 or more (Alexopoulos 2000). Four studies used the MADRS, two requiring a score of 22 or more (Gorwood 2007; Klysner 2002), one a score of 11 or more (OADIG 1993), and the other a score of 10 or more (Wilkinson 2009). Three studies also allowed recurrence to be identified by clinical judgement (Gorwood 2007; OADIG 1993; Reynolds 1999a), one by RDC (Alexopoulos 2000), and one by DSMIIIR criteria (Wilson 2003).

\section{Secondary outcomes}

No study reported long-term recurrence rates of depression after discontinuation of treatments. One study measured changes in observer-rated Clinical Global Impression (CGI) (Gorwood 2007). No studies reported social functioning measures or quality of life measures. Six of the seven studies reported death rates; one study did not state death rates (Alexopoulos 2000), but it was apparent that no deaths occurred during follow-up. One study reported overall drop-out rates without identifying drop-outs specifically due to adverse effects and deaths, and the study authors provided no further data (OADIG 1993).

\section{Acceptability}

Six of the seven studies reported overall drop-out rates. One study did not state drop-out rates, but it was apparent that no dropouts occurred during follow-up (Alexopoulos 2000). Three of the studies reported drop-out rates due to drug-related adverse effects (Gorwood 2007; Klysner 2002; Wilson 2003). One study reported overall drop-out rates without identifying drop-outs specifically due to adverse effects and deaths, and study authors provided no further data (OADIG 1993).

\section{Excluded studies}

The most frequent reason for exclusion of studies was inclusion in trials of participants aged 60 years and over with younger adults, with no separate analysis of data from older participants. We excluded two trials by Reynolds et al., one because it compared two serum levels of the same antidepressant (Reynolds 1999b), and the other because some participants received augmentation with lithium or perphenazine, which was not discontinued at randomisation (Reynolds 2006). See Characteristics of excluded studies table.

\section{Studies awaiting classification}

We identified no studies awaiting classification.

\section{Ongoing studies}

We identified no ongoing studies.

\section{Risk of bias in included studies}

See Figure 2 and Figure 3 for summary graphs. 
Figure 2. Risk of bias graph: review authors' judgements about each risk of bias item presented as percentages across all included studies.

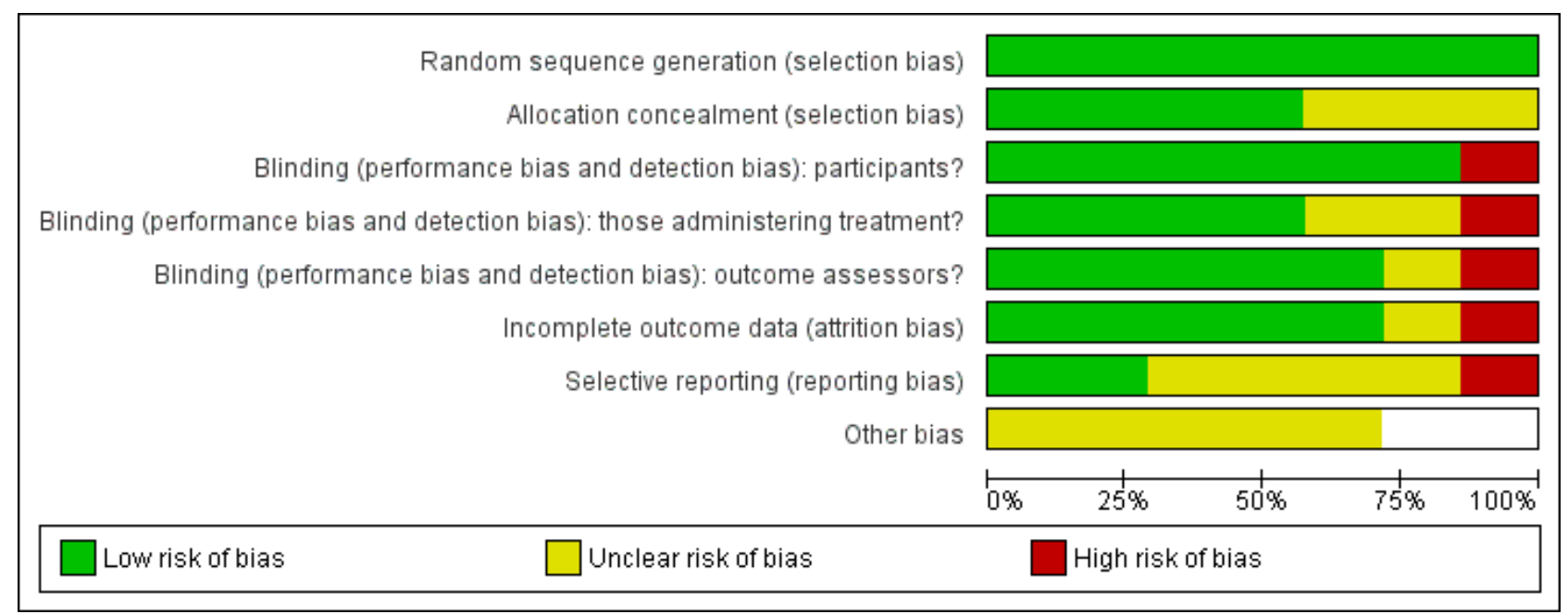


Figure 3. Risk of bias summary: review authors' judgements about each risk of bias item for each included study.

\begin{tabular}{|c|c|c|c|c|c|c|c|c|}
\hline & 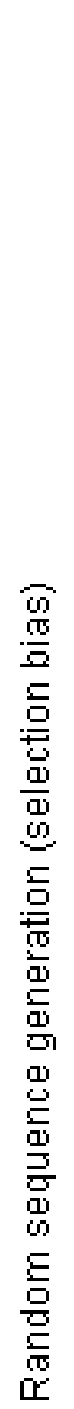 & 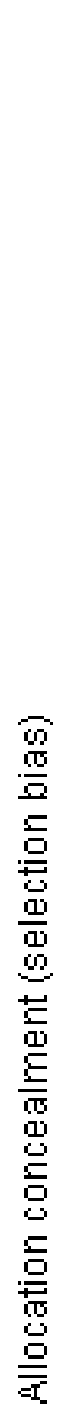 & 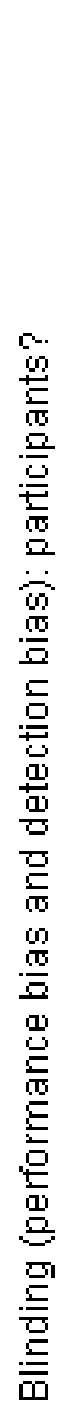 & 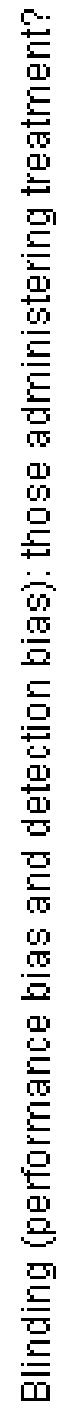 & 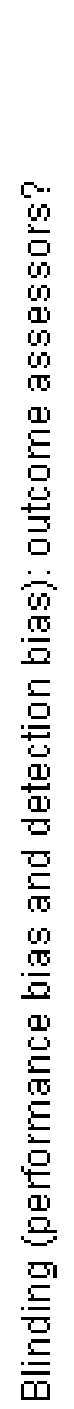 & 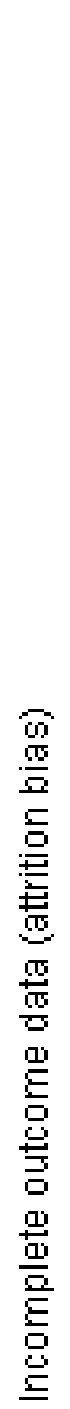 & 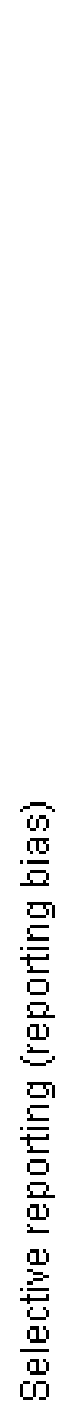 & 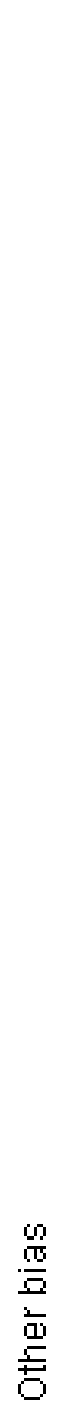 \\
\hline Alexopoulos 2000 & + & $?$ & + & $?$ & + & $?$ & + & $?$ \\
\hline Gowwood 2007 & + & + & + & + & + & + & $?$ & $?$ \\
\hline Klysner 2002 & + & $?$ & + & $?$ & + & + & & $?$ \\
\hline OADIG 1993 & + & $?$ & + & C & $?$ & & $?$ & $?$ \\
\hline Reynolds 1999a & . & & 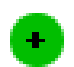 & & + & 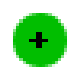 & $?$ & \\
\hline Wilkinson 2009 & + & & & & & & + & \\
\hline Wilson 2003 & + & & + & + & + & + & $?$ & $?$ \\
\hline
\end{tabular}




\section{Allocation}

\section{Sequence generation}

All studies used adequate sequence generation. All reported using random allocation, although not all studies stated the randomisation method. Two studies also employed stratification (OADIG 1993; Wilkinson 2009).

\section{Allocation concealment}

Four studies used adequate allocation concealment (Gorwood 2007; Reynolds 1999a; Wilkinson 2009; Wilson 2003). Allocation concealment was unclear in the remaining studies.

\section{Blinding}

\section{Blinding of participants}

The six studies that investigated antidepressant medication achieved blinding of participants using placebo arms (Alexopoulos 2000; Gorwood 2007; Klysner 2002; OADIG 1993; Reynolds 1999a; Wilson 2003). The two trials involving psychological therapies could not achieve blinding of participants as psychological therapies involve active participation from people receiving the treatment (Reynolds 1999a; Wilkinson 2009).

\section{Blinding of those delivering treatment}

There was adequate blinding of those delivering treatment in four of the studies (Gorwood 2007; OADIG 1993; Reynolds 1999a; Wilson 2003). Blinding was unclear in two of the studies (Alexopoulos 2000; Klysner 2002). In the two studies with psychological therapy arms, blinding was not possible (Reynolds 1999a; Wilkinson 2009).

\section{Blinding of assessors}

Blinding of assessors was adequate in five of the studies (Alexopoulos 2000; Gorwood 2007; Klysner 2002; Reynolds 1999a; Wilson 2003), and unclear in one (OADIG 1993). Blinding inadequate in Wilkinson 2009 as the study authors report that, during follow-up assessments, some participants used terms that indicated they had become familiar with CBT, the intervention under investigation, causing unblinding of the assessor.

\section{Incomplete outcome data}

All studies addressed incomplete data (Alexopoulos 2000; Gorwood 2007; Klysner 2002; OADIG 1993; Reynolds 1999a; Wilkinson 2009; Wilson 2003).

\section{Selective reporting}

Only one study was free from selective reporting as the study protocol was available to the authors (Wilkinson 2009). There were no other study protocols available so risk of bias in the other six studies was uncertain.

\section{Other potential sources of bias}

All seven studies involved antidepressant medication; one involved a range of medications (Wilkinson 2009), while the others involved single agents. Involvement by pharmaceutical companies in trials may introduce bias as companies hold a vested interest in the results. Three studies were funded by pharmaceutical companies (Klysner 2002; OADIG 1993; Wilson 2003). The funding of Gorwood 2007 was unclear but employees of a pharmaceutical company were among the investigators. The funding of Alexopoulos 2000 was also unclear. Independent grant-giving bodies funded the remaining studies (Reynolds 1999a; Wilkinson 2009).

Six of the seven studies involved titration from active antidepressant to placebo antidepressant (Alexopoulos 2000; Gorwood 2007; Klysner 2002; OADIG 1993; Reynolds 1999a; Wilson 2003). This can introduce bias through carry-over therapeutic effects if titration is slow, or by discontinuation symptoms if titration is rapid. Two studies described gradual tapering of antidepressant dose under double-blind conditions; in one study, this was over 10 weeks (Alexopoulos 2000), and in the other study was over six weeks (Reynolds 1999a). In Gorwood 2007, participants randomised to receive placebo underwent direct switch from escitalopram $10 \mathrm{mg}$ daily or titration over one week from escitalopram $20 \mathrm{mg}$ daily. The remaining studies did not state the procedures for titration (Klysner 2002; OADIG 1993; Wilson 2003).

Two trials included delivery of psychological treatments (Reynolds 1999a; Wilkinson 2009). Poor treatment fidelity is a potential source of bias in psychological treatment trials. However, both trials used psychological therapists with high levels of training and included supervision in the relevant therapy (IPT (Reynolds 1999a) and group CBT (Wilkinson 2009)). Both trials also used a therapist competency scale to measure treatment fidelity. Therefore, this potential source of bias was low in these studies.

Studies reported different drop-out rates. Higher rates of drop-out may occur in people taking active medication and experiencing adverse effects, leading to bias.

\section{Effects of interventions}

See: Summary of findings for the main comparison Antidepressant medication compared with placebo at 12 months' follow-up

We performed intention-to-treat analyses in all comparisons.

\section{Antidepressants versus placebo}

\section{Primary outcomes}

\subsection{Recurrence rate of depression at 12 months}

There was a statistically significant difference favouring antidepressants in reducing recurrence at 12 months compared with placebo (three RCTs, $\mathrm{n}=247$, RR $0.67,95 \% \mathrm{Cl} 0.55$ to 0.82 ) (Figure 4). This translated to an NNTB of 5. Fixed-effect modelling found the same effect. We downgraded the outcome from high to low quality of evidence due to imprecision and risk of bias. 
Figure 4. Forest plot of comparison: 1 Antidepressant versus placebo, outcome: 1.2 Recurrence.

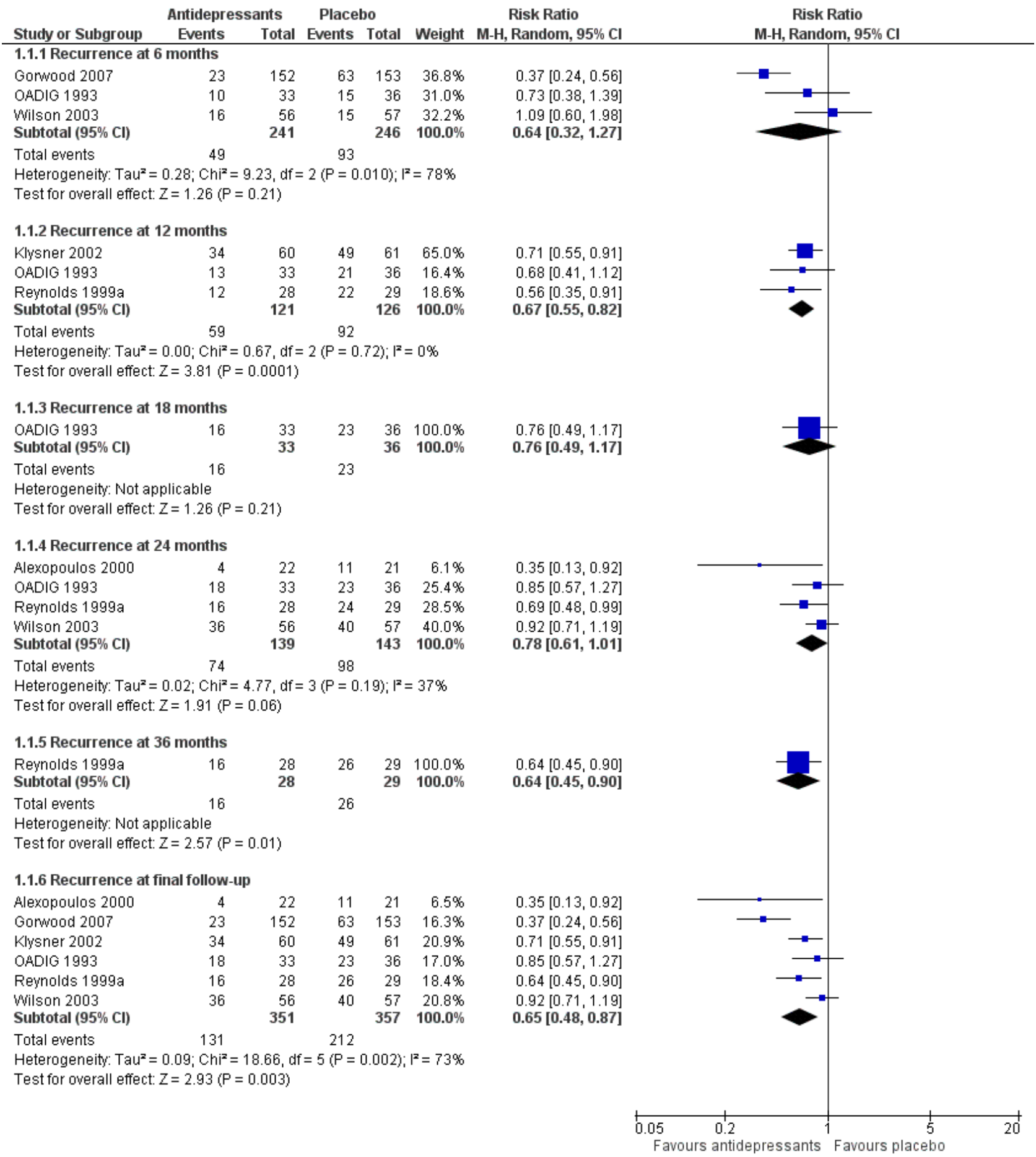

\subsection{Overall drop-out rates at 12 months}

\section{Secondary outcomes}

There was no difference in drop-out rates at 12 months (one RCT, $n=121$ ). We downgraded the outcome from high to low quality of evidence due to imprecision.

\subsection{Relapse/recurrence rates of depression at other time points}

There was no significant reduction in relapse rates at six months in people taking antidepressants compared with people taking placebo (three RCTs, $n=487$; Figure 4). There was a high degree of heterogeneity between the three trials in this analysis $(12=78 \%)$, the possible reason being that two of the trials used a lower cutoff to determine relapse, and they included people from secondary 
care (who had probably been more severely depressed) (OADIG 1993; Wilson 2003). Excluding these two trials from the analysis resulted in a significant benefit of antidepressant treatment in the one remaining trial (Gorwood 2007).

There was no significant reduction in recurrence rates at 18 months in people taking antidepressants compared with people taking placebo in the one trial yielding data (one RCT, $n=69$; Figure 4).

There was no significant reduction in recurrence rates at 24 months in people taking antidepressants compared with people taking placebo (four RCTs, $n=282$; Figure 4). There was a moderate degree of heterogeneity between the four trials in this analysis $\left(1^{2}=\right.$ $37 \%$ ), with one trial being an outlier (Alexopoulos 2000). When we removed this trial from the analysis, the heterogeneity was reduced $\left(\mathrm{I}^{2}=0 \%\right)$ but the result remained insignificant.

In the three trials of TCAs, antidepressant treatment was superior to placebo at 24 months.

There was a significant difference favouring the antidepressant group in reducing recurrence at 36 months compared with placebo in the one trial reporting data at 36 months ( $n=57, \mathrm{RR} 0.64,95 \%$ $\mathrm{Cl} 0.45$ to 0.90; Reynolds 1999a) (Figure 4). This translated to an NNTB of 4. Participants in this trial were generally younger, less cognitively impaired, and experienced less physical illness than participants in other trials in the review.

\subsection{Global clinical impression by the clinician}

One study presented continuous data measuring changes in observer-rated CGI ( $\mathrm{n}=305$; Gorwood 2007) as MDs using SDs calculated from the study authors' Cls for MDs (Higgins 2011). There was no significant difference in symptom severity between antidepressant and placebo at six months.

\subsection{Global clinical impression by the participant}

We found no data on global clinical impression by the participant.

\subsection{Social functioning}

We found no data on social functioning.

\subsection{Quality of life}

We found no data on quality of life.

\subsection{Deaths}

Comparison of death rates was possible for antidepressant versus placebo at 24 and 36 months, and antidepressant versus combination of antidepressant and psychological therapies at six and 12 months. There were no significant differences in any of these analyses.

\subsection{Acceptability: overall drop-out rates at other time points}

Comparison of overall drop-out rates (excluding deaths) was possible for antidepressant medication versus placebo at six months (one RCT, $\mathrm{n}=305$ ), 24 months (one RCT, $\mathrm{n}=113$ ), and 36 months (one RCT, $n=57$ ). There were no significant differences (Figure 5). 
Figure 5. Forest plot of comparison: 1 Antidepressant versus placebo, outcome: 1.6 Overall drop-out rates (excluding deaths).

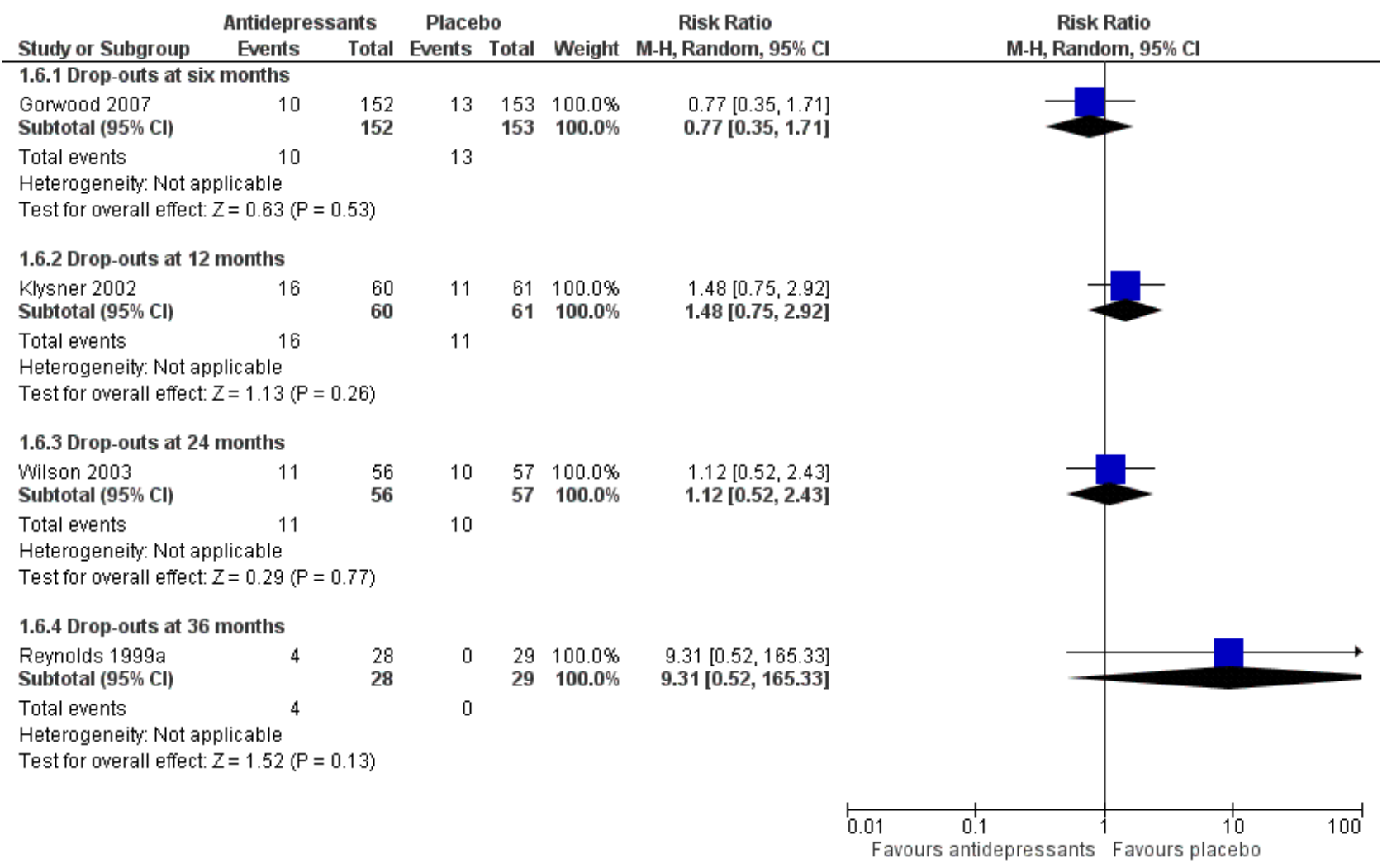

\subsection{Acceptability: drop-out rates due to drug-related adverse effects}

There were no significant differences in drop-outs due to drugrelated adverse effects in the analyses at six months (one RCT, $\mathrm{n}=305$ ), 12 months (one RCT, $\mathrm{n}=121$ ), or 24 months (one RCT, $n=234)$. Only one trial reported qualitative data on adverse effects encountered at a statistically greater frequency with antidepressant (citalopram) than with placebo (Klysner 2002). These were increased sweating, tremor, and fatigue.

\section{Psychological therapies versus placebo or treatment as usual/waiting list}

\section{Primary outcomes}

\subsection{Recurrence rate of depression at $\mathbf{1 2}$ months}

In the one trial comparing psychological therapies (IPT) with placebo medication ( $\mathrm{n}=54$; Reynolds 1999a), there was no significant difference in recurrence at 12 months.

\subsection{Overall drop-out rate at $\mathbf{1 2}$ months}

We found no data on overall drop-out rate at 12 months.

\section{Secondary outcomes}

\subsection{Relapse/recurrence rate of depression at other time points}

In the one trial comparing psychological therapies (IPT) with placebo medication ( $\mathrm{n}=54$; Reynolds 1999a), there was no significant difference in recurrence at 24 months.
In the one trial comparing psychological therapies (IPT) with placebo medication ( $\mathrm{n}=54$; Reynolds 1999a), there was no significant difference in recurrence at 36 months.

\subsection{Global clinical impression by the clinician}

We found no data on global clinical impression by the clinician.

\subsection{Global clinical impression by the participant}

We found no data on global clinical impression by the participant.

\subsection{Social functioning}

We found no data on social functioning.

\subsection{Quality of life}

We found no data on quality of life.

\subsection{Deaths}

We found no data on deaths.

\subsection{Acceptability: overall drop-out rate}

One study yielded data to compare overall drop-out rates (excluding deaths) at 36 months in the comparisons of antidepressant versus psychological therapies, psychological therapies versus placebo, and combination of antidepressant and placebo versus psychological therapies alone $(n=54$; Reynolds 1999a). There were no significant differences in any of these three comparisons. 
2.10 Acceptability: drop-out rates due to drug-related adverse effects

We found no data on drop-out rates due to drug-related adverse effects.

\section{Antidepressants/psychological therapies combination versus drug placebo}

Primary outcomes

\subsection{Recurrence rate of depression at $\mathbf{1 2}$ months}

There was a significant difference at 12 months favouring combination in the one trial comparing antidepressant/ psychological therapies combination with drug placebo alone $(n=$ 54, RR 0.42, 95\% Cl 0.23 to 0.77; Reynolds 1999a) (Figure 6).

Figure 6. Forest plot of comparison: 7 Antidepressant/psychological therapies combination versus drug placebo, outcome: 7.1 Recurrence.

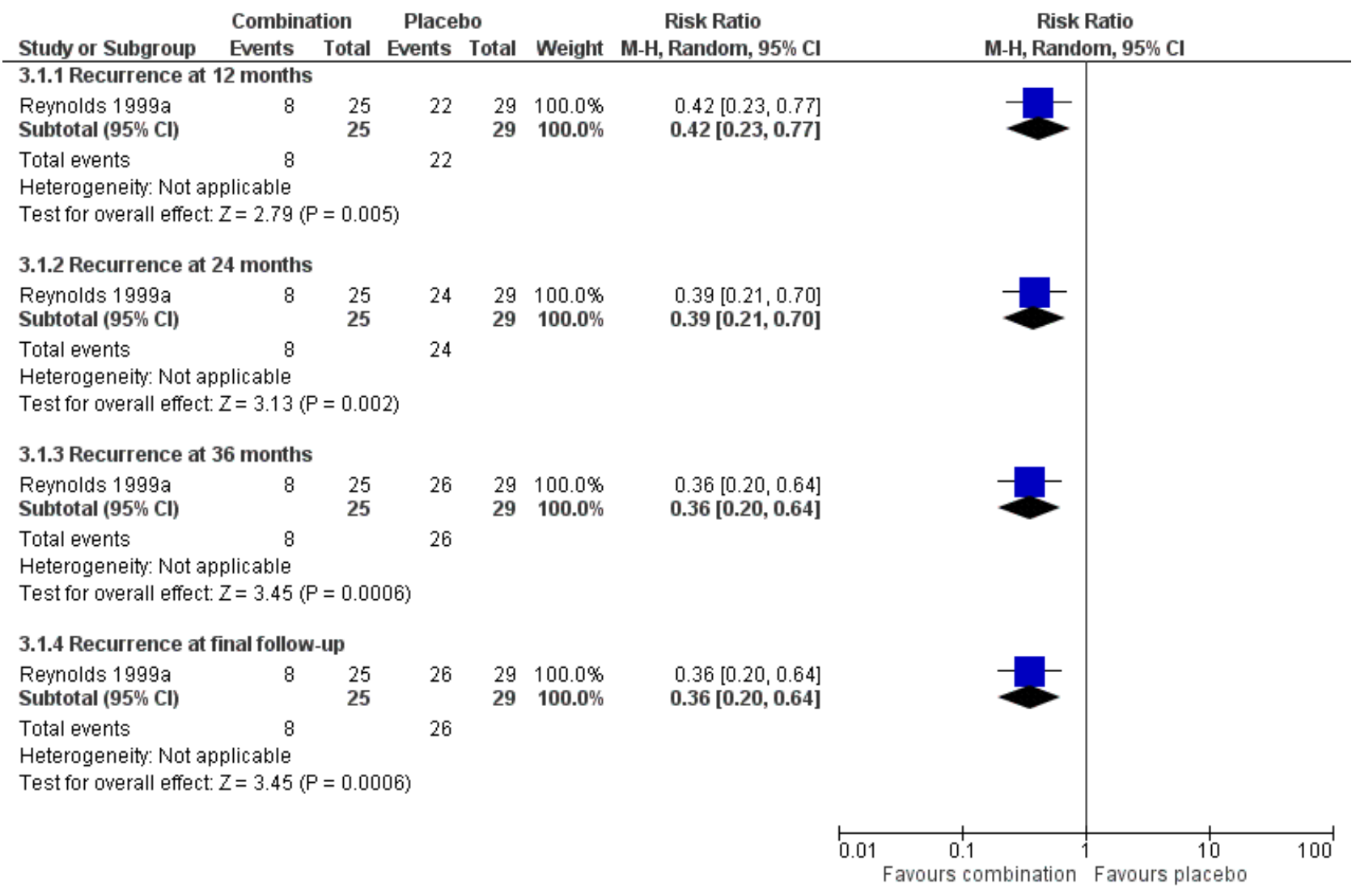

\subsection{Overall drop-out rate at 12 months}

There was no significant difference in overall drop-out rate at 12 months (one RCT; $\mathrm{n}=54$ ).

\section{Secondary outcomes}

\subsection{Relapse/recurrence rate of depression at other time points}

There was a significant difference at 24 months favouring combination in the one trial comparing antidepressant/ psychological therapies combination with drug placebo alone $\mathrm{n}=$ 54, RR 0.39, 95\% Cl 0.21 to 0.70; Reynolds 1999a) (Figure 6).

There was a significant difference at 36 months favouring combination in the one trial comparing antidepressant/ psychological therapies combination with drug placebo alone $(\mathrm{n}=$ 54, RR 0.36, 95\% Cl 0.20 to 0.64; Reynolds 1999a) (Figure 6).

\subsection{Global clinical impression by the clinician}

We found no data on global clinical impression by the clinician.

\subsection{Global clinical impression by the participant}

We found no data on global clinical impression by the participant.

\subsection{Social functioning}

We found no data on social functioning.

\subsection{Quality of life}

We found no data on quality of life.

\subsection{Deaths}

We found no data on deaths. 


\subsection{Acceptability: overall drop-out rate at other time points}

Comparison of overall drop-out rates (excluding deaths) was possible for combination of antidepressant and psychological therapies with placebo at six, 12 , and 24 months, with no significant differences found (one RCT; $n=54$ ).

\subsection{Acceptability: drop-out rates due to drug-related adverse effects}

We found no data on drop-out rates due to drug-related adverse effects.

\section{Antidepressant versus psychological therapies}

\section{Primary outcomes}

\subsection{Recurrence rate of depression at $\mathbf{1 2}$ months}

There was no significant difference in recurrence rates at 12 months in people taking an antidepressant compared with people receiving psychological therapies in the one trial comparing recurrence rate of depression at 12 months ( $n=53, \mathrm{RR} 0.82,95 \% \mathrm{Cl} 0.47$ to 1.46 ; Reynolds 1999a) (Figure 7).

Figure 7. Forest plot of comparison: 2 Antidepressant versus psychological therapies, outcome: 2.1 Recurrence.

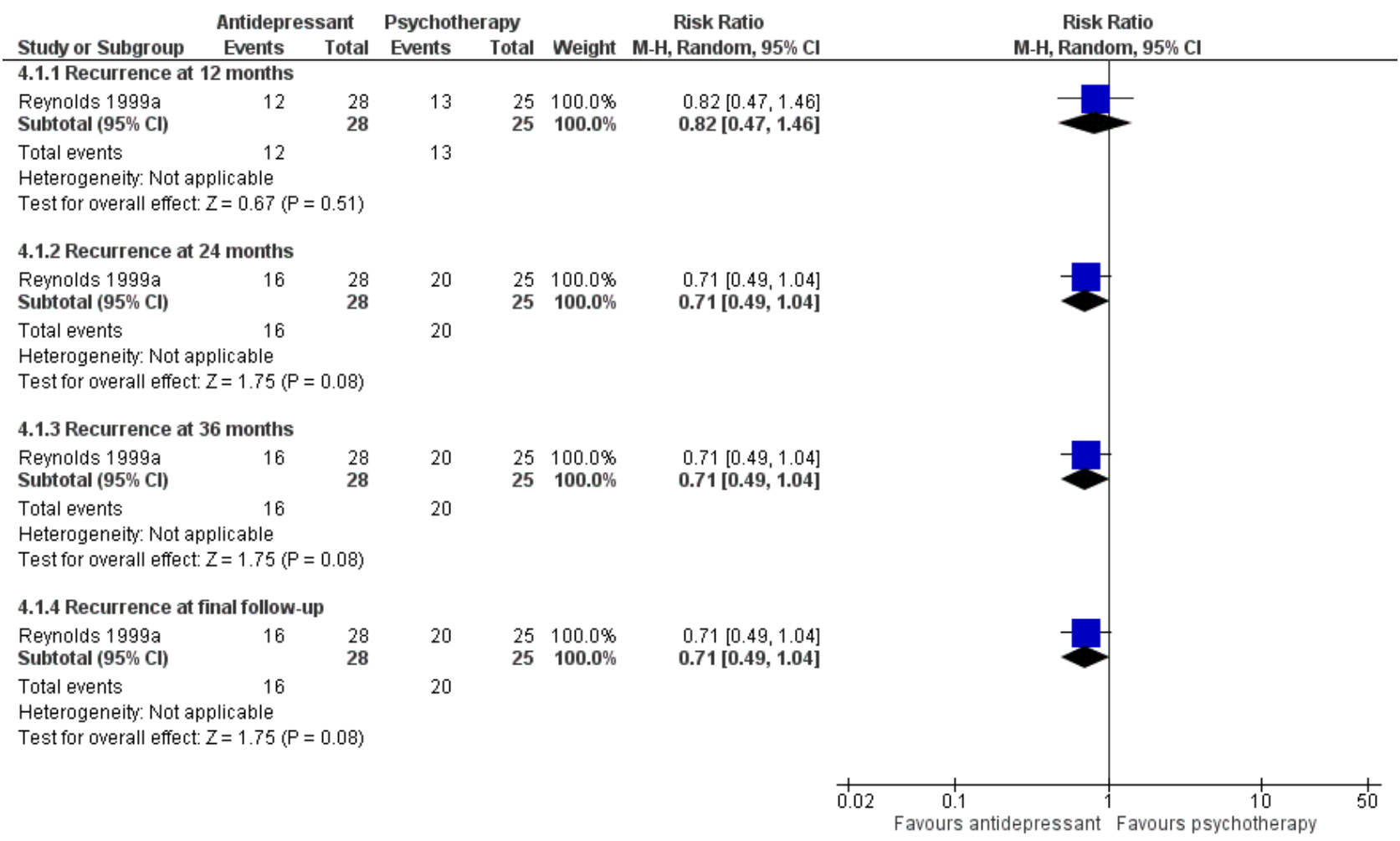

\subsection{Overall drop-out rate at 12 months}

We found no data on overall drop-out rate at 12 months.

\section{Secondary outcomes}

\subsection{Relapse/recurrence rate of depression at other time points}

There was no significant difference in recurrence rate at 24 months in people taking an antidepressant compared with people receiving psychological therapies in the one trial comparing relapse/recurrence rate of depression at other time points $(n=53$, RR 0.71, 95\% Cl 0.49 to 1.04; Reynolds 1999a) (Figure 7).

\subsection{Global clinical impression by the clinician}

We found no data on global clinical impression by the clinician.

\subsection{Global clinical impression by the participant}

We found no data on global clinical impression by the participant.

\subsection{Social functioning}

\subsection{Quality of life}

We found no data on quality of life.

\subsection{Deaths}

We found no data on deaths.

\subsection{Acceptability: overall drop-out rate}

One study yielded data to compare overall drop-out rates (excluding deaths) at 36 months in the comparisons of antidepressant versus psychological therapies, psychological therapies versus placebo, and combination of antidepressant and placebo versus psychological therapies alone $(n=54$; Reynolds 1999a). There were no significant differences in any of these three comparisons.

\subsection{Acceptability: drop-out rates due to drug-related adverse effects}

We found no data on drop-out rates due to drug-related adverse effects.

We found no data on social functioning. 
5. Antidepressant/psychological therapies combination versus antidepressants alone

\section{Primary outcomes}

\subsection{Recurrence rate of depression at 12 months}

There was no significant difference in recurrence at 12 months in people receiving antidepressant/psychological therapies combination compared with people receiving antidepressant alone. There were two trials in this analysis $(n=98)$ with low heterogeneity (Figure 8). This analysis also included data from Wilkinson 2009, which the study authors adjusted for clustering.

\section{Figure 8. Forest plot of comparison: 5 Antidepressant/psychological therapies combination versus antidepressant} alone, outcome: 5.1 Recurrence.

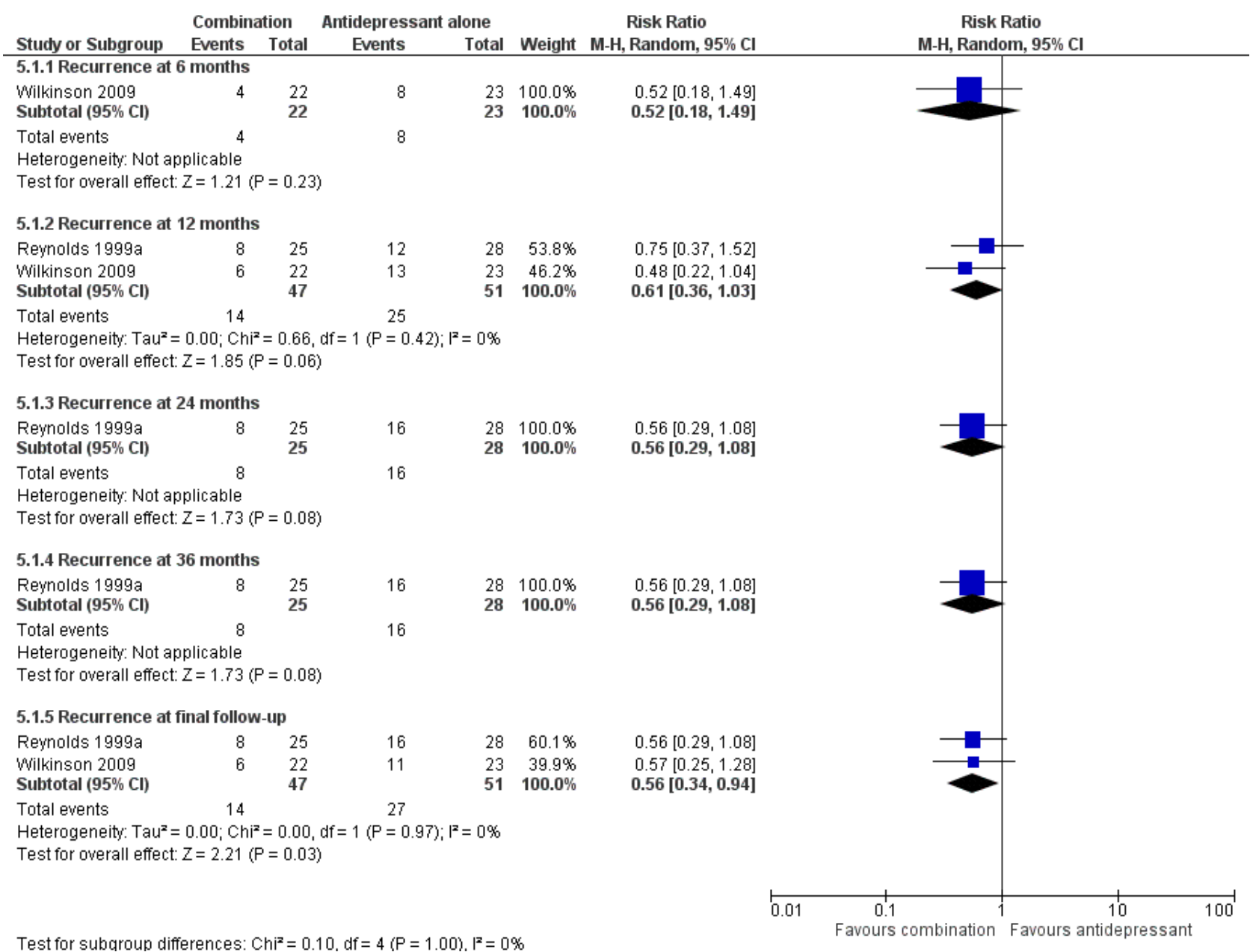

\subsection{Overall drop-out rates at $\mathbf{1 2}$ months}

We found no data on overall drop-out rates at 12 months.

\section{Secondary outcomes}

\subsection{Relapse/recurrence rate of depression at other time points}

In the one trial reporting relevant data, there was no significant reduction in relapse at six months in people receiving antidepressant/psychological therapies combination compared with people receiving antidepressant alone $(n=45$; Wilkinson 2009) (Figure 8). This was a group-based intervention; the study authors adjusted the calculation of RR to allow for clustering.

In the one trial reporting data, there was no significant reduction in recurrence at 24 months in people receiving antidepressant/

psychological therapies combination compared with people receiving antidepressant alone $(n=53$; Figure 8$)$.

In the one trial reporting data, there was no significant reduction in recurrence at 36 months in people receiving antidepressant/ psychological therapies combination compared with people receiving antidepressant alone $(n=53$; Figure 8$)$.

\subsection{Global clinical impression by the clinician}

We found no data on global clinical impression by the clinician.

\subsection{Global clinical impression by the participant}

We found no data on Global clinical impression by the participant. 


\subsection{Social functioning}

We found no data on social functioning.

\subsection{Quality of life}

We found no data on quality of life.

\subsection{Deaths}

Comparison of death rates was possible for combination of antidepressant and psychological therapy versus antidepressant alone at six months (one RCT, $n=45$ ), 12 months (two RCTs, $n=98$ ), 24 months (one RCT, $n=53$ ), and 36 months (one RCT; $n=53$ ). There were no significant differences in any of these analyses.

\subsection{Acceptability: overall drop-out rate}

We found no data on overall drop-out rate.

\subsection{Acceptability: drop-out rates due to drug-related adverse effects}

We found no data on drop-out rates due to drug-related adverse effects.

\section{Antidepressants/psychological therapies combination versus psychological therapies alone}

\section{Primary outcomes}

\subsection{Recurrence rate of depression at 12 months}

In the one trial comparing the combination of psychological therapies and antidepressant with psychological therapies (IPT) alone, combination was not superior to psychological therapies alone at 24 months ( $\mathrm{n}=50, \mathrm{RR} 0.62,96 \% \mathrm{Cl} 0.31$ to 1.22 ; Reynolds 1999a) (Figure 9).

\section{Figure 9. Forest plot of comparison: 6 Antidepressant/psychological therapies combination versus psychological} therapies alone, outcome: 6.1 Recurrence.

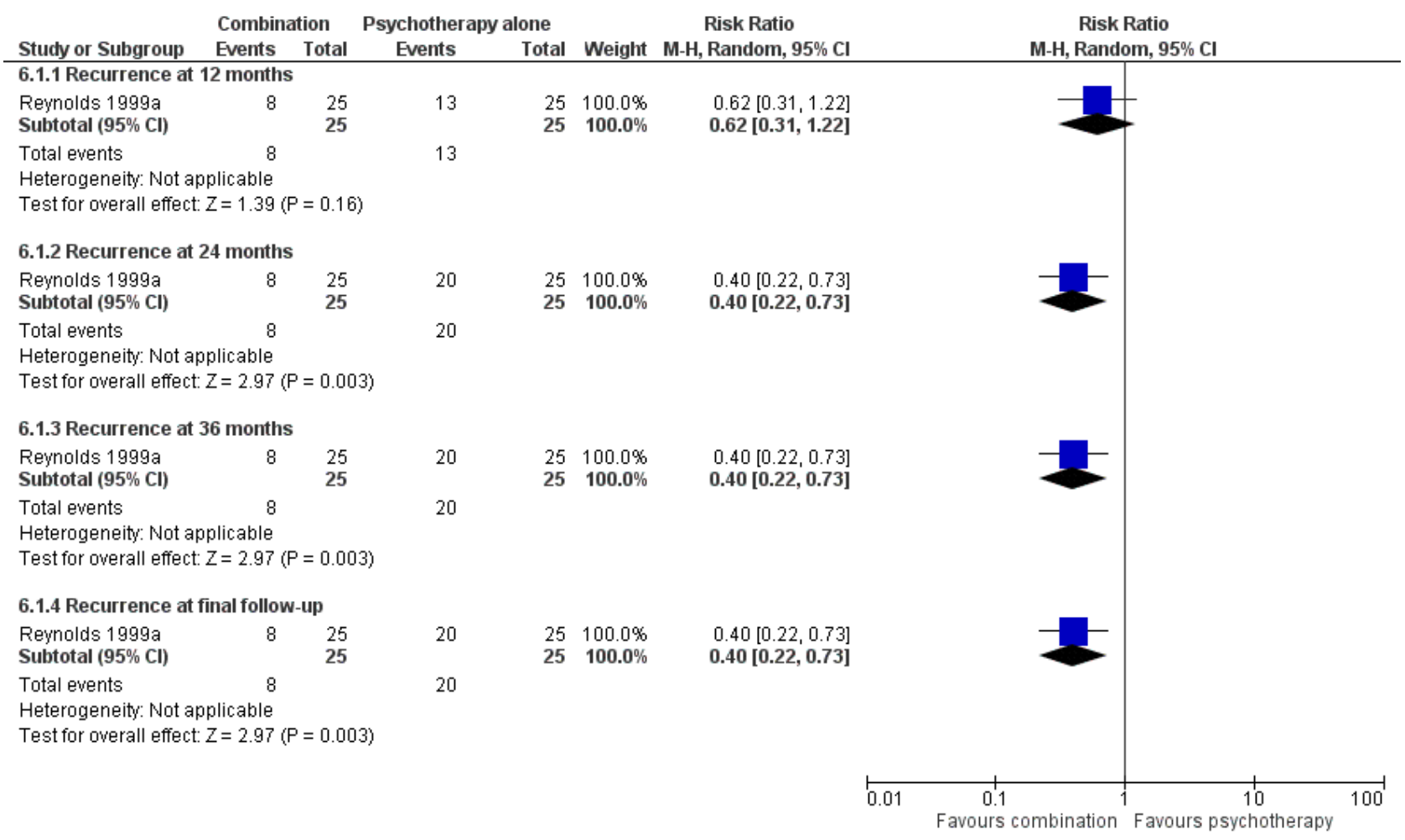

\subsection{Overall drop-out rate at 12 months}

We found no data on overall drop-out rate at 12 months.

\section{Secondary outcomes}

\subsection{Relapse/recurrence rate of depression at other time points}

In the one trial comparing the combination of psychological therapies and antidepressant with psychological therapies (IPT) alone, combination was superior to psychological therapies at 24 and 36 months ( $n=50$, RR 0.40, 95\% Cl 0.22 to 0.73; Reynolds 1999a) (Figure 9).

\subsection{Global clinical impression by the clinician}

\subsection{Global clinical impression by the participant}

We found no data on global clinical impression by the participant.

\subsection{Social functioning}

We found no data on social functioning.

\subsection{Quality of life}

We found no data on quality of life.

6.8 Deaths

We found no data on deaths.

We found no data on global clinical impression by the clinician. 


\subsection{Acceptability: overall drop-out rate}

One study yielded data to compare overall drop-out rates (excluding deaths) at 36 months in the comparisons of antidepressant versus psychological therapies, psychological therapies versus placebo, and combination of antidepressant and placebo versus psychological therapies alone (Reynolds 1999a). There were no significant differences in any of these three comparisons.

\subsection{Acceptability: drop-out rates due to drug-related adverse effects}

We found no data on drop-out rates due to drug-related adverse effects.

\section{Subgroup analyses}

It was not possible to perform either of the a priori subgroup analyses as the required data were not reported.

\section{Sensitivity analyses}

In the original review, we performed two a priori sensitivity analyses of recurrence rates in studies comparing antidepressant with placebo, on the basis of risk of bias in studies. In the first sensitivity analysis, we omitted the studies with unclear allocation concealment (Alexopoulos 2000; Klysner 2002; OADIG 1993), which produced no change in significant findings. In the second sensitivity analysis, we omitted the one study with inadequate blinding of assessors (Wilkinson 2009), which produced no change in significant findings.

We performed three additional sensitivity analyses in the original review. In the first, we removed Alexopoulos 2000 (as an outlier) from the analysis of recurrence rates in studies comparing antidepressant with placebo; this did not affect the overall findings. In the second, we removed Reynolds 1999a from the analysis (on the basis of younger age of participants); this did not affect the overall findings. In the third, we removed Klysner 2002 from the analysis of recurrence rates as the only study with a drop-out rate of over $20 \%$; this did not affect the overall findings.

In this update, we performed further sensitivity analyses in response to feedback on the original review (received 20 April 2015). These analyses were to assess the effect of excluding drop-outs from recurrence rates in Reynolds 1999a. The study authors used censoring of drop-outs for their survival analysis whereas this review used the more conservative intention-totreat for point-in-time analysis. We assumed that all drop-outs had occurred during year one of follow-up as the study authors were unable to provide exact timings of the drop-outs. The sensitivity analyses produced no changes in significant findings except in comparison six (antidepressants/psychological therapies combination versus psychological therapies alone) where the combination of antidepressant and psychological therapy became superior to psychological therapy alone at 12 months, in the one study making this comparison.

\section{DISCUSSION}

\section{Summary of main results}

This updated review was based on data from seven studies from which six comparisons were possible, involving 803 participants. Six of the studies compared continuation/ maintenance antidepressant treatment with placebo. Only two studies involved psychological therapies. Both of these examined the effect of psychological therapies in combination with antidepressant medication compared with medication alone and one also compared the combination with both psychological therapies alone and placebo alone. Follow-up intervals varied between the studies from six to 36 months.

\section{Antidepressants versus placebo}

Results for the primary outcomes are shown in Summary of findings for the main comparison.

Six trials involving 708 participants compared continuation/ maintenance antidepressant treatment with placebo, three trials using TCAs and three using SSRIs. Continuation/maintenance antidepressant medication reduced risk of recurrence after 12 months with an NNTB of 5 . There was marked clinical heterogeneity in the studies and significant numbers of drop-outs, but the direction of the effect was in favour of antidepressants in all trials. There was no statistically significant risk reduction for recurrence at 24 months when the analysis included all six studies. However, when data from the three trials of TCAs were analysed separately, there was a statistically significant reduction in recurrence risk with an NNTB of 5. It might be assumed that drop-outs due to adverse effects would be greater with TCAs. However, there were no data that addressed this question as the only trials reporting drop-outs due to adverse effects separately were the trials of SSRIs.

In the one trial in which participants were followed up for 36 months, maintenance antidepressant medication reduced risk of recurrence after with an NNTB of 5 (Reynolds 1999a). Participants in this trial were relatively young and cognitively unimpaired compared to participants in other trials. In this trial, in addition to outcome assessments, participants receiving placebo also attended medication clinics for physical assessment. For the purpose of this review, we considered this a placebo condition comparable to other studies in this comparison, but the medication clinic contact could be considered as an active treatment component.

\section{Antidepressants versus psychological therapies}

Only one trial, involving 53 participants, compared an antidepressant (nortriptyline) with a psychological therapy (IPT). There was no significant difference in terms of recurrence of depression. Therefore, the available data were too limited to allow for any clear conclusion on the comparative efficacy of antidepressants and psychological therapies. There were no deaths among participants.

\section{Antidepressant/psychological therapies combination versus antidepressant}

Two trials involving 98 participants compared a combination of continuation/maintenance antidepressant and psychological therapies with antidepressant alone. There was low heterogeneity between the two studies, despite their using different psychological treatments (group CBT and IPT). There was no significant difference in terms of recurrence of depression and no separate data on drop-outs due to adverse effects. Only one trial reported dropouts due to deaths, with no difference between combination of continuation/maintenance antidepressant and psychological therapies and control. The available data were too limited to allow for any clear conclusions on comparative efficacy. 


\section{Psychological therapies versus drug placebo}

Only one trial compared IPT with drug placebo, in 54 participants. Overall, there was no significant difference in recurrence. There were no deaths recorded in either arm. They did not report dropouts due to adverse effects.

\section{Antidepressant/psychological therapies combination versus psychological therapies alone}

Only one trial compared antidepressant/psychological therapies combination with psychological therapies alone (IPT) in 50 participants. There was a significant superiority of combination over psychological therapy alone at 24 and 36 months of follow-up, but no significant difference at 12 months' follow-up. They reported no deaths. They did not report drop-outs due to adverse effects. Although this suggests that at two and three years the combination is more efficacious, it is possible that the finding in this one study has arisen by chance.

\section{Antidepressant/psychological therapies combination versus drug placebo}

Only one trial compared antidepressant/psychological therapies combination with drug placebo in 54 participants. Overall, combination treatment was significantly superior to placebo at 12 , 24, and 36 months' follow-up with an NNTB of 2 at 12 months and 3 at 36 months. They reported no deaths and did not record dropouts due to adverse effects.

\section{Overall completeness and applicability of evidence}

We identified only a small number of trials of antidepressant medication including two TCA drugs (nortriptyline and dothiepin) and three SSRIs (escitalopram, citalopram, and sertraline). Thus, evidence is lacking on other classes of antidepressant drug such as SNRIs, MAOIs, and mirtazapine (a NASSA), and other types of TCAs.

We included only two trials involving psychological therapies so clearly further evaluation of psychological therapies is required, including IPT, CBT, and other psychological therapies such as psychodynamic, behavioural, and mindfulness-based cognitive therapy.

The follow-up periods of the included trials varied. Only one trial followed up participants for as long as 36 months.

Data on tolerability of treatments were lacking as most studies did not record drop-out specifically due to adverse effects and deaths.

For this review, the outcome used as a measure of efficacy was recurrence rates at six-month intervals, that is, the raw number of new episodes detected at these intervals. However, in practice, the effect of treatment may be to delay the onset of episodes of depression by varying periods, which may still represent a clinically beneficial change. Some studies used survival analysis to capture this, but it is not reported in this review. It is also possible that treatment may reduce the severity of subsequent episodes (Montgomery 1992) which, again, may be of clinical benefit but is not addressed in this review.

\section{Quality of the evidence}

\section{Limitations in study design or execution (risk of bias)}

All of the trials were randomised and double-blind. However, only one trial specifically discusses whether blinding of psychological therapies was successful (Wilkinson 2009). Allocation concealment was unclear in four of the seven studies. We judged two studies to have employed selective reporting of outcome data.

The clinical effects of discontinuing antidepressants in placebocontrolled maintenance trials could increase the apparent rates of relapse and recurrence in placebo arms thereby increasing in the apparent efficacy of antidepressants (Montgomery 1992). This would be most likely if careful dose titration is not employed. In the three studies in this review employing placebo antidepressant arms, procedures for antidepressant withdrawal were not clear.

\section{Inconsistency of results}

Data were incomplete in places, for instance on the timing of dropouts in Reynolds 1999a; so, in this review, we assumed that all drop-outs were in the first year of follow-up. Drop-out rates varied between studies from 0\% (Alexopoulos 2000) to 22\% (Klysner 2002). A sensitivity analysis omitting Klysner 2002 did not affect overall the outcome.

\section{Indirectness of evidence}

All studies directly addressed the main review question, that of prevention of relapse and recurrence in older people remitted from an episode of depression while taking antidepressant medication.

\section{Imprecision}

There was a low number of studies in the review. For instance, only one study reported data on the primary outcome of overall dropouts at 12 months in antidepressant medication versus placebo.

\section{Publication bias}

We produced a funnel plot to assess possible publication bias in the trials included in the main comparison (antidepressants versus placebo) (Figure 10). The total number of studies (fewer than 10) means that application of a formal test of asymmetry was not appropriate. Simple visual inspection suggested possible publication bias with under-reporting of small trials showing no effect; however, we identified no unpublished studies in communications with experts and known researchers in the field. 
Figure 10. Funnel plot of comparison: 1 Antidepressant versus placebo, outcome: 1.2 Recurrence.

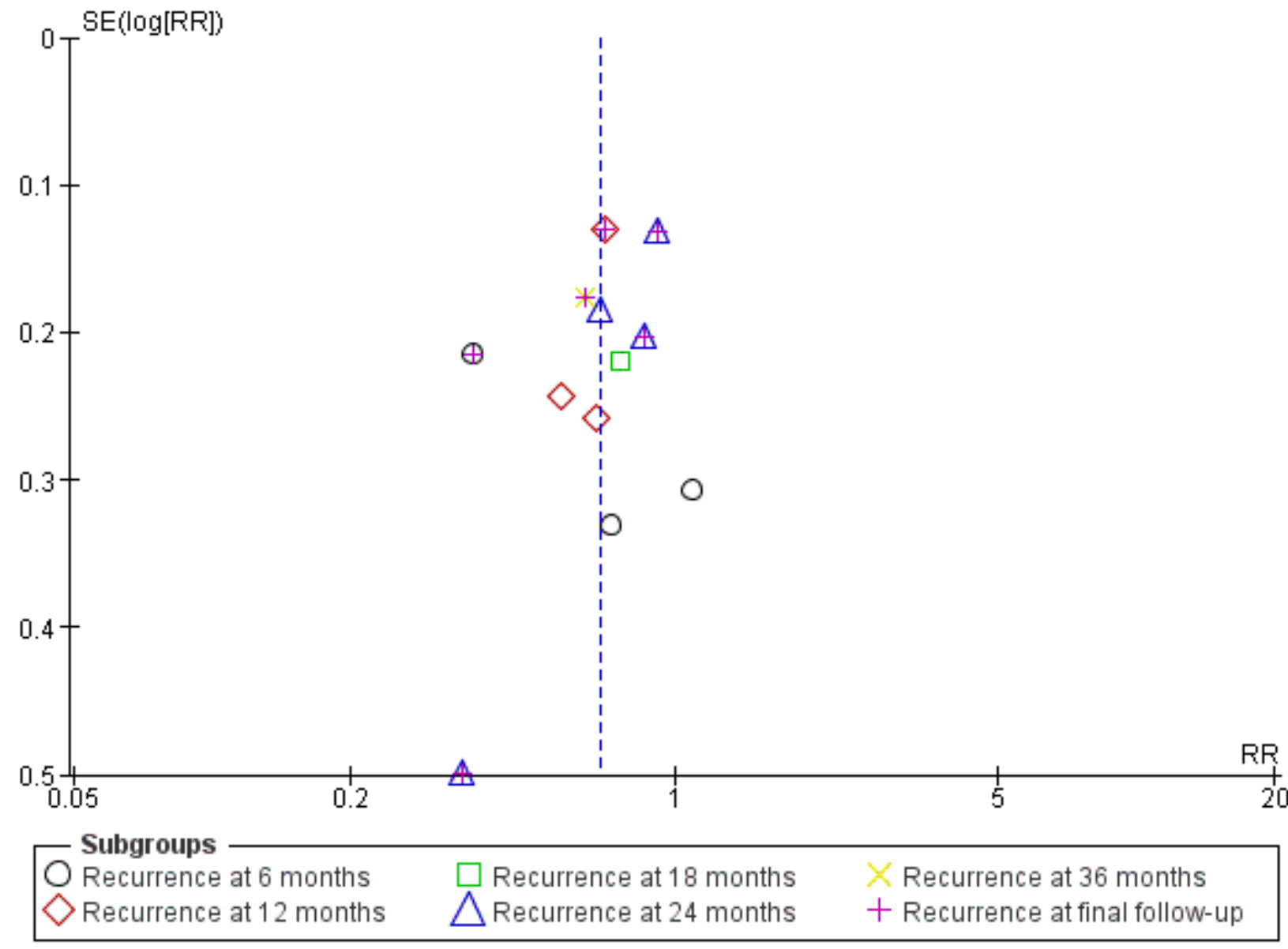

\section{Potential biases in the review process}

The search in this review was based on the Cochrane Common Mental Disorders (CCMD) Controlled Register of Trials (which is largely composed of searches of already published literature), as well as the review authors' own searches. Therefore, it is possible that there are unpublished trials that we are not aware of although it is expected that these would have been identified through the communications that were made with experts and researchers in the field.

It is clear that there was significant between-trial clinical heterogeneity in this review. For instance, participants in some trials were more cognitively impaired, some had greater physical morbidity, some were older on average, and some had been treated as inpatients. Some trials used more stringent criteria for remission before randomisation, while run-in and dose-tapering periods varied between trials.

Another potential source of heterogeneity was the range of psychological treatments included in the review. However, only one analysis combined results from different psychological treatments (combination versus antidepressants at 12 months) and heterogeneity was low. This potential source of heterogeneity might be addressed in future versions of this review by categorising psychological treatments, for instance, including problem-solving therapies in CBT.
For the purposes of this review, we treated medication clinic and placebo in Reynolds 1999b as a pure placebo condition. Face-toface clinician contact in the medication clinic could be regarded as making this an active intervention. However, we believe this to be an adequate comparison as it helps to control for the effect of clinician contact in the parallel psychological treatment condition, IPT.

Recruiting older people to clinical research trials can be difficult due to the burden of research, and communication difficulties, etc. (Forster 2010). Therefore, selection bias in studies may have arisen in this review if the participants who were successfully recruited were not representative of people in the general clinical population.

When study sponsors have an interest in the outcome of a study, there is a risk of bias in the reporting of results. This review did not include data on funding source of studies so the potential for funding bias was not assessed.

Despite the differences between trials, we believe that metaanalysis was appropriate. We addressed heterogeneity using the random-effects model in meta-analysis as this allows for clinical heterogeneity between trial populations. The randomeffects model does emphasise the results from smaller trials, which are often those most prone to bias. However, when we performed a fixed-effect analysis for the main finding of the review (reduced 
recurrence rates for antidepressant medication versus placebo at 12 months), there was no difference in the overall relative risks calculated. We also examined the effects of clinical heterogeneity using sensitivity analysis with change in overall findings.

This review used a point-in-time dichotomous outcome (recurrence rate from intention-to-treat analyses) for the main meta-analysis. While we believe this to be the most appropriate method for the review, it is acknowledged that it may produce more conservative estimates of treatment effect than survival analysis and use of hazard ratios (Michiels 2005).

Some of the analyses in this review used very small numbers of studies and may not have had sufficient statistical power to detect small effect sizes. However, we did not perform a power calculation to assess this.

The effects of antidepressant discontinuation can be misinterpreted as symptoms of depression recurrence. Therefore, there is an argument for excluding recurrences in the first four weeks of randomisation from analysis, although we did not apply this strategy in this review.

\section{Agreements and disagreements with other studies or reviews}

In one review of RCTs of continuation/maintenance antidepressant treatment with adults of all ages, five of 31 included trials were with older adults, although there was no separate analysis of these trials (Geddes 2003). Continuing treatment with antidepressants reduced the odds of relapse by $70 \%$, compared with a reduction in this review (specifically with adults aged 60 years and over) of $52 \%$ at final outcome.

Kok et al. evaluated the efficacy of antidepressant treatment in the prevention of recurrence of depression in older people through a systematic review of literature and meta-analysis of seven RCTs (Kok 2011). We excluded two trials that were included in Kok's meta-analysis from this review: the first because it included participants aged 55 years and above with no separate analysis of data from participants aged 60 years and above (Georgotas 1989); and the second because participants were allowed to continue augmentation treatments after randomisation (Reynolds 2006). We included the other six trials from Kok's review in the equivalent comparison in this review. There were also some methodological differences in Kok's meta-analysis: only final follow-up data from six to 36 months were pooled, with no breakdown by followup interval; drop-outs from treatment were not included in recurrences/relapses; and in extracting data from Reynolds 1999a, Kok et al. combined data from participants receiving interpersonal psychological therapies with participants in drug placebo arms. However, despite the differences between the reviews, Kok et al. reported a comparable NNTB of 3.6 (to be rounded to 4 ) to prevent one additional recurrence/relapse, and no difference in tolerability between TCAs and SSRIs.

Frederick et al. reported an expert-panel informed narrative review of treatments for late-life depression, but this did not include continuation or maintenance treatments (Frederick 2007).

The review authors are not aware of any other reviews of trials of continuation/maintenance psychological therapies in late-life depression.

\section{AUTHORS' CONCLUSIONS}

\section{Implications for practice}

As far as the review authors are aware, this is the first systematic review of both antidepressants and psychological therapies in the prevention of recurrence of depression in people aged 60 years and over who have recovered from a depressive illness while taking antidepressant medication. Although there was a significant reduction in recurrence rates in three trials comparing selective serotonin reuptake inhibitors or tricyclic antidepressants with placebo medication at 12 months' follow-up, the metaanalysis was relatively underpowered due to small sample sizes; analyses at other time points did not reach statistical significance. In addition, the quality of this evidence was low as assessed with the GRADE guideline development tool. Therefore, on the basis of this review, we can make no firm recommendations on the optimum period of antidepressant maintenance treatment with older adults. Therefore, the best evidence to date comes from trials with adults of all ages (NICE 2010), which is to continue treatment for at least six months, or for two years or longer if there is a known high likelihood of recurrence or significant clinical risks. As trials reported significant numbers of drop-outs, it is possible that the benefit of treatment is greater in people remaining on antidepressant medication. There was no difference in treatment acceptability (as measured by overall drop-outs and drop-outs due to adverse effects) or death rates between antidepressant and placebo.

There was no significant overall benefit for antidepressant treatment at 24 months' follow-up in four trials with 282 participants, but when we combined data from the three trials of tricyclic antidepressant medication (169 participants), there was a significant reduction in recurrence (number needed to treat for an additional beneficial outcome (NNTB) $=5$ ). In the one trial that followed up participants taking a tricyclic antidepressant for 36 months, there was evidence of benefit of treatment compared with placebo (NNTB = 4). Thus, it is possible that tricyclic antidepressants have significant longer-term benefits (two to three years) in the prevention of recurrence of depression.

On the basis of this review, it is not possible to make recommendations on the characteristics of people most likely to benefit from long-term antidepressant treatment.

There were only two small trials of psychological therapies in the review and we can make no firm recommendations on the use of psychological therapies in the prevention of recurrence in older adults. Therefore, the best evidence to date comes from trials with adults of all ages (NICE 2010), which is to consider cognitive behavioural therapy or mindfulness-based cognitive therapy if depression is recurrent. It is possible that in 'younger old' adults (aged 60 to 70 years) without significant physical health problems or cognitive impairment, IPT may be as efficacious as tricyclic antidepressant at preventing recurrence for up to three years.

The effects of combining psychological therapies with antidepressant are also unclear. Combined data from the two trials showed no significant benefit of combination compared with antidepressant therapy alone. In one trial, psychological therapies appeared as effective as combined treatment at 12 months' followup, but not in longer-term follow-up. 


\section{Implications for research}

This review included only a small number of trials with small numbers of participants. Larger trials are needed to confirm the longer-term benefits of antidepressant medication in older people. A direct comparison of selective serotonin reuptake inhibitors with tricyclic antidepressants would determine whether tricyclic antidepressants are superior and equally acceptable in older people; this might include both low- and high-dose tricyclic antidepressant arms as there is a trade-off between clinical benefits and adverse effects with this class of antidepressant (Reynolds 1999b).

Despite the apparent benefit of maintaining antidepressant treatment, one-year recurrence rates in people remaining on treatment are high (around 50\% in this review). Thus, it is important that future research identifies additional strategies that might improve outcomes. This research should include further, larger trials of a broader range of interventions, including psychological therapies. In one study by Reynolds 2011, the addition of the cholinesterase inhibitor donepezil to maintenance antidepressant medication did not further reduce recurrence rate.

Trial participants in this review were mainly the 'younger old' and physically well. A further study with participants aged 70 years and over demonstrated benefit from antidepressant medication but a poorer response to interpersonal psychological therapies (Reynolds 2006, excluded from this review). Some large and important studies addressing maintenance treatments do include older adults in among adults of all ages. For instance, a study of mindfulness-based cognitive therapy published since the original review included participants up to 79 years of age but without separate analysis of data from older participants (Kuyken 2015). We believe that it is important that future trials of maintenance treatments in late-life depression, both with antidepressants and psychological therapies, are conducted solely with populations of participants representative of older adults increasingly encountered in routine clinic practice, that is, over 70 years of age, experiencing mild-to-moderate cognitive impairment, and with comorbid physical illnesses. This would properly address the impact of age-related clinical factors on response to different treatment modalities. It is also important to understand the precise role of neuropsychological deficits in late-life depression better and the extent to which they are reversed by treatment (Korsnes 2015).

Future studies should examine the reasons for drop-out and include quality of life measures and cost-effectiveness analysis.

\section{ACKNOWLEDGEMENTS}

We would like to thank the staff of the Oxford Health NHS Foundation Trust libraries and Oxford University Radcliffe Science Library for their help in obtaining studies and members of the editorial team of the Cochrane Depression, Anxiety and Neurosis Review Group for their editorial assistance with this review. We would also like to thank Nicola Williams (née Alder) of the Centre for Statistics in Medicine for performing the cluster analysis on data from Wilkinson 2009. 


\section{R E F E R E N C E S}

\section{References to studies included in this review}

Alexopoulos 2000 \{published data only\}

Alexopoulos GS, Barnett SM, Young RC, Kalayam B, Kakuma T, Gabrielle M, et al. Executive dysfunction and long-term outcomes of geriatric depression. Archives of General Psychiatry 2000;57:285-90.

\section{Gorwood 2007 \{published data only\}}

Dolberg O, Lonn LS, Kvist K. Factors predicting relapse in elderly patients with major depressive disorder treated with escitalopram in an outpatient setting. Current Medical Research and Opinion 2014;30(7):1301-7. [10.1185/03007995.2014.904770]

* Gorwood P, Weiller E, Lemming O, Katona C. Escitalopram prevents relapse in older patients with major depressive disorder. American Journal of Geriatric Psychiatry 2007;15(7):581-93.

Lyketsos CG, Weiller E, Katona C, Gorwood P. Are old-old patients with major depression more likely to relapse than young-old patients during continuation treatment with escitalopram?. BMC Geriatrics 2011;11:2.

\section{Klysner 2002 \{published data only\}}

Bent-Hansen J, Lunde M, Klysner R, Andersen M, Tanghoj P, Solstad $\mathrm{K}$, et al. The validity of the depression rating scales in discriminating between citalopram and placebo in depression recurrence in the maintenance therapy of elderly unipolar patients with major depression. Pharmacopsychiatry 2003;36(6):313-6.

* Klysner R, Bent-Hansen J, Hansen HL, Lunde M, Pleidrup E, Poulsen DL, et al. Efficacy of citalopram in the prevention of recurrent depression in elderly patients: placebo-controlled study of maintenance therapy. British Journal of Psychiatry 2002;181:29-35.

Klysner R, Pledrup E, Hansen HL, Loldrup Poulsen D, Hansen JB, Lunde $\mathrm{M}$, et al. The effectiveness of citalopram in the prevention of depression recurrence in elderly patients. 14th Annual Meeting of the American Association for Geriatric Psychiatry; 2001 Feb 23-26; San Francisco, CA. 2001.

Klysner R, Pleidrup E, Hansen HL, Bent-Hansen J, Loldrup PD, Lunde $M$, et al. The effectiveness of citalopram in the prevention of depression recurrence in elderly patients. International Journal of Neuropsychopharmacology 2000;3(Suppl 3):211.

Klysner R, Pleidrup E, Hansen HL, Bent-Hansen J, Loldrup Poulsen D, Hopfner Petersen HE. The effectiveness of citalopram in the prevention of depression recurrence in elderly patients. 153rd Annual Meeting of the American Psychiatric Association; 2000 May 13-18; Chicago, IL. 2000:NR472.

\section{OADIG 1993 \{published data only\}}

Old Age Depression Interest Group. How long should the elderly take antidepressants? A double-blind placebo-controlled study of continuation/prophylaxis therapy with dothiepin. British Journal of Psychiatry 1993;162:175-82.
Reynolds 1999a \{published data only\}

Dew MA, Reynolds CF 3rd, Mulsant B, Frank E, Houck PR, Mazumdar S, et al. Initial recovery patterns may predict which maintenance therapies for depression will keep older adults well. Journal of Affective Disorders 2001;65(2):155-66.

Lenze EJ, Dew MA, Mazumdar S, Begley AE, Cornes C, Miller MD, et al. Combined pharmacotherapy and psychotherapy in maintenance treatment of late-life depression: effects on social adjustment, perception of health, and quality of life. 14th Annual Meeting of the American Association for Geriatric Psychiatry; 2001 Feb 23-26; San Francisco. 2001.

Miller MD, Frank E, Cornes C, Houck PR, Reynolds CF 3rd. The value of maintenance interpersonal psychotherapy (IPT) in older adults with different IPT foci. American Journal of Geriatric Psychiatry 2003;11(1):97-102.

Reynolds CF 3rd, Frank E, Dew MA, Houck PR, Miller M, Mazumdar S, et al. Treatment of 70(+)-year-olds with recurrent major depression. Excellent short-term but brittle longterm response. American Journal of Geriatric Psychiatry 1999;7(1):64-9.

* Reynolds CF III, Frank E, Perel JM, Imber SD, Cornes C, Miller MD, et al. Nortriptyline and interpersonal psychotherapy as maintenance therapies for recurrent major depression. A randomized controlled trial in patients older than 59 years. JAMA 1999;281(1):39-45.

\section{Wilkinson 2009 \{published data only\}}

Wilkinson P, Alder N, Juszczak E, Matthews H, Merritt C, Montgomery $\mathrm{H}$, et al. A pilot randomised controlled trial of a brief cognitive behavioural group intervention to reduce recurrence rates in late life depression. International Journal of Geriatric Psychiatry 2009;24:68-75.

\section{Wilson 2003 \{published data only\}}

Abou-Saleh M, Abou-Saleh MT, Wilson K. Prevention of relapse recurrence of depression: sertraline vs placebo in the elderly. XII World Congress of Psychiatry; 2002 Aug 24-29; Yokohama, Japan. 2002.

* Wilson KCM, Mottram PG, Ashworth L, Abou-Saleh MT. Older community residents with depression: long-term treatment with sertraline. British Journal of Psychiatry 2003;182:492-7.

\section{References to studies excluded from this review}

\section{Reynolds 1999b \{published data only\}}

Reynolds CF III, Perel JM, Frank E, Cornes C, Miller MD, Houck PR, et al. Three-year outcomes of maintenance nortriptyline treatment in late-life depression: a study of two fixed plasma levels. American Journal of Psychiatry 1999;156(8):1177-81.

\section{Reynolds 2006 \{published data only\}}

Carreira K, Miller MD, Frank E, Houck PR, Morse JQ, Dew MA, et al. A controlled evaluation of monthly maintenance Interpersonal psychotherapy in late-life depression with varying 
levels of cognitive function. International Journal of Geriatric Psychiatry 2008;23:1110-3.

Dombrovski AY, Lenze EJ, Dew MA, Mulsant BH, Pollock BG, Houck PR, et al. Maintenance treatment for old-age depression preserves health-related quality of life: a randomized, controlled trial of paroxetine and interpersonal psychotherapy. Journal of the American Geriatrics Society 2007;55(9):1325-32.

* Reynolds CF, Dew MA, Pollock BG, Mulsant BH, Frank E, Miller MD, et al. Maintenance treatment of major depression in old age. New England Journal of Medicine 2006;354:1130-8.

\section{Additional references}

\section{Abou-Saleh 2010}

Abou-Saleh MT, Katona C. Pharmacological treatment of depression. In: Abou-Saleh MT, Katona C editor(s). Principles and Practice of Geriatric Psychiatry. 3rd Edition. Chichester: Wiley, 2010:537-42.

\section{APA 1994}

American Psychiatric Association (APA). Diagnostic and Statistical Manual version IV. Washington, DC: American Psychiatric Association, 1994.

\section{Areán 2007}

Areán PA, Alexopoulos GS. Psychosocial interventions for mental illness in late-life. International Journal of Geriatric Psychiatry 2007;22:99-100.

\section{Beck 1996}

Beck AT, Steer RA, Brown GK. The Beck Depression Inventory. San Antonio, Texas: The Psychological Corporation, 1996.

\section{Blackburn 1997}

Blackburn IM, Moore RG. Controlled acute and follow-up trial of cognitive therapy and pharmacotherapy in out-patients with recurrent depression. British Journal of Psychiatry 1997;171:328-34.

\section{Blackburn 2001}

Blackburn I, James IA, Milne DL, Baker C, Standart S, Garland A, et al. The Revised Cognitive Therapy Scale (CTS$\mathrm{R})$ : psychometric properties. Behavioural and Cognitive Psychotherapy 2001;29:431-46.

\section{Blazer 2000}

Blazer D. Psychiatry and the oldest old. American Journal of Psychiatry 2000;157:1915-24.

\section{Cole 1997}

Cole MG, Bellevance F. The prognosis of depression in old age. American Journal of Geriatric Psychiatry 1997;5:4-14.

\section{Copeland 1976}

Copeland JRM, Kelleher MJ, Kellett JM, Gourlay AJ, Gurland BJ, Fleiss JL, et al. A semi-structured clinical interview for the assessment of diagnosis and mental state in the elderly: the Geriatric Mental State Schedule. Development and reliability. Psychological Medicine 1976;6(3):439-49.

\section{Evans 2003}

Evans $\mathrm{O}$, Singleton $\mathrm{N}$, Meltzer $\mathrm{H}$, Stewart R, Pince M. The mental health of older people. The mental health of older people. London: HMSO, 2003.

\section{Feighner 1972}

Feighner JP, Robins E, Guze SB, Woodruff RA Jr, Winokur G, Munoz R. Diagnostic criteria for use in psychiatric research. Archives of General Psychiatry 1972;26(1):57-63.

\section{Forster 2010}

Forster E, Jones L, Saxton JM, Flower DJ, Foulds G, Powers $\mathrm{HJ}$, et al. Recruiting older people to a randomised controlled dietary intervention trial - how hard can it be? BMC Medical Research Methodology 2010;10:17. [DOI: 10.1186/1471-2288-10-17]

\section{Frank 1991}

Frank E, Prien R, Jarrett RB, Keller MB, Kupfer DJ, Lavori PW, et al. Conceptualization and rationale for consensus definitions of terms in major depressive disorder. Archives of General Psychiatry 1991;48:851-5.

\section{Frederick 2007}

Frederick JT, Steinman LE, Prohaska T, Satariano WA, Bruce M, Bryant L, et al for the Late Life Depression Special Interest Project Panelists. Community-based treatment of late life depression. An expert panel-informed literature review. American Journal of Preventive Medicine 2007;33(3):222-49.

\section{Gansler 2015}

Gansler DA, Suvak M, Arean P, Alexopoulos GS. Role of executive dysfunction and dysexecutive behaviour in late-life depression and disability. American Journal of Geriatric Psychiatry 2015;23(10):1038-45.

\section{Garner 2008}

Garner J. Psychological treatments: psychodynamic psychotherapy. Oxford Textbook of Old Age Psychiatry. Oxford: OUP, 2008:275-83.

\section{Geddes 2003}

Geddes J, Carney S, Davies C, Furukawa T, Kupfer D, Frank E, et al. Relapse prevention with antidepressant drug treatment in depressive disorders: a systematic review. Lancet 2003;361:653-61.

\section{Georgotas 1989}

Georgotas A, McCue RE, Cooper TB. A placebo-controlled comparison of nortriptyline and phenelzine in maintenance therapy of elderly depressed patients. Archives of General Psychiatry 1989;46:783-6.

\section{GRADEpro [Computer program]}

McMaster University. GRADEpro. McMaster University, 2014.

\section{Guy 1976}

Guy W. Clinical Global Impressions: ECDEU Assessment Manual for Psychopharmacology. Rockville, MD: National Institute of Mental Health, 1976. 


\section{Hamilton 1960}

Hamilton M. A rating scale for depression. Journal of Neurology, Neurosurgery and Psychiatry 1960;23:56-62.

\section{Higgins 2011}

Higgins JPT, Green S (editors). Cochrane Handbook for Systematic Reviews of Interventions Version 5.1.0 [updated March 2011]. The Cochrane Collaboration, 2011. Available from www.cochrane-handbook.org.

\section{Katona 2002}

Katona CL, Livingstone $\mathrm{G}$. How well do antidepressants work in older people: a systematic review of number needed to treat. Journal of Affective Disorders 2002;69:47-52.

\section{Kok 2011}

Kok RM, Heeren TJ, Nolen WA. Continuing treatment of depression in the elderly: a systematic review and metaanalysis of double-blinded randomized controlled trials with antidepressants. American Journal of Geriatric Psychiatry 2011;19(3):249-55.

\section{Korsnes 2015}

Korsnes MS, Ulstein ID. Cognitive effects of late life depression: review of neuropsychological findings. Journal of Behavioral and Brain Science 2015;4:141-57.

\section{Kuyken 2015}

Kuyken W, Hayes R, Barrett B, Byng R, Dalgleish T, Kessler D, et al. Effectiveness and cost-effectiveness of mindfulness-based cognitive therapy compared with maintenance antidepressant treatment in the prevention of depressive relapse or recurrence (PREVENT): a randomised controlled trial. Lancet 2015;386 (9988):63-73.

\section{Lenze 2005}

Lenze EJ, Schulz R, Martire LM, Zdaniuk B, Glass T, Kop WJ, et al. The course of functional decline in older people with persistently elevated depressive symptoms: longitudinal survey from the Cardiovascular Health Study. Journal of the American Geriatrics Society 2005;53(4):569.

\section{Luborsky 1962}

Luborsky L. Clinician's judgments of mental health. Archives of General Psychiatry 1962;7:407-17.

\section{Michiels 2005}

Michiels S, Piedbois P, Burdett S. Meta-analysis when only the median survival times are known: a comparison with individual patient data results. International Journal of Technology Assessment in Health Care 2005;21(1):119-25.

\section{Miller 2003}

Miller MD, Frank E, Cornes C, Houck PR, Reynolds CF 3rd. The value of maintenance interpersonal psychotherapy (IPT) in older adults with different IPT foci. American Journal of Geriatric Psychiatry 2003;11(1):97-102.

\section{Montgomery 1979}

Montgomery S, Åsberg M. A new depression scale designed to be sensitive to change. British Journal of Psychiatry 1979;134:382-9.

\section{Montgomery 1992}

Montgomery SA, Montgomery DB. Prophylactic treatment in recurrent unipolar depression. In: Montgomery S, Rouillon F editor(s). Long-term Treatment of Depression. Chichester: Wiley, 1992:53-79.

\section{Mottram 2009}

Mottram PG, Wilson K, Strobl JJ. Antidepressants for depressed elderly. Cochrane Database of Systematic Reviews 2009, Issue 1. [DOI: 10.1002/14651858.CD003491.pub2]

\section{NICE 2010}

National Institute for Health and Care Excellence. The treatment and management of depression in adults (updated version). National Clinical Practice Guideline 90, 2010. www.nice.org.uk/ Guidance/cg90 (accessed 8 August 2016).

\section{Paykel 2005}

Paykel E, Scott J, Cornwall P, Abbott R, Crane C, Pope M, et al. Duration of relapse prevention after cognitive therapy in residual depression: follow-up of controlled trial. Psychological Medicine 2005;35:59-68.

\section{Percudani 2005}

Percudani MBC, Fortino I, Petrovich L. Antidepressant drug prescribing among elderly subjects: a population-based study. International Journal of Geriatric Psychiatry 2005;20:113-8.

\section{RevMan 2014 [Computer program]}

The Nordic Cochrane Centre. Review Manager (RevMan) [Computer program]. Version 5.3. Copenhagen: The Cochrane Collaboration, 2014.

\section{Reynolds 2011}

Reynolds CF 3rd, Butters MA, Lopez O, Pollock BG, Dew MA, Mulsant $\mathrm{BH}$, et al. Maintenance treatment of depression in old age. A randomized, double-blind, placebo-controlled evaluation of the efficacy and safety of donepezil combined with antidepressant pharmacotherapy. Archives of General Psychiatry 2011;68(1):51-60.

\section{Segal 2002}

Segal ZV, Williams JMG, Teasdale JD. Mindfulness-based Cognitive Therapy for Depression: a New Approach to Preventing Relapse. New York: Guilford Press, 2002.

\section{Serfaty 2009}

Serfaty M, Haworth D, Blanchard M, Buszewicz M, Murad S, King M. Clinical effectiveness of individual cognitive behavioral therapy for depressed older people in primary care. Archives of General Psychiatry 2009;66(12):1332-40.

\section{Valkonova 2013}

Valkanova V, Ebmeier KP. Vascular risk factors and depression in later life: a systematic review and meta-analysis. Biological Psychiatry 2013;73:406-13. 


\section{Wagner 1992}

Wagner EF, Frank E, Steiner SC. Discriminating maintenance treatments for recurrent depression: development and implementation of a rating scale. Journal of Psychotherapy Practice and Research 1992;22:281-91.

\section{Ware 1993}

Ware JE, Snow KK, Kosinski M, Gandek B. SF-36 Health Survey Manual and Interpretation Guide. Boston, MA: New England Medical Centre, 1993.

\section{WHO 1992}

World Health Organization. International Classification of Diseases, 10th Revision. Geneva: World Health Organization, 1992.

\section{WHO 2015}

World Health Organization. World Report on Ageing and Health, 2015. Geneva: World Health Organization.

\section{Wilkinson 2010}

Wilkinson P. Psychotherapy of depression and dysthymia. Principles and Practice of Geriatric Psychiatry. 3rd Edition. Chichester: Wiley, 2010:543-51.

\section{Wilson 2008}

Wilson K, Mottram PG, Vassilas C. Psychotherapeutic treatments for older depressed people. Cochrane Database of Systematic Reviews 2008, Issue 1. [DOI: 10.1002/14651858.CD004853.pub2]

\section{Zarit 1998}

Zarit SH, Zarit JM. Mental Disorders in Older Adults. New York: Guilford, 1998.

\section{References to other published versions of this review \\ Wilkinson 2012}

Wilkinson P, Izmeth Z. Continuation and maintenance treatments for depression in older people. Cochrane Database of Systematic Reviews 2012, Issue 11. [DOI: 10.1002/14651858.CD006727.pub2]

* Indicates the major publication for the study

\section{CHARACTERISTICS OF STUDIES}

Characteristics of included studies [ordered by study ID]

\section{Alexopoulos 2000}

\begin{tabular}{|c|c|}
\hline Methods & Design: placebo-controlled parallel trial \\
\hline \multirow[t]{11}{*}{ Participants } & $\begin{array}{l}\text { Participants: people with unipolar major depressive episode according to DSM-IV, RDC, and HDRS treat- } \\
\text { ed with nortriptyline in the acute episode and } 16 \text {-week continuation phase }\end{array}$ \\
\hline & Sex: $63 \%$ women \\
\hline & Age: $\geq 60$ years; mean 73 years \\
\hline & Unit of allocation: participant \\
\hline & Number randomised: 43 \\
\hline & Number completing (including recurrences): 43 . No attrition reported \\
\hline & Setting: psychiatry outpatient clinic in USA (Cornell University) \\
\hline & $\begin{array}{l}\text { Inclusion criteria: achieved remission from depressive episode while taking nortriptyline and remained } \\
\text { in remission for } 16 \text { weeks' continuation treatment; HDRS } \leq 10 \text {; Cornell } \leq 6\end{array}$ \\
\hline & $\begin{array}{l}\text { Exclusion criteria: other psychiatric disorder; severe medical illness or neurological disorder; MMSE } \leq \\
16 ; \text { living > } 45 \text { minutes from clinic; no informants }\end{array}$ \\
\hline & Ethnicity: not stated \\
\hline & $\begin{array}{l}\text { Baseline characteristics: } 46 \% 1 \text { previous depressive episode; } 14 \% 2 \text { previous episodes; } 8 \%>2 \text { previous } \\
\text { episodes }\end{array}$ \\
\hline \multirow[t]{3}{*}{ Interventions } & 2 treatments: \\
\hline & - Nortriptyline (level $60 \mathrm{ng} / \mathrm{mL}$ to $150 \mathrm{ng} / \mathrm{mL}$ ) and medication clinic \\
\hline & - Drug placebo after 10 weeks' titration, and medication clinic \\
\hline
\end{tabular}


Alexopoulos 2000 (Continued)

\section{Duration of intervention: 2 years}

Duration of trial: 2 years

Length of follow-up: participants were not followed up beyond the end of the intervention period

Dose adjustment: not stated

$\begin{array}{ll}\text { Outcomes } & \text { Primary outcome: recurrence of major depression on RDC/DSM-IV and HDRS } \geq 17 \\ \text { Secondary outcome: course of depressive symptoms in participants not experiencing recurrence }\end{array}$

Notes Study also examined relationship between executive dysfunction and recurrence

\section{Risk of bias}

\begin{tabular}{lll}
\hline Bias & Authors' judgement & Support for judgement \\
\hline $\begin{array}{l}\text { Random sequence genera- } \\
\text { tion (selection bias) }\end{array}$ & Low risk & $\begin{array}{l}\text { Investigators report that "...subjects were assigned either to nortriptyline ...or } \\
\text { to placebo maintenance treatment... using random computer numbers" (p. 287, } \\
\text { box, col. 1) }\end{array}$ \\
\hline $\begin{array}{l}\text { Allocation concealment } \\
\text { (selection bias) }\end{array}$ & Unclear risk & No details reported. Authors contacted but no more information available \\
\hline $\begin{array}{l}\text { Blinding (performance } \\
\text { bias and detection bias) } \\
\text { participants? }\end{array}$ & Low risk & $\begin{array}{l}\text { Investigators report that "...subjects were followed up under double-blind con- } \\
\text { ditions" (p. 287, box, col. 1) }\end{array}$ \\
\hline
\end{tabular}

Blinding (performance $\quad$ Unclear risk No details reported
bias and detection bias)
those administering treat-
ment?

\begin{tabular}{|c|c|c|}
\hline $\begin{array}{l}\text { Blinding (performance } \\
\text { bias and detection bias) } \\
\text { outcome assessors? }\end{array}$ & Low risk & $\begin{array}{l}\text { Investigators report that "...subjects were followed up under double-blind con- } \\
\text { ditions" (p. } 287 \text {, box, col. 1) }\end{array}$ \\
\hline
\end{tabular}
outcome assessors?

Incomplete outcome data Unclear risk No attrition or missing data reported but protocol not available
(attrition bias)

All outcomes

\begin{tabular}{|c|c|c|}
\hline $\begin{array}{l}\text { Selective reporting (re- } \\
\text { porting bias) }\end{array}$ & Low risk & $\begin{array}{l}\text { Study protocol not available but it seemed clear that the published report in- } \\
\text { cludes all expected outcomes }\end{array}$ \\
\hline Other bias & Unclear risk & $\begin{array}{l}\text { Participants randomised to receive placebo underwent tapering of nortripty- } \\
\text { line dose during a } 10 \text {-week transition phase. It was unclear whether this transi- } \\
\text { tion took place before starting maintenance follow-up. If so, it would have de- } \\
\text { layed maintenance phase compared with nortriptyline arm; if not, there was } \\
\text { risk of carry-over effects }\end{array}$ \\
\hline
\end{tabular}

\section{Gorwood 2007}

\begin{tabular}{ll}
\hline Methods & Placebo-controlled parallel trial \\
\hline Participants & $\frac{\text { Participants: outpatients with DSM-IV major depressive disorder and MADRS } \geq 22 \text { whose depression re- }}{\text { mitted with } 12 \text { weeks of escitalopram } 10 \mathrm{mg} \text { or } 20 \mathrm{mg}}$
\end{tabular}


Sex: approximately $79 \%$ women

Age: $\geq 65$ years; mean 73 years

Unit of allocation: participant

Number randomised: 305

Number completing (including recurrences): 282

Setting: private or hospital clinics in 46 centres across 7 European countries

Inclusion criteria: achieved remission defined as MADRS $\leq 12$ and remained in remission for 16 weeks while continuing escitalopram

Exclusion criteria: MMSE $\leq 23$; unstable or serious medical illness; current or past mania or schizophrenia; organic mental disorders; substance abuse; suicide risk; recent treatment with antipsychotic drugs, mood stabilisers or ECT; known resistance to antidepressant treatment; concurrent psychological therapies

Ethnicity: approximately $100 \%$ white

Baseline characteristics: one third of participants aged $>75$ years

- Escitalopram $10 \mathrm{mg}$ or $20 \mathrm{mg}$ (continuing dose achieved in acute open-label phase)

- Placebo (including 1 week' titration for participants receiving $20 \mathrm{mg}$ in acute phase)

Duration of intervention: 24 weeks

Duration of trial: 36 weeks

Length of follow-up: Participants were not followed up beyond the end of the intervention period.

Dose adjustment: none

Outcomes Primary outcome: recurrence as judged by investigator or MADRS $\geq 22$

Secondary outcome: change in scores on MADRS

Other outcomes: change in scores on CGI-S and CGI-I

Notes

\section{Risk of bias}

\begin{tabular}{lll}
\hline Bias & Authors' judgement & Support for judgement \\
\hline $\begin{array}{l}\text { Random sequence genera- } \\
\text { tion (selection bias) }\end{array}$ & Low risk & $\begin{array}{l}\text { Investigators reported that "...eligible patients were assigned to escitalo- } \\
\text { pram or placebo treatment according to a computer-generated randomization } \\
\text { list..." (p. 583, col. 2) }\end{array}$ \\
\hline $\begin{array}{l}\text { Allocation concealment } \\
\text { (selection bias) }\end{array}$ & Low risk & $\begin{array}{l}\text { Investigators reported that "...the details of the randomization series were un- } \\
\text { known to any of the investigators and were contained in a set of sealed opaque } \\
\text { envelopes. At each study center, sequentially enrolled patients were assigned } \\
\text { the lowest randomization number available in blocks of four" (p. 583, col. 2) }\end{array}$ \\
\hline $\begin{array}{l}\text { Blinding (performance } \\
\text { bias and detection bias) } \\
\text { participants? }\end{array}$ & Low risk & $\begin{array}{l}\text { Investigators reported that "All study personnel and participants were blinded } \\
\text { to treatment assignment for the duration of the study" (p. 583, col. 2) }\end{array}$ \\
\hline
\end{tabular}




\section{Gorwood 2007 (Continued)}

Blinding (performance Low risk Investigators reported that "All study personnel and participants were blinded bias and detection bias) to treatment assignment for the duration of the study" (p. 583, col. 2)

those administering treatment?

\begin{tabular}{lll}
\hline $\begin{array}{l}\text { Blinding (performance } \\
\text { bias and detection bias) } \\
\text { outcome assessors? }\end{array}$ & Low risk & $\begin{array}{l}\text { Investigators reported that "All study personnel and participants were blinded } \\
\text { to treatment assignment for the duration of the study" (p. 583, col. 2) }\end{array}$ \\
\hline $\begin{array}{l}\text { Incomplete outcome data } \\
\begin{array}{l}\text { (attrition bias) } \\
\text { All outcomes }\end{array}\end{array}$ & Low risk & $\begin{array}{l}\text { Investigators reported that 219 out of } 305 \text { randomised participants completed } \\
\text { the study. Intention-to-treat analysis performed using last observation carried } \\
\text { forward and mixed model repeated-measures analysis }\end{array}$ \\
\hline $\begin{array}{l}\text { Selective reporting (re- } \\
\text { porting bias) }\end{array}$ & Unclear risk & Protocol not available, but report appeared to include all expected outcomes \\
\hline \begin{tabular}{l} 
Other bias \\
\hline
\end{tabular} & Unclear risk & Medication tapering regimen unclear \\
\hline
\end{tabular}

Klysner 2002

Methods Design: placebo-controlled parallel trial

\section{Participants}

Participants: recruited through screening, diagnosed with DSM-IV unipolar major depression and MADRS $\geq 22$ whose depression remitted with 8 weeks' open-label citalopram $20 \mathrm{mg}, 30 \mathrm{mg}$, or $40 \mathrm{mg}$ (titrated according to response and adverse effects)

Sex: $77 \%$ women

Age: $\geq 65$ years; mean 74 years

Unit of allocation: participant

Number randomised: 121

Number completing (including recurrences): 94 at 48 weeks

Setting: research clinic in Denmark

Inclusion criteria: achieved remission defined as MADRS $\leq 11$ and remaining in remission during 16 weeks' continuation treatment

Exclusion criteria: index depressive episode $\geq 1$ year; schizophrenia; mania; severe physical illness; alcohol problems; recent treatment with other antidepressant drugs, psychotropic drugs, or ECT; suicidal ideas

Ethnicity: not stated

Baseline characteristics: $75 \%$ in first depressive episode

- Citalopram at same dose as in open-label continuation phase (20 mg, $30 \mathrm{mg}$, or $40 \mathrm{mg}$ )

- Placebo; titration procedure not stated

Duration of intervention: 48 weeks

Duration of trial: 104 weeks

Length of follow-up: minimum 48 weeks 
Klysner 2002 (Continued)

Dose adjustment: none

Outcomes $\quad$ Primary outcome: time to recurrence defined as MADRS $\geq 22$ on 2 occasions in the same week

Secondary outcomes: tolerability of citalopram according to participant report and clinical evaluation

Notes

\section{Risk of bias}

Bias Authors' judgement Support for judgement

Random sequence genera- Low risk tion (selection bias)

Investigators reported that "...patients...were randomised on a 1:1 basis, using a block size of 10..." (p. 30, col. 1)

Allocation concealment Unclear risk Author contacted but details not available

(selection bias)

Blinding (performance $\quad$ Low risk Investigators describe study as 'double-blind' (p. 30, col. 1)
bias and detection bias)
participants?

Blinding (performance Unclear risk Author contacted but details not available

bias and detection bias)

those administering treat-

ment?

Blinding (performance Low risk Investigators described study as 'double-blind' (p. 30, col. 1)
bias and detection bias)
outcome assessors?

\begin{tabular}{lll}
\hline $\begin{array}{l}\text { Incomplete outcome data } \\
\text { (attrition bias) } \\
\text { All outcomes }\end{array}$ & Low risk & Drop-outs were accounted for and intention-to-treat analysis was performed \\
\hline $\begin{array}{l}\text { Selective reporting (re- } \\
\text { porting bias) }\end{array}$ & High risk & $\begin{array}{l}\text { Protocol not available. Data presented for main outcome only (recurrence on } \\
\text { MADRS) but not for other measures (CGI-S, HDRS, and MES) }\end{array}$ \\
\hline Other bias & Unclear risk & Tapering regimen unclear \\
\hline
\end{tabular}

\section{OADIG 1993}

\begin{tabular}{ll}
\hline Methods & Design: placebo-controlled parallel trial \\
\hline Participants & $\frac{\text { Participants: people with RDC major depressive episode and receiving any treatment in acute phase }}{\text { (including ECT) }}$ \\
& Sex: $73 \%$ women \\
& Age: $\geq 60$ years; mean 76 years (SD 6.2) \\
& Unit of allocation: participant \\
& Number randomised: 69 \\
& Number completing (including recurrences): 58 \\
& Setting: Old Age Psychiatry outpatient, inpatient and community services in 15 UK NHS centres
\end{tabular}


OADIG 1993 (Continued)

Inclusion criteria: in remission defined as MADRS $\leq 10$ and remaining in remission for 8 weeks' continuation treatment

Exclusion criteria: serious physical illness; contraindication to tricyclic antidepressant; clinical diagnosis of dementia; MTS $\leq 24$; investigator considered participant unsuitable

Ethnicity: not stated

Baseline characteristics: $37 \%$ had onset depression at $<65$ years

Interventions
- Dothiepin 75 mg daily
- Placebo; titration procedure not stated
Duration of intervention: 2 years
Duration of trial: 2 years
Length of follow-up: participants were not followed up beyond the intervention period
Dose adjustment: not stated

Outcomes Primary outcome: recurrence of depression (MADRS > 10 or clinical judgement of investigator)

Secondary outcomes: none

Notes

\section{Risk of bias}

Bias Authors' judgement Support for judgement

Random sequence genera- Low risk Investigators reported that "Patients were randomly assigned on double-blind tion (selection bias) $\quad$ parallel-group basis..." and that "In the randomisation patients were stratified to ensure that those who had received ECT for the index illness were evenly divided between the groups" (p. 176, col. 2)

\begin{tabular}{lll}
\hline $\begin{array}{l}\text { Allocation concealment } \\
\text { (selection bias) }\end{array}$ & Unclear risk & $\begin{array}{l}\text { No comment in paper. Clarification was sought from investigators but no fur- } \\
\text { ther details were available }\end{array}$ \\
\hline $\begin{array}{l}\text { Blinding (performance } \\
\text { bias and detection bias) } \\
\text { participants? }\end{array}$ & Low risk & $\begin{array}{l}\text { Trial described as 'double-blind' in title but no detail of blinding procedures in } \\
\text { text. Sought clarification from investigators who recalled that medication was } \\
\text { dispensed in coded packets to blind from participants. Review authors judged } \\
\text { that blinding of participants was ensured }\end{array}$
\end{tabular}

\begin{tabular}{|c|c|c|}
\hline $\begin{array}{l}\text { Blinding (performance } \\
\text { bias and detection bias) } \\
\text { those administering treat- } \\
\text { ment? }\end{array}$ & Low risk & $\begin{array}{l}\text { Trial described as 'double-blind' in title but no detail of blinding procedures in } \\
\text { text. Sought clarification from investigators who recalled that dispensing phar- } \\
\text { macists were blind to medication type through use of coded packets. Review } \\
\text { authors judged that blinding of personnel was ensured }\end{array}$ \\
\hline
\end{tabular}

Blinding (performance Unclear risk bias and detection bias) outcome assessors?
Trial described as 'double-blind' in title but no detail of blinding procedures in text. Sought clarification from investigators who recalled that assessing clinicians were blind to medication type through use of coded packets. However, as assessors were participants' own psychiatrists, review authors judged that they may have detected tricyclic antidepressant adverse effects in participants taking dothiepin

\begin{tabular}{|c|c|c|}
\hline $\begin{array}{l}\text { Incomplete outcome data } \\
\text { (attrition bias) }\end{array}$ & High risk & $\begin{array}{l}\text { Reasons for drop-outs given (p. } 117 \text {, col. } 1 \text { ) but no intention-to-treat analysis } \\
\text { performed. In this review, all drop-outs were treated as recurrences }\end{array}$ \\
\hline
\end{tabular}


OADIG 1993 (Continued)

All outcomes

Selective reporting (re- Unclear risk porting bias)
Study protocol was not available, but it seemed that the published report included all expected outcomes. No evidence of selective reporting of subsets or change from stated outcomes

Other bias Unclear risk Medication tapering regimen unclear

Outcome assessment with the MADRS was performed by 'more than 20 raters'. The investigators judged that there may have been poor inter-rater reliability, but pointed out that results from all the centres were consistent (p. 179, col. 2)

Reynolds 1999a

Methods Design: $2 \times 2$ factorial randomised, placebo-controlled trial

Participants

Participants: people identified at screening to have major depression according to SADS-L and HDRS and who received acute treatment with nortriptyline (plasma level $80 \mathrm{ng} / \mathrm{mL}$ to $120 \mathrm{ng} / \mathrm{mL}$ ) and weekly IPT. Some participants received augmentation with lithium or perphenazine, which was discontinued before randomisation. $49 \%$ were clinically referred; remainder from media recruitment, etc. All were at least in their second lifetime episode of depression with inter-episode wellness of $\leq 3$ years

\section{Sex: $75 \%$ women}

Age: $\geq 60$ years; mean 67 years

Unit of allocation: participant

Number randomised: 124.107 remained in remission during transition and entered maintenance treatment

Number completing (including recurrences): 96

Setting: university-based geropsychiatry research clinic

Inclusion criteria: achieved remission defined as 17 -item HDRS $\leq 10$ and who remained in remission during 16 weeks' continuation treatment with nortriptyline and IPT

Exclusion criteria: medical contraindications to nortriptyline treatment; delusional depression; concurrent diagnosis of dysthymia

Ethnicity: 93\% white

Baseline characteristics: mean number of previous episodes 3.9; mean MMSE 29/30

- Nortriptyline titrated to achieve plasma level $80 \mathrm{ng} / \mathrm{mL}$ to $120 \mathrm{ng} / \mathrm{mL}$ with medication clinic attendance

- Placebo after 6 weeks' titration, with medication clinic attendance

- Monthly IPT with nortriptyline (plasma level $80 \mathrm{ng} / \mathrm{mL}$ to $120 \mathrm{ng} / \mathrm{mL}$ )

- Monthly IPT with placebo

Duration of intervention: 3 years

Duration of trial: 7 years

Length of follow-up: 3 years or until recurrence

Dose adjustment: see below 
Reynolds 1999a (Continued)

Outcomes
Primary outcomes: recurrence of major depression by RDC at interview with research nurse and independent confirmation by 'senior psychiatrist'

Secondary outcomes: Hamilton Depression Rating Scale, Beck Depression Inventory, Global Assessment Scale, Åsberg Side-Effect Scale (used by non-blind monitoring committee for dose adjustment; not reported)

Other outcomes: orthostatic blood pressure, pulse, weight (not reported)

\section{Notes}

\section{Risk of bias}

\begin{tabular}{lll}
\hline Bias & Authors' judgement & Support for judgement \\
\hline $\begin{array}{l}\text { Random sequence genera- } \\
\text { tion (selection bias) }\end{array}$ & Low risk & $\begin{array}{l}\text { Investigators reported that participants "were randomly assigned to one of four } \\
\text { maintenance conditions.... The randomization schedule was generated by the } \\
\text { project statistician..." (p. 41). "The method to generate the allocation schedule } \\
\text { was a Fortran program using the DIGITAL VAX/VMS operating system..." (p. 41). } \\
\text { Block randomisation of } 4 \text { participants }\end{array}$ \\
\end{tabular}

$\begin{array}{ll}\begin{array}{l}\text { Allocation concealment } \\ \text { (selection bias) }\end{array} & \text { "Only the pharmacist and the open monitoring committee...had knowledge of } \\ \text { randomized assignment to nortriptyline or placebo" (p. 41, col. 2) }\end{array}$

\begin{tabular}{ll}
\hline $\begin{array}{l}\text { Blinding (performance } \\
\text { bias and detection bias) }\end{array} \quad$ Low risk & $\begin{array}{l}\text { Participants blind to drug treatment through use of placebo. Blinding to psy- } \\
\text { chological therapies (IPT) not possible }\end{array}$
\end{tabular}
participants?

\begin{tabular}{|c|c|c|}
\hline $\begin{array}{l}\text { Blinding (performance } \\
\text { bias and detection bias) } \\
\text { those administering treat- } \\
\text { ment? }\end{array}$ & Low risk & $\begin{array}{l}\text { "The treatment team, outcome assessors, and data analyst were blind to treat- } \\
\text { ment assignment" (p. } 41, \text { col. 2). Therapists administering IPT could not have } \\
\text { been blind to psychological therapies, but would have been blind to medica- } \\
\text { tion assignment }\end{array}$ \\
\hline
\end{tabular}

\begin{tabular}{|c|c|c|}
\hline $\begin{array}{l}\text { Blinding (performance } \\
\text { bias and detection bias) } \\
\text { outcome assessors? }\end{array}$ & Low risk & $\begin{array}{l}\text { "The treatment team, outcome assessors, and data analyst were blind to treat- } \\
\text { ment assignment" (p. 41, col. 2) }\end{array}$ \\
\hline
\end{tabular}

\begin{tabular}{|c|c|c|}
\hline $\begin{array}{l}\text { Incomplete outcome data } \\
\text { (attrition bias) } \\
\text { All outcomes }\end{array}$ & Low risk & 107 participants commenced maintenance treatment and all accounted for \\
\hline $\begin{array}{l}\text { Selective reporting (re- } \\
\text { porting bias) }\end{array}$ & Unclear risk & $\begin{array}{l}\text { Study protocol not available. Outcome reported on recurrence according to } \\
\text { RDC. Methods section indicated that during follow-up, HDRS, BDI, and GAS } \\
\text { scale measures taken, but no data reported }\end{array}$ \\
\hline
\end{tabular}

Wilkinson 2009

\begin{tabular}{ll}
\hline Methods & Design: randomised parallel group trial \\
\hline Participants & $\begin{array}{l}\text { Participants: people who were diagnosed retrospectively as having experienced an episode of major } \\
\text { depression according to ICD-10 criteria and had been treated at a therapeutic dose with any antide- } \\
\text { pressant }\end{array}$
\end{tabular}

\section{Sex: $62 \%$ women}

Age: $\geq 60$ years; mean approximately 74 years 
Wilkinson 2009 (Continued)

\section{Unit of allocation: participant}

Number randomised: 45

Number completing (including recurrences): 36

Setting: primary care and specialist old age psychiatry services (inpatient, outpatient, and community) in 2 NHS UK centres (Oxford and Southampton)

Inclusion criteria: in remission/recovery from an episode of major depression defined as no longer meeting ICD-10 criteria for depression and MADRS $\leq 9$, remaining in remission during continuation treatment of depression for $\geq 8$ weeks and intending to continue treatment for $\geq 1$ year

Exclusion criteria: MMSE $\leq 23$; bipolar disorder; severe alcohol problems

Ethnicity: not stated

Baseline characteristics: approximately $20 \%$ had had 1 previous depressive episode; approximately $48 \%$ had $\geq 2$ previous episodes

\begin{tabular}{|c|c|}
\hline \multirow[t]{5}{*}{ Interventions } & $\begin{array}{l}2 \text { treatments: } \\
\text { - Continuation of whichever antidepressant medication the person was taking at randomisation } \\
\text { - Continuation of antidepressant and } 8 \text { sessions of group CBT. (Clarification from authors on class of } \\
\text { antidepressant: } 42 \% \text { venlafaxine; } 33 \% \text { SSRI; } 7 \% \text { mirtazapine; } 4 \% \text { tricyclic antidepressant; } 14 \% 2 \text { dif- } \\
\text { ferent antidepressants from these classes, possibly in combination, but data not available) }\end{array}$ \\
\hline & Duration of intervention: 1 year (antidepressant); 12 weeks (group CBT) \\
\hline & Duration of trial: 1 year \\
\hline & Length of follow-up: 1 year \\
\hline & Dose adjustment: none \\
\hline
\end{tabular}

Outcomes $\quad$ Primary outcome: recurrence defined as MADRS $\geq 10$

Secondary outcome: recurrence defined as $\mathrm{BDI} \geq 12$

Notes

\section{Risk of bias}

\begin{tabular}{lll}
\hline Bias & Authors' judgement & Support for judgement \\
\hline $\begin{array}{l}\text { Random sequence genera- } \\
\text { tion (selection bias) }\end{array}$ & Low risk & "Allocation to treatment was generated centrally by the study statistician using \\
& & MINIM... a purpose-written computer programme..." (p. 69, col. 2).
\end{tabular}

Allocation concealment
(selection bias)
(selection bias)

High risk

Blinding (performance High risk
bias and detection bias)
participants?

Blinding (performance bias and detection bias) those administering treatment?

High risk

\author{
"The nature of the CBT-G [group cognitive therapy treatment] meant that par- \\ ticipants could not be blinded to treatment allocation" (p. 69, col. 2)
}

The therapist who administered group CBT could not have been blind to assignment. However, therapist was not involved in outcome assessment
Blinding (performance High risk bias and detection bias)
"To keep the nurse blind to treatment, participants were requested not to disclose their treatment allocation" (p. 69, col. 2) but "this study may have been 
Wilkinson 2009 (Continued) outcome assessors? subject to observer bias if participants had difficulty concealing their treatment from the trial nurse" (p. 74, col. to indicate their familiarity with the treatment e.g. 'negative automatic thoughts'

$\begin{array}{ll}\begin{array}{l}\text { Incomplete outcome data } \\ \text { (attrition bias) }\end{array} & \text { Low risk } \\ \text { All outcomes } & \begin{array}{l}45 \text { participants randomised; } 9 \text { lost to follow-up (p. 71, fig. 1). "Analysis followed } \\ \text { a pre-specified plan with participants being analysed in the groups to which they } \\ \text { were allocated" (p. 69, col. 2). }\end{array}\end{array}$

(attrition bias) a pre-specified plan with participants being analysed in the groups to which they

Selective reporting (re- Low risk porting bias)

Outcome data presented on both prespecified outcomes. Protocol available to review authors and no other outcomes specified

Wilson 2003

\begin{tabular}{|c|c|}
\hline Methods & Design: placebo-controlled parallel trial \\
\hline \multirow[t]{11}{*}{ Participants } & $\begin{array}{l}\text { Participants: people with an episode of major depression diagnosed using AGECAT and DSM-III criteria } \\
\text { and HDRS who were treated for } 8 \text { weeks with sertraline }\end{array}$ \\
\hline & Sex: $71 \%$ women \\
\hline & Age: $\geq 65$ years; mean approximately 77 years (approximate SD 7) \\
\hline & Unit of allocation: participant \\
\hline & Number randomised: 113 \\
\hline & Number completing (including recurrences): 86 \\
\hline & $\begin{array}{l}\text { Setting: } 4 \text { NHS Old Age Psychiatry community services, } 20 \text { NHS general practices, and referrals from a } \\
\text { community survey in Liverpool, UK }\end{array}$ \\
\hline & $\begin{array}{l}\text { Inclusion criteria: achieving remission defined as HDRS } \leq 10 \text { and remaining in remission during continu- } \\
\text { ation treatment for } 4 \text { weeks }\end{array}$ \\
\hline & $\begin{array}{l}\text { Exclusion criteria: MMSE } \leq 11 \text {; severe and unstable physical illness; alcohol misuse; concomitant treat- } \\
\text { ment with other psychotropic drugs, warfarin, or anticonvulsants; significant suicidal ideas and delu- } \\
\text { sions }\end{array}$ \\
\hline & Ethnicity: not stated \\
\hline & $\begin{array}{l}\text { Baseline characteristics: mean MMSE scores approximately } 31 \text { (out of } 35 \text { ). Approximately } 71 \% \text { in first } \\
\text { episode of depression }\end{array}$ \\
\hline \multirow[t]{7}{*}{ Interventions } & 2 treatments: \\
\hline & $\begin{array}{l}\text { - Sertraline at therapeutic dose established in acute and continuation phases (50 mg to } 150 \mathrm{mg} \text { ) or, in } \\
\text { case of participants treated with } 200 \mathrm{mg} \text {, dose reduced to } 150 \mathrm{mg}\end{array}$ \\
\hline & $\begin{array}{l}\text { - Placebo equivalent to sertraline dose established in acute and continuation phases; titration proce- } \\
\text { dure not stated }\end{array}$ \\
\hline & Duration of intervention: 100 weeks \\
\hline & Duration of trial: 128 weeks \\
\hline & Length of follow-up: 100 weeks \\
\hline & Dose adjustment: during open phases only; no adjustment after randomisation \\
\hline
\end{tabular}

Outcomes

Primary outcome: recurrence of major depression defined as HDRS $\geq 13$ and meeting DSM-III-R criteria 
Wilson 2003 (Continued)

Secondary outcomes: none

Notes

\section{Risk of bias}

\begin{tabular}{lll}
\hline Bias & Authors' judgement & Support for judgement \\
\hline $\begin{array}{l}\text { Random sequence genera- } \\
\text { tion (selection bias) }\end{array}$ & Low risk & $\begin{array}{l}\text { "A computer-generated randomisation list was provided by Pfizer Ltd." (p. 492, } \\
\text { col. 3) }\end{array}$
\end{tabular}

tion (selection bias) col. 3)

Allocation concealment $\quad$ Low risk
(selection bias)

"A company independent of the sponsor and trialist was responsible for...randomisation...Participants eligible for the maintenance phase were allocated to the next number at their dosage level. Codes were maintained in opaque, sealed envelopes... External research auditors maintained the security of the codes..." (p. 492, col. 3)

\begin{tabular}{|c|c|c|}
\hline $\begin{array}{l}\text { Blinding (performance } \\
\text { bias and detection bias) } \\
\text { participants? }\end{array}$ & Low risk & $\begin{array}{l}\text { "The [randomisation] list was stratified by dosage and was used to produce } \\
\text { numbered containers for the identical capsules or either sertraline or place- } \\
\text { bo" (p. 492, col. 3) }\end{array}$ \\
\hline
\end{tabular}

Blinding (performance Low risk

bias and detection bias)

"A company independent of the sponsor and trialist was responsible for packagthose administering treating the trial drugs..." (p. 492, col. 3)

ment?

$\begin{array}{ll}\begin{array}{l}\text { Blinding (performance } \\ \text { bias and detection bias) } \\ \text { outcome assessors? }\end{array} & \text { Low risk }\end{array} \quad \begin{aligned} & \text { Trial described as double-blind (p. 1). "A company independent of the sponsor } \\ & \text { and trialist was responsible for packaging the trial drugs..." (p. 492, col. 3) }\end{aligned}$

outcome assessors?

Incomplete outcome data Low risk All participants accounted for and intention-to-treat analysis performed
(attrition bias)

All outcomes

\begin{tabular}{|c|c|c|}
\hline $\begin{array}{l}\text { Selective reporting (re- } \\
\text { porting bias) }\end{array}$ & Unclear risk & $\begin{array}{l}\text { Data reported on primary outcome (recurrence on HDRS cut-off). No data on } \\
\text { MADRS but judged this to have been baseline measure only }\end{array}$ \\
\hline
\end{tabular}

\begin{tabular}{ll}
\hline Other bias $\quad$ Unclear risk $\quad$ Medication tapering regimen unclear \\
\hline
\end{tabular}

AGECAT: Automated Geriatric Examination for Computer Assisted Taxonomy; BDI: Beck Depression Inventory; CBT: cognitive behavioural therapy; CGI: Clinical Global Impression; CGI-I: Clinical Global Impression - Improvement scale; CGI-S: Clinical Global Impression - Severity scale; DSM: Diagnostic and Statistical Manual; ECT: electroconvulsive therapy; GAS: Global Assessment Scale; HDRS: Hamilton Depression Rating Scale; IPT: interpersonal therapy; MADRS: Montgomery-Åsberg Depression Rating Scale; MES: Melancholia Scale; MMSE: Mini-Mental State Examination; MTS: Mental Test Score; NHS: National Health Service; RDC: Research Diagnostic Criteria; SADS-L: Schedule for Affective Disorders and Schizophrenia - Lifetime Version; SD: standard deviation; SSRI: selective serotonin reuptake inhibitor.

Characteristics of excluded studies [ordered by study ID]

\begin{tabular}{ll}
\hline Study & Reason for exclusion \\
\hline Reynolds 1999b & Comparing 2 serum levels of same antidepressant \\
\hline Reynolds 2006 & $\begin{array}{l}\text { Some received augmentation with lithium or perphenazine that was not discontinued at randomi- } \\
\text { sation }\end{array}$ \\
\hline
\end{tabular}


DATA AND ANALYSES

\section{Comparison 1. Antidepressant versus placebo}

\begin{tabular}{|c|c|c|c|c|}
\hline Outcome or subgroup title & No. of studies & $\begin{array}{l}\text { No. of partici- } \\
\text { pants }\end{array}$ & Statistical method & Effect size \\
\hline 1 Recurrence & 6 & & Risk Ratio (M-H, Random, 95\% Cl) & Subtotals only \\
\hline 1.1 Recurrence at 6 months & 3 & 487 & Risk Ratio (M-H, Random, 95\% Cl) & $0.64[0.32,1.27]$ \\
\hline 1.2 Recurrence at 12 months & 3 & 247 & Risk Ratio (M-H, Random, 95\% Cl) & $0.67[0.55,0.82]$ \\
\hline 1.3 Recurrence at 18 months & 1 & 69 & Risk Ratio (M-H, Random, 95\% Cl) & $0.76[0.49,1.17]$ \\
\hline 1.4 Recurrence at 24 months & 4 & 282 & Risk Ratio (M-H, Random, 95\% Cl) & $0.78[0.61,1.01]$ \\
\hline 1.5 Recurrence at 36 months & 1 & 57 & Risk Ratio (M-H, Random, 95\% Cl) & $0.64[0.45,0.90]$ \\
\hline $\begin{array}{l}\text { 1.6 Recurrence at final fol- } \\
\text { low-up }\end{array}$ & 6 & 708 & Risk Ratio (M-H, Random, 95\% Cl) & $0.65[0.48,0.87]$ \\
\hline $\begin{array}{l}2 \text { Recurrence at } 12 \text { months } \\
\text { (fixed-effect) }\end{array}$ & 3 & 247 & Risk Ratio (M-H, Fixed, 95\% Cl) & $0.67[0.54,0.82]$ \\
\hline $\begin{array}{l}3 \text { Recurrence at } 24 \text { months } \\
\text { (studies of tricyclic antidepres- } \\
\text { sants only) }\end{array}$ & 3 & 169 & Risk Ratio (M-H, Random, 95\% Cl) & $0.70[0.50,0.99]$ \\
\hline $\begin{array}{l}4 \text { Reduction in symptom sever- } \\
\text { ity }\end{array}$ & 1 & & Mean Difference (IV, Fixed, 95\% CI) & Subtotals only \\
\hline 4.1 CGI-Severity at 6 months & 1 & 305 & Mean Difference (IV, Fixed, 95\% CI) & $-0.76[-1.04,-0.48]$ \\
\hline 4.2 CGI-Intensity at 6 months & 1 & 305 & Mean Difference (IV, Fixed, 95\% Cl) & $-0.77[-1.06,-0.48]$ \\
\hline 5 Death & 4 & & Risk Ratio (M-H, Random, 95\% Cl) & Subtotals only \\
\hline 5.1 Deaths at 6 months & 1 & 305 & Risk Ratio (M-H, Random, 95\% Cl) & $0.0[0.0,0.0]$ \\
\hline 5.2 Deaths at 12 months & 2 & 178 & Risk Ratio (M-H, Random, 95\% Cl) & $0.0[0.0,0.0]$ \\
\hline 5.3 Deaths at 24 months & 3 & 291 & Risk Ratio (M-H, Random, 95\% Cl) & $1.02[0.21,4.83]$ \\
\hline 5.4 Deaths at 36 months & 1 & 57 & Risk Ratio (M-H, Random, 95\% Cl) & $0.0[0.0,0.0]$ \\
\hline 5.5 Deaths at final follow-up & 3 & 475 & Risk Ratio (M-H, Random, 95\% Cl) & $1.02[0.21,4.83]$ \\
\hline $\begin{array}{l}6 \text { Overall drop-out rates (ex- } \\
\text { cluding deaths) }\end{array}$ & 4 & & Risk Ratio (M-H, Random, 95\% Cl) & Subtotals only \\
\hline 6.1 Drop-outs at six months & 1 & 305 & Risk Ratio (M-H, Random, 95\% Cl) & $0.77[0.35,1.71]$ \\
\hline 6.2 Drop-outs at 12 months & 1 & 121 & Risk Ratio (M-H, Random, 95\% Cl) & $1.48[0.75,2.92]$ \\
\hline
\end{tabular}




\begin{tabular}{lllll}
\hline Outcome or subgroup title & No. of studies & $\begin{array}{l}\text { No. of partici- } \\
\text { pants }\end{array}$ & Statistical method & Effect size \\
\hline 6.3 Drop-outs at 24 months & 1 & 113 & Risk Ratio (M-H, Random, 95\% Cl) & $1.12[0.52,2.43]$ \\
\hline 6.4 Drop-outs at 36 months & 1 & 57 & Risk Ratio (M-H, Random, 95\% Cl) & $9.31[0.52,165.33]$ \\
\hline $\begin{array}{l}7 \text { Drop-outs due to adverse ef- } \\
\text { fects }\end{array}$ & 3 & & Risk Ratio (M-H, Random, 95\% Cl) & Subtotals only \\
\hline 7.1 Drop-outs at 6 months & 1 & & Risk Ratio (M-H, Random, 95\% Cl) & $0.58[0.17,1.92]$ \\
\hline 7.2 Drop-outs at 12 months & 1 & 305 & Risk Ratio (M-H, Random, 95\% Cl) & $0.76[0.28,2.07]$ \\
\hline 7.3 Drop-outs at 24 months & 2 & 121 & Risk Ratio (M-H, Random, 95\% Cl) & $0.71[0.27,1.84]$ \\
\hline
\end{tabular}

Analysis 1.1. Comparison 1 Antidepressant versus placebo, Outcome 1 Recurrence.

\begin{tabular}{|c|c|c|c|c|c|}
\hline Study or subgroup & $\begin{array}{c}\text { Antide- } \\
\text { pressants } \\
\mathrm{n} / \mathrm{N}\end{array}$ & $\begin{array}{c}\text { Placebo } \\
\mathrm{n} / \mathrm{N} \\
\end{array}$ & $\begin{array}{c}\text { Risk Ratio } \\
\text { M-H, Random, } 95 \% \mathrm{Cl} \\
\end{array}$ & Weight & $\begin{array}{c}\text { Risk Ratio } \\
\text { M-H, Random, } 95 \% \mathrm{Cl}\end{array}$ \\
\hline \multicolumn{6}{|c|}{ 1.1.1 Recurrence at 6 months } \\
\hline Gorwood 2007 & $23 / 152$ & $63 / 153$ & $\rightarrow-$ & $36.83 \%$ & $0.37[0.24,0.56]$ \\
\hline OADIG 1993 & $10 / 33$ & $15 / 36$ & & $30.98 \%$ & $0.73[0.38,1.39]$ \\
\hline Wilson 2003 & $16 / 56$ & $15 / 57$ & 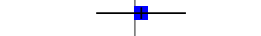 & $32.19 \%$ & $1.09[0.6,1.98]$ \\
\hline Subtotal $(95 \% \mathrm{Cl})$ & 241 & 246 & & $100 \%$ & $0.64[0.32,1.27]$ \\
\hline \multicolumn{6}{|c|}{ Total events: 49 (Antidepressants), 93 (Placebo) } \\
\hline \multicolumn{6}{|c|}{ Heterogeneity: $\operatorname{Tau}^{2}=0.28 ; \mathrm{Chi}^{2}=9.23, \mathrm{df}=2(\mathrm{P}=0.01) ; \mathrm{I}^{2}=78.32 \%$} \\
\hline \multicolumn{6}{|c|}{ Test for overall effect: $Z=1.26(P=0.21)$} \\
\hline \multicolumn{6}{|c|}{ 1.1.2 Recurrence at 12 months } \\
\hline Klysner 2002 & $34 / 60$ & $49 / 61$ & + & $65.01 \%$ & $0.71[0.55,0.91]$ \\
\hline OADIG 1993 & $13 / 33$ & $21 / 36$ & 一 & $16.39 \%$ & $0.68[0.41,1.12]$ \\
\hline Reynolds 1999a & $12 / 28$ & $22 / 29$ & $\longrightarrow$ & $18.6 \%$ & $0.56[0.35,0.91]$ \\
\hline Subtotal $(95 \% \mathrm{Cl})$ & 121 & 126 & $>$ & $100 \%$ & $0.67[0.55,0.82]$ \\
\hline \multicolumn{6}{|c|}{ Total events: 59 (Antidepressants), 92 (Placebo) } \\
\hline \multicolumn{6}{|c|}{ Heterogeneity: $\mathrm{Tau}^{2}=0 ; \mathrm{Chi}^{2}=0.67, \mathrm{df}=2(\mathrm{P}=0.72) ; \mathrm{I}^{2}=0 \%$} \\
\hline \multicolumn{6}{|c|}{ Test for overall effect: $Z=3.81(P=0)$} \\
\hline \multicolumn{6}{|c|}{ 1.1.3 Recurrence at 18 months } \\
\hline OADIG 1993 & $16 / 33$ & $23 / 36$ & & $100 \%$ & $0.76[0.49,1.17]$ \\
\hline Subtotal $(95 \% \mathrm{Cl})$ & 33 & 36 & & $100 \%$ & $0.76[0.49,1.17]$ \\
\hline \multicolumn{6}{|c|}{ Total events: 16 (Antidepressants), 23 (Placebo) } \\
\hline \multicolumn{6}{|c|}{ Heterogeneity: Not applicable } \\
\hline \multicolumn{6}{|c|}{ Test for overall effect: $Z=1.26(P=0.21)$} \\
\hline \multicolumn{6}{|c|}{ 1.1.4 Recurrence at 24 months } \\
\hline Alexopoulos 2000 & $4 / 22$ & $11 / 21$ & - & $6.07 \%$ & $0.35[0.13,0.92]$ \\
\hline OADIG 1993 & $18 / 33$ & $23 / 36$ & $\rightarrow-$ & $25.44 \%$ & $0.85[0.57,1.27]$ \\
\hline Reynolds 1999a & $16 / 28$ & $24 / 29$ & $\rightarrow$ & $28.51 \%$ & $0.69[0.48,0.99]$ \\
\hline Wilson 2003 & $36 / 56$ & $40 / 57$ & H & $39.98 \%$ & $0.92[0.71,1.19]$ \\
\hline Subtotal $(95 \% \mathrm{Cl})$ & 139 & 143 & & $100 \%$ & $0.78[0.61,1.01]$ \\
\hline
\end{tabular}




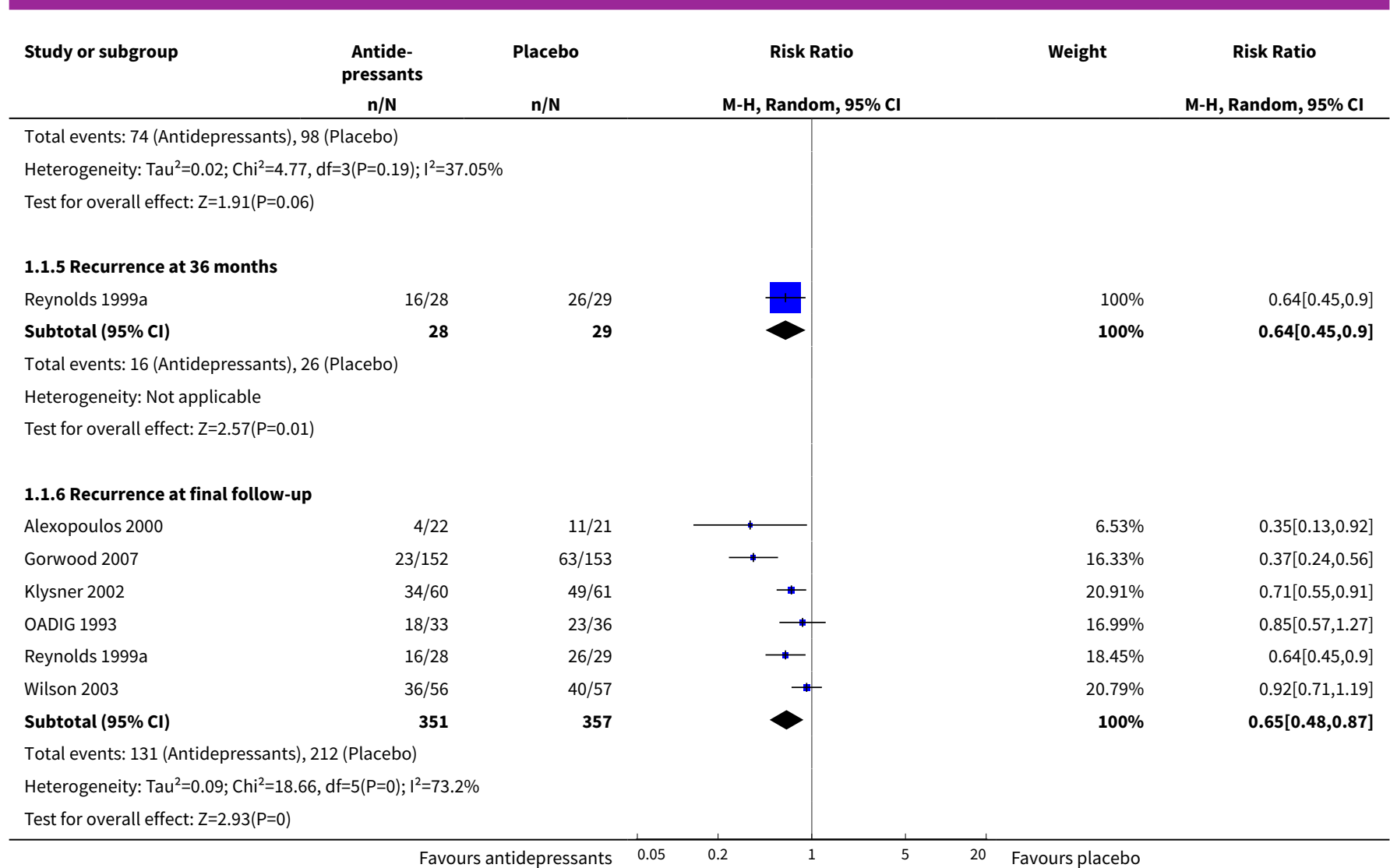

Analysis 1.2. Comparison 1 Antidepressant versus placebo, Outcome 2 Recurrence at 12 months (fixed-effect).

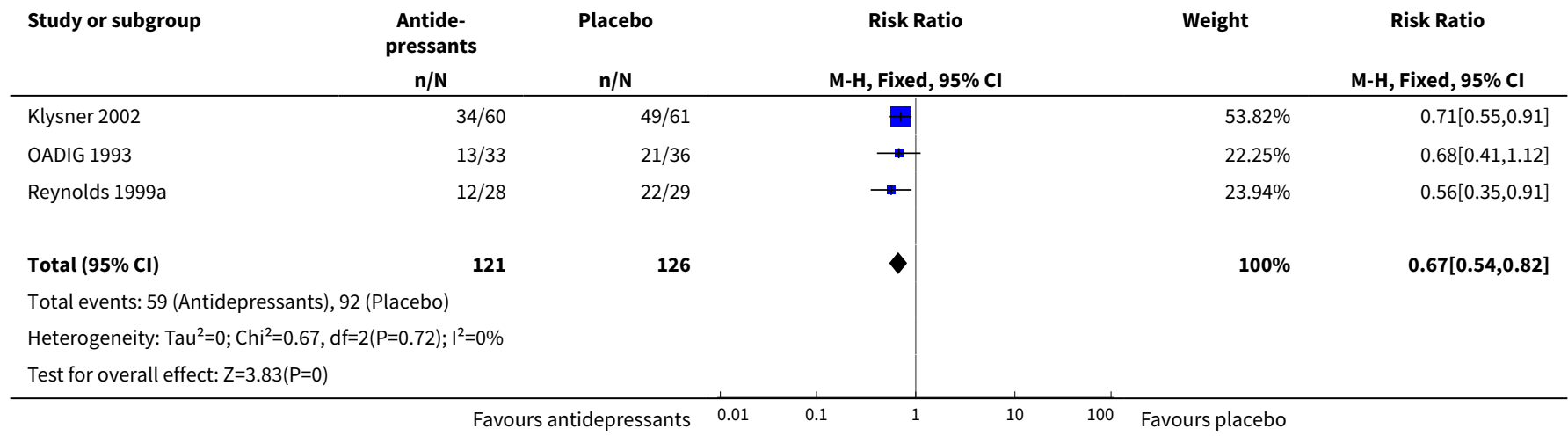

Analysis 1.3. Comparison 1 Antidepressant versus placebo, Outcome 3 Recurrence at 24 months (studies of tricyclic antidepressants only).

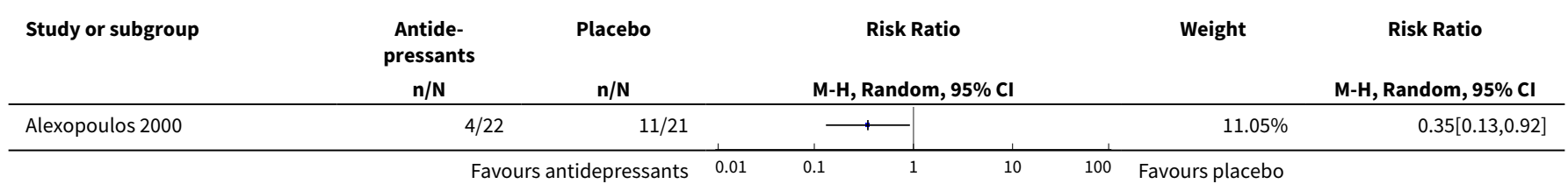




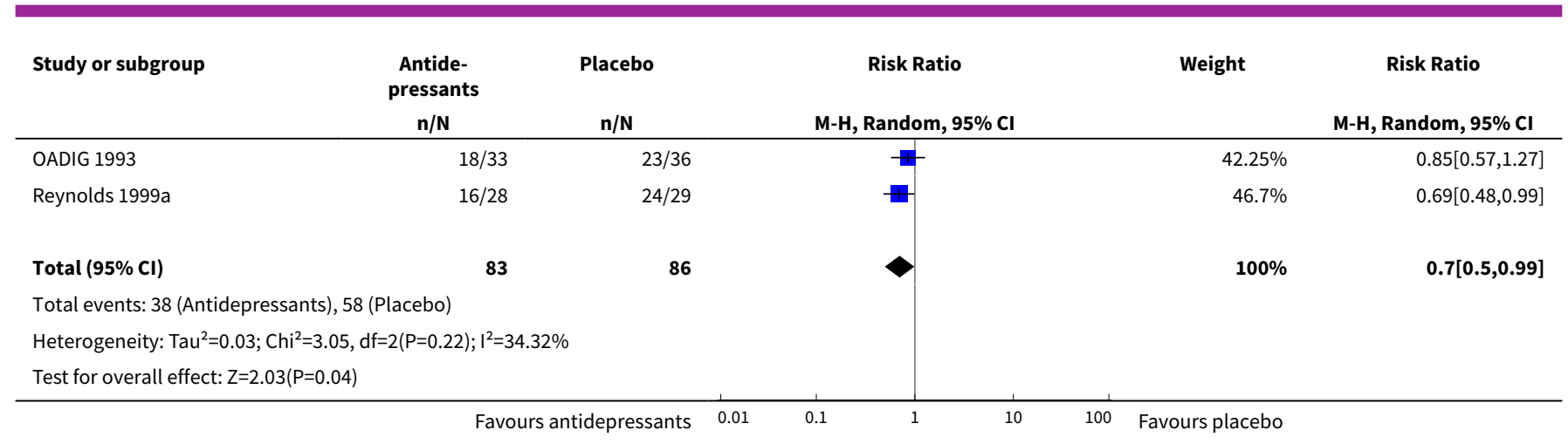

Analysis 1.4. Comparison 1 Antidepressant versus placebo, Outcome 4 Reduction in symptom severity.

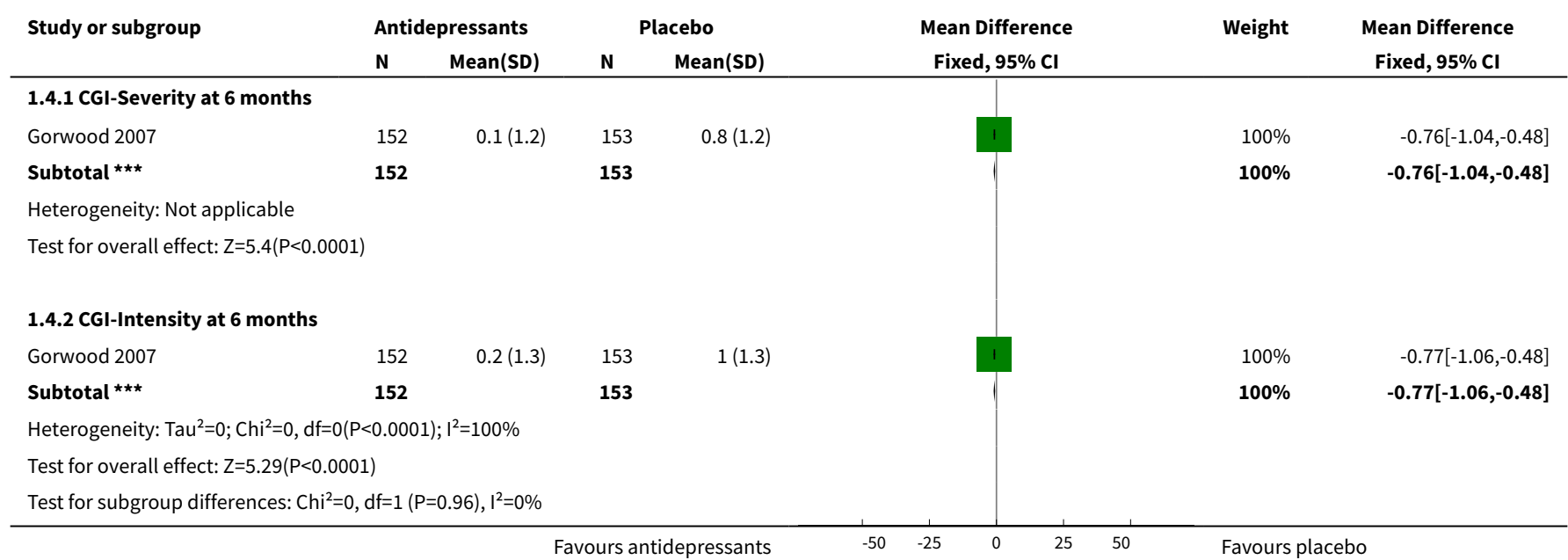

Analysis 1.5. Comparison 1 Antidepressant versus placebo, Outcome 5 Death.

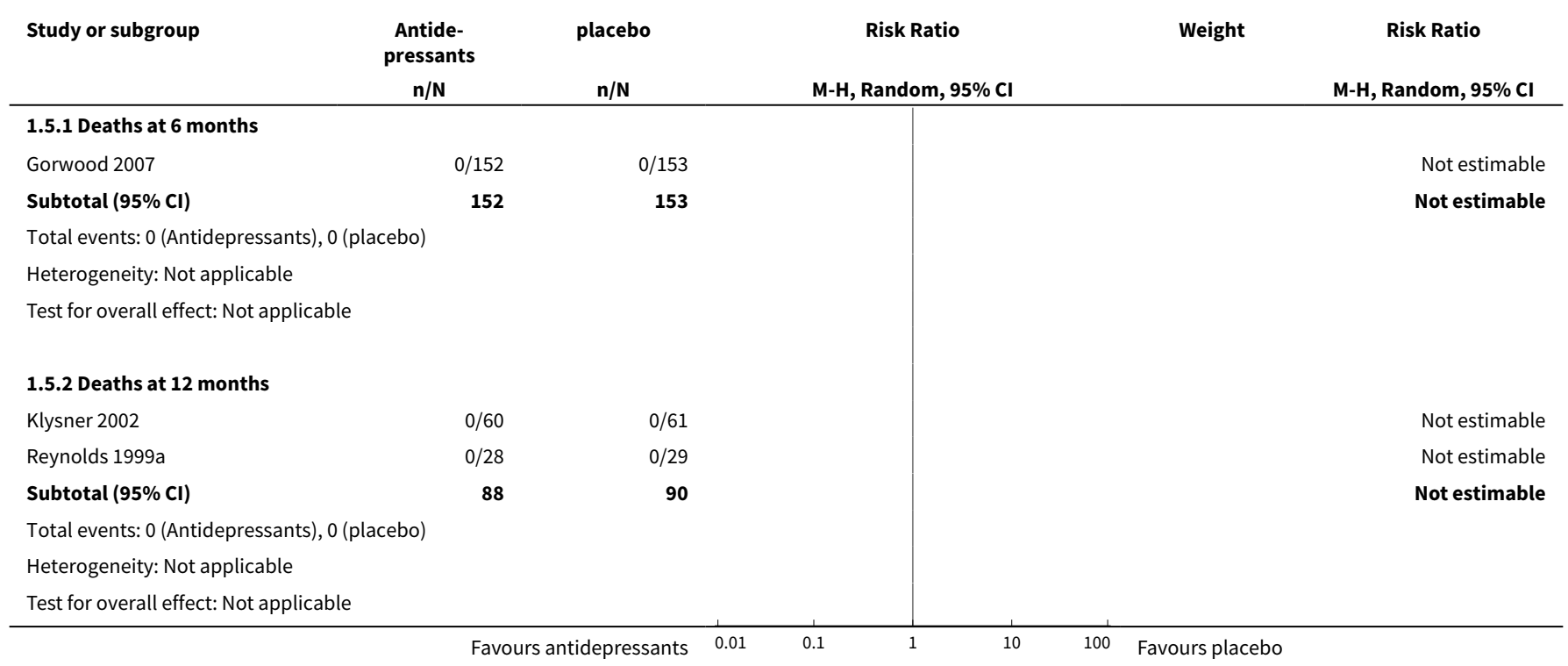




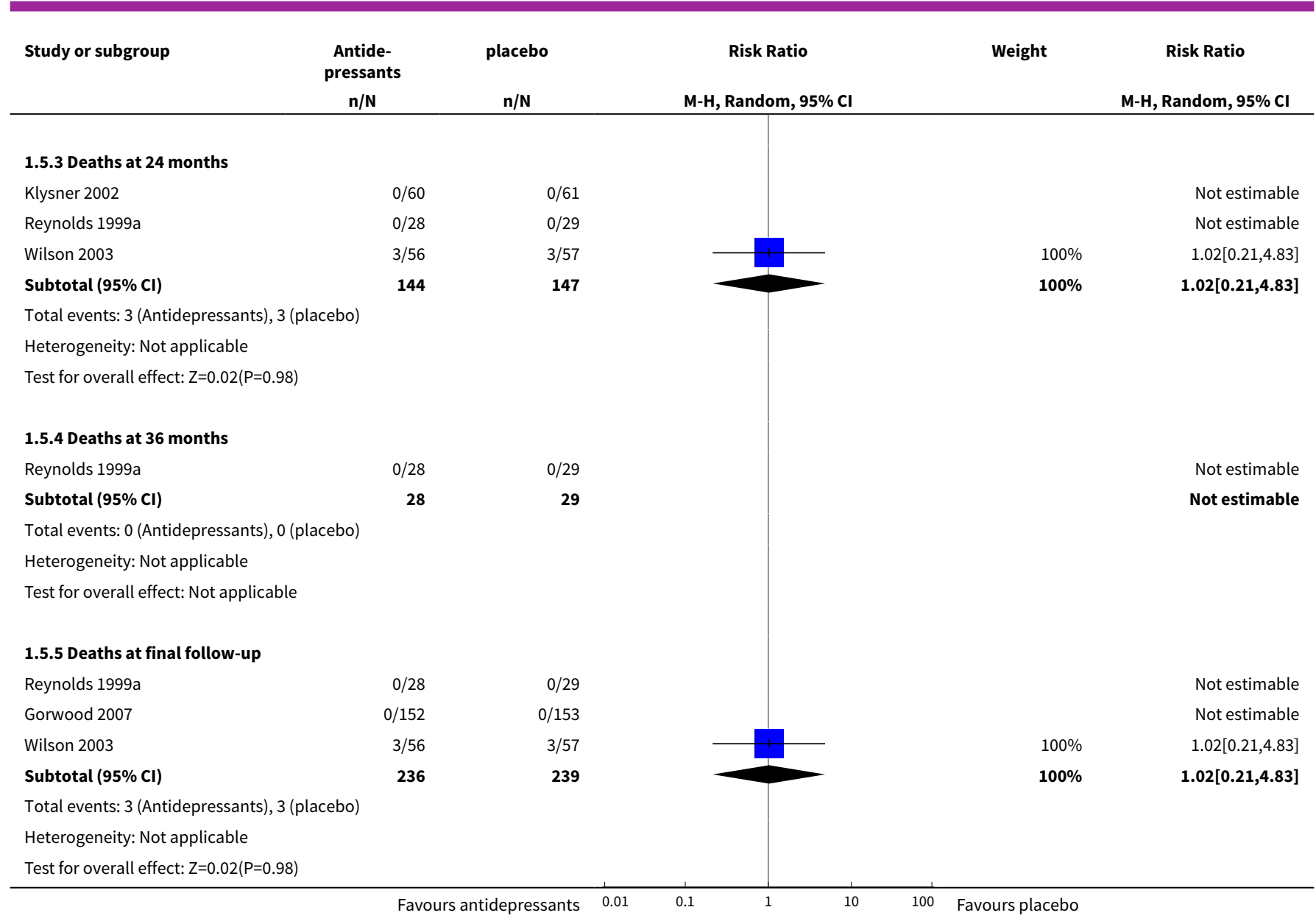

Analysis 1.6. Comparison 1 Antidepressant versus placebo, Outcome 6 Overall drop-out rates (excluding deaths).

\begin{tabular}{|c|c|c|c|c|c|}
\hline Study or subgroup & $\begin{array}{c}\text { Antide- } \\
\text { pressants } \\
\mathrm{n} / \mathrm{N} \\
\end{array}$ & $\begin{array}{l}\text { Placebo } \\
\text { n/N }\end{array}$ & $\begin{array}{c}\text { Risk Ratio } \\
\text { M-H, Random, } 95 \% \mathrm{CI}\end{array}$ & Weight & $\begin{array}{c}\text { Risk Ratio } \\
\text { M-H, Random, } 95 \% \mathrm{Cl}\end{array}$ \\
\hline \multicolumn{6}{|c|}{ 1.6.1 Drop-outs at six months } \\
\hline Gorwood 2007 & $10 / 152$ & $13 / 153$ & & $100 \%$ & $0.77[0.35,1.71]$ \\
\hline Subtotal $(95 \% \mathrm{CI})$ & 152 & 153 & & $100 \%$ & $0.77[0.35,1.71]$ \\
\hline \multicolumn{6}{|c|}{ Total events: 10 (Antidepressants), 13 (Placebo) } \\
\hline \multicolumn{6}{|c|}{ Test for overall effect: $Z=0.63(P=0.53)$} \\
\hline \multicolumn{6}{|c|}{ 1.6.2 Drop-outs at 12 months } \\
\hline Klysner 2002 & $16 / 60$ & $11 / 61$ & & $100 \%$ & $1.48[0.75,2.92]$ \\
\hline Subtotal $(95 \% \mathrm{Cl})$ & 60 & 61 & & $100 \%$ & $1.48[0.75,2.92]$ \\
\hline \multicolumn{6}{|c|}{ Total events: 16 (Antidepressants), 11 (Placebo) } \\
\hline \multicolumn{6}{|c|}{ Test for overall effect: $Z=1.13(P=0.26)$} \\
\hline \multicolumn{6}{|c|}{ 1.6.3 Drop-outs at 24 months } \\
\hline Wilson 2003 & $11 / 56$ & $10 / 57$ & & $100 \%$ & $1.12[0.52,2.43]$ \\
\hline Subtotal $(95 \% \mathrm{CI})$ & 56 & 57 & & $100 \%$ & $1.12[0.52,2.43]$ \\
\hline
\end{tabular}




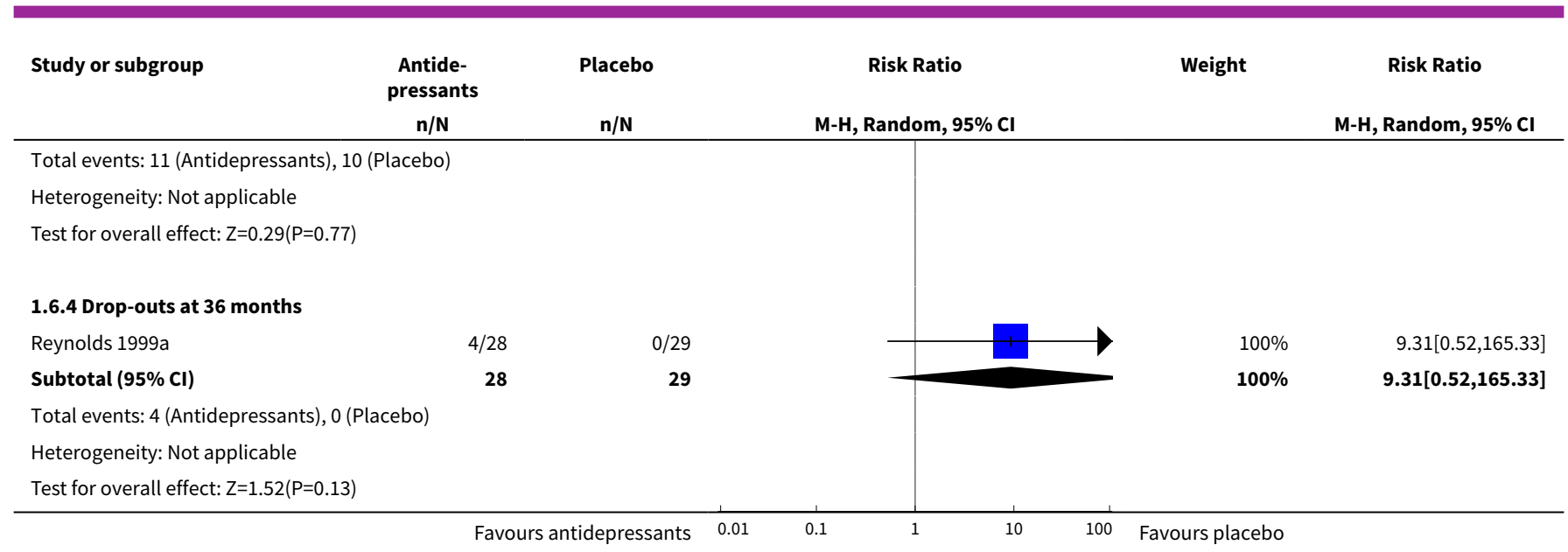

\section{Analysis 1.7. Comparison 1 Antidepressant versus placebo, Outcome 7 Drop-outs due to adverse effects.}

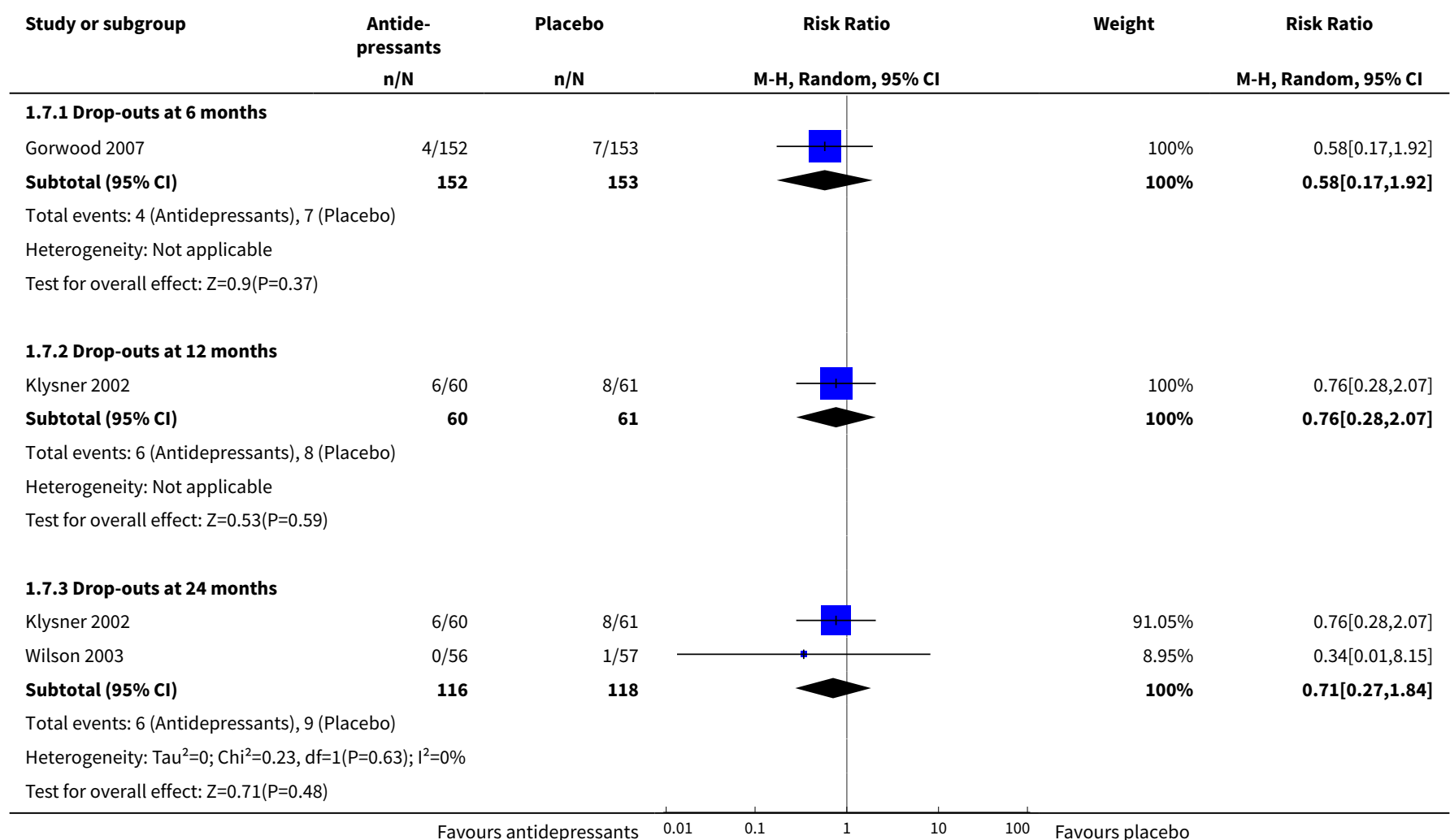

\section{Comparison 2. Psychological therapies versus drug placebo}

\begin{tabular}{lllll}
\hline Outcome or subgroup title & No. of studies & $\begin{array}{l}\text { No. of partici- } \\
\text { pants }\end{array}$ & Statistical method & Effect size \\
\hline 1 Recurrence & 1 & Risk Ratio (M-H, Random, 95\% Cl) & Subtotals only \\
\hline
\end{tabular}




\begin{tabular}{|c|c|c|c|c|}
\hline Outcome or subgroup title & No. of studies & $\begin{array}{l}\text { No. of partici- } \\
\text { pants }\end{array}$ & Statistical method & Effect size \\
\hline $\begin{array}{l}1.1 \text { Recurrence at } 12 \\
\text { months }\end{array}$ & 1 & 54 & Risk Ratio (M-H, Random, 95\% Cl) & $0.69[0.45,1.05]$ \\
\hline $\begin{array}{l}1.2 \text { Recurrence at } 24 \\
\text { months }\end{array}$ & 1 & 54 & Risk Ratio (M-H, Random, 95\% Cl) & $0.97[0.75,1.25]$ \\
\hline $\begin{array}{l}1.3 \text { Recurrence at } 36 \\
\text { months }\end{array}$ & 1 & 54 & Risk Ratio (M-H, Random, 95\% Cl) & $0.89[0.71,1.13]$ \\
\hline 2 Deaths & 1 & 216 & Risk Ratio (M-H, Random, 95\% Cl) & $0.0[0.0,0.0]$ \\
\hline 2.1 Deaths at 12 months & 1 & 54 & Risk Ratio (M-H, Random, 95\% Cl) & $0.0[0.0,0.0]$ \\
\hline 2.2 Deaths at 24 months & 1 & 54 & Risk Ratio (M-H, Random, 95\% Cl) & $0.0[0.0,0.0]$ \\
\hline 2.3 Deaths at 36 months & 1 & 54 & Risk Ratio (M-H, Random, 95\% Cl) & $0.0[0.0,0.0]$ \\
\hline 2.4 Deaths at final outcome & 1 & 54 & Risk Ratio (M-H, Random, 95\% Cl) & $0.0[0.0,0.0]$ \\
\hline $\begin{array}{l}3 \text { Overall drop-out rates (ex- } \\
\text { cluding deaths) }\end{array}$ & 1 & 54 & Risk Ratio (M-H, Random, 95\% Cl) & $10.38[0.59,183.92]$ \\
\hline 3.1 Drop-outs at 36 months & 1 & 54 & Risk Ratio (M-H, Random, 95\% Cl) & $10.38[0.59,183.92]$ \\
\hline
\end{tabular}

\section{Analysis 2.1. Comparison 2 Psychological therapies versus drug placebo, Outcome 1 Recurrence.}

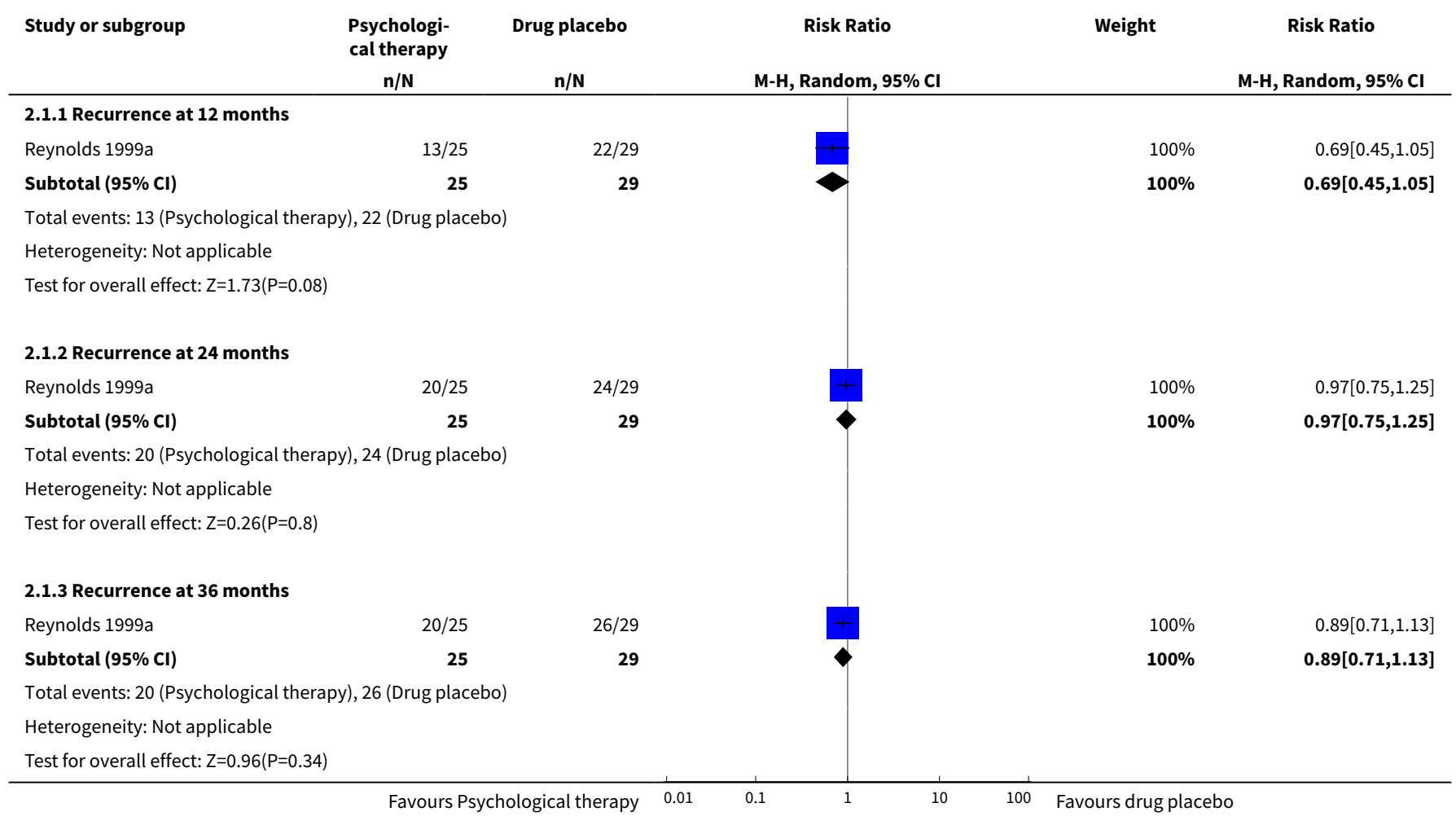


Analysis 2.2. Comparison 2 Psychological therapies versus drug placebo, Outcome 2 Deaths.

\begin{tabular}{|c|c|c|c|c|}
\hline Study or subgroup & $\begin{array}{l}\text { Experimental } \\
\mathrm{n} / \mathrm{N}\end{array}$ & $\begin{array}{l}\text { Control } \\
n / N\end{array}$ & $\begin{array}{c}\text { Risk Ratio } \\
\text { M-H, Random, } 95 \% \mathrm{Cl}\end{array}$ & Risk Ratio \\
\hline
\end{tabular}

2.2.1 Deaths at 12 months

Reynolds 1999a

$0 / 25$

$0 / 29$

Subtotal $(95 \% \mathrm{CI})$

Total events: 0 (Experimental), 0 (Control)

Heterogeneity: Not applicable

Test for overall effect: Not applicable

\subsubsection{Deaths at 24 months}

Reynolds 1999a

Subtotal $(95 \% \mathrm{Cl})$

Total events: 0 (Experimental), 0 (Control)

Heterogeneity: Not applicable

Test for overall effect: Not applicable

\subsubsection{Deaths at 36 months}

Reynolds 1999a

Subtotal $(95 \% \mathrm{CI})$

Total events: 0 (Experimental), 0 (Control)

Heterogeneity: Not applicable

Test for overall effect: Not applicable

\subsubsection{Deaths at final outcome}

Reynolds 1999a

Subtotal $(95 \% \mathrm{Cl})$

Total events: 0 (Experimental), 0 (Control)

Heterogeneity: Not applicable

Test for overall effect: Not applicable

Total events: 0 (Experimental), 0 (Control)

Analysis 2.3. Comparison 2 Psychological therapies versus drug placebo, Outcome 3 Overall drop-out rates (excluding deaths).

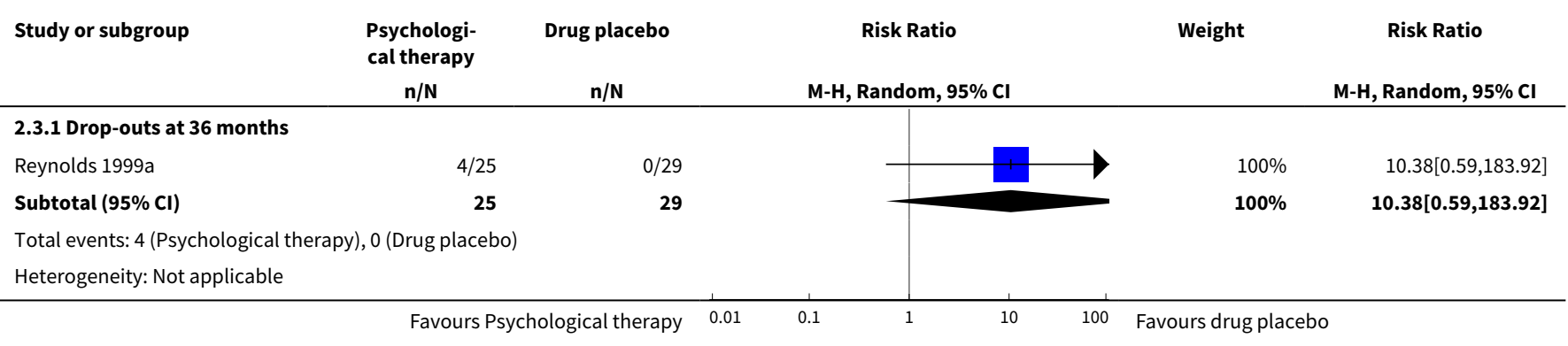




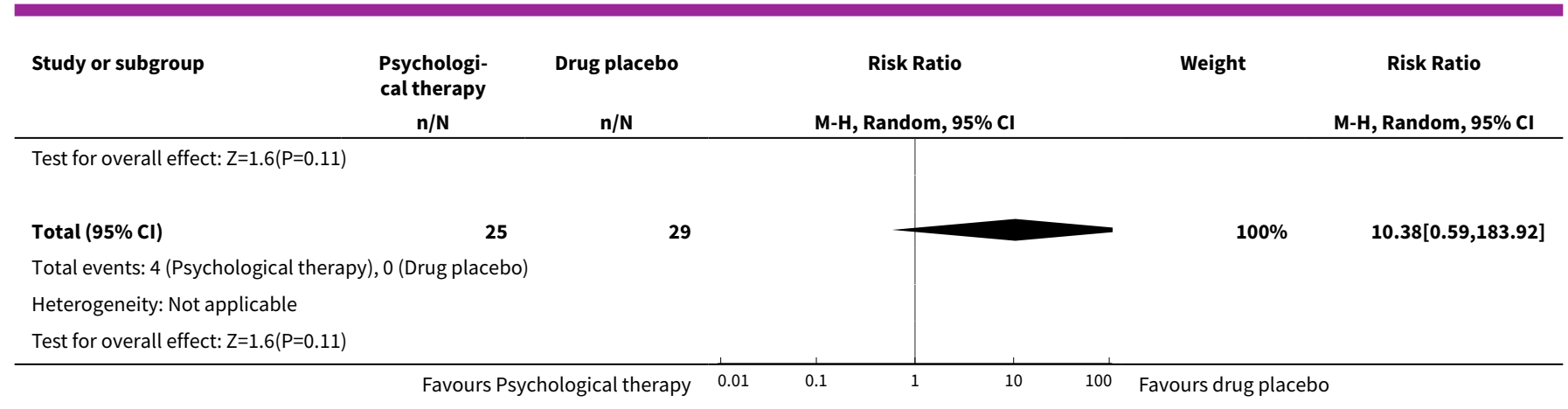

Comparison 3. Antidepressant/psychological therapies combination versus drug placebo

\begin{tabular}{|c|c|c|c|c|}
\hline Outcome or subgroup title & No. of studies & $\begin{array}{l}\text { No. of partici- } \\
\text { pants }\end{array}$ & Statistical method & Effect size \\
\hline 1 Recurrence & 1 & & Risk Ratio $(\mathrm{M}-\mathrm{H}$, Random, 95\% Cl) & Subtotals only \\
\hline 1.1 Recurrence at 12 months & 1 & 54 & Risk Ratio $(\mathrm{M}-\mathrm{H}$, Random, 95\% Cl) & $0.42[0.23,0.77]$ \\
\hline 1.2 Recurrence at 24 months & 1 & 54 & Risk Ratio (M-H, Random, 95\% Cl) & $0.39[0.21,0.70]$ \\
\hline 1.3 Recurrence at 36 months & 1 & 54 & Risk Ratio (M-H, Random, 95\% Cl) & $0.36[0.20,0.64]$ \\
\hline $\begin{array}{l}\text { 1.4 Recurrence at final fol- } \\
\text { low-up }\end{array}$ & 1 & 54 & Risk Ratio $(\mathrm{M}-\mathrm{H}$, Random, 95\% Cl) & $0.36[0.20,0.64]$ \\
\hline 2 Death & 1 & & Risk Ratio (M-H, Random, 95\% Cl) & Subtotals only \\
\hline 2.1 Death at 12 months & 1 & 54 & Risk Ratio (M-H, Random, 95\% Cl) & $0.0[0.0,0.0]$ \\
\hline 2.2 Death at 24 months & 1 & 54 & Risk Ratio (M-H, Random, 95\% Cl) & $0.0[0.0,0.0]$ \\
\hline 2.3 Death at 36 months & 1 & 54 & Risk Ratio (M-H, Random, 95\% Cl) & $0.0[0.0,0.0]$ \\
\hline 2.4 Death at final follow-up & 1 & 54 & Risk Ratio (M-H, Random, 95\% Cl) & $0.0[0.0,0.0]$ \\
\hline $\begin{array}{l}3 \text { Overall drop-out rates (ex- } \\
\text { cluding deaths) }\end{array}$ & 1 & 54 & Risk Ratio (M-H, Random, 95\% Cl) & $8.08[0.44,149.20]$ \\
\hline
\end{tabular}

Analysis 3.1. Comparison 3 Antidepressant/psychological therapies combination versus drug placebo, Outcome 1 Recurrence.

\begin{tabular}{|c|c|c|c|c|c|}
\hline Study or subgroup & $\begin{array}{c}\text { Combination } \\
n / N\end{array}$ & $\begin{array}{c}\text { Placebo } \\
\mathbf{n} / \mathbf{N}\end{array}$ & $\begin{array}{c}\text { Risk Ratio } \\
\text { M-H, Random, } 95 \% \mathrm{CI}\end{array}$ & Weight & $\begin{array}{c}\text { Risk Ratio } \\
\text { M-H, Random, } 95 \% \text { CI }\end{array}$ \\
\hline \multicolumn{6}{|c|}{ 3.1.1 Recurrence at 12 months } \\
\hline Subtotal $(95 \% \mathrm{Cl})$ & 25 & 29 & & $100 \%$ & $0.42[0.23,0.77]$ \\
\hline \multicolumn{6}{|c|}{ Total events: 8 (Combination), 22 (Placebo) } \\
\hline \multicolumn{6}{|c|}{ Heterogeneity: Tau $^{2}=0 ; \mathrm{Chi}^{2}=0, \mathrm{df}=0(P<0.0001) ; I^{2}=100 \%$} \\
\hline & & combination $\quad 0.01$ & 0.1 & 100 Favours placebo & \\
\hline
\end{tabular}




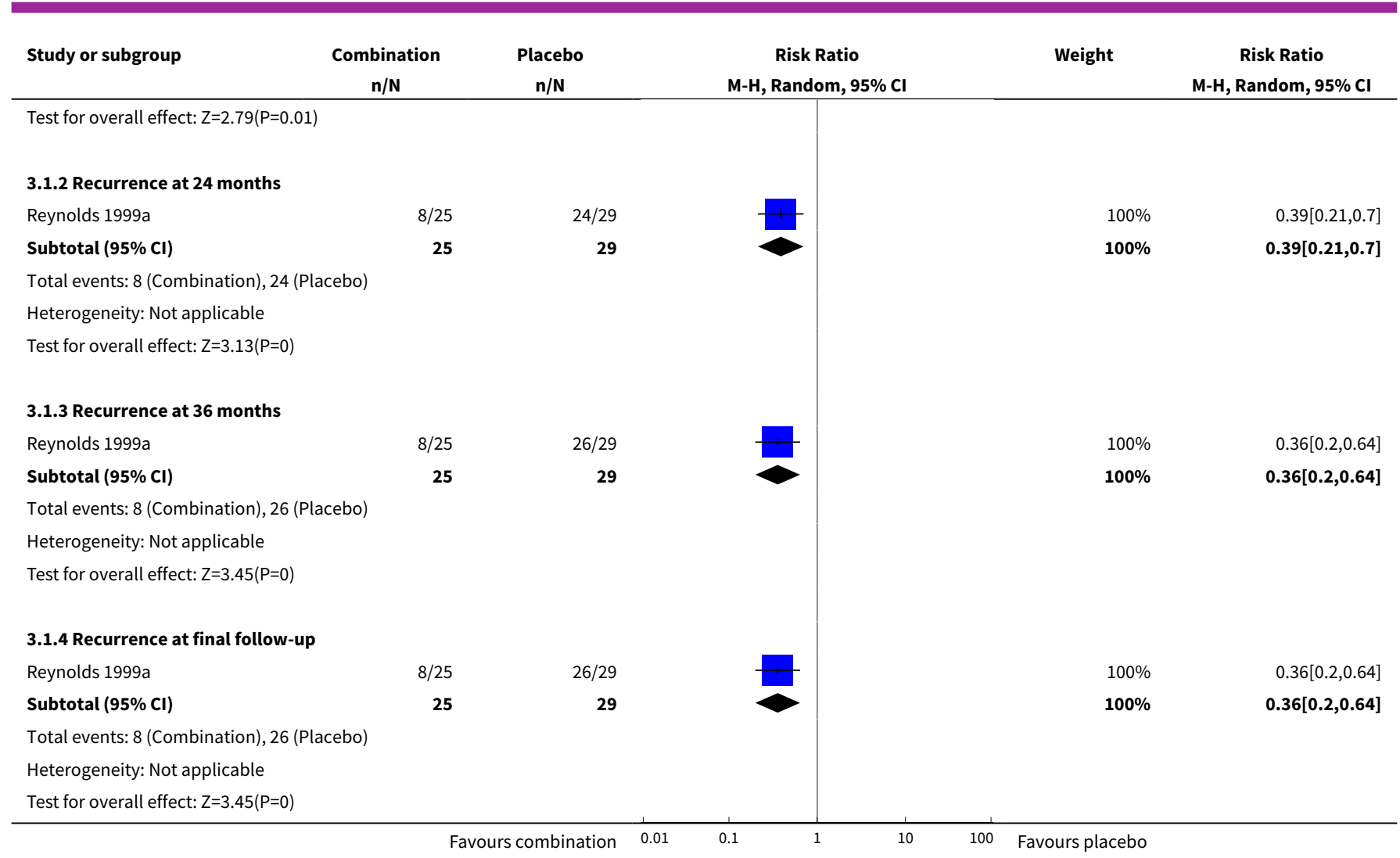

Analysis 3.2. Comparison 3 Antidepressant/psychological therapies combination versus drug placebo, Outcome 2 Death.

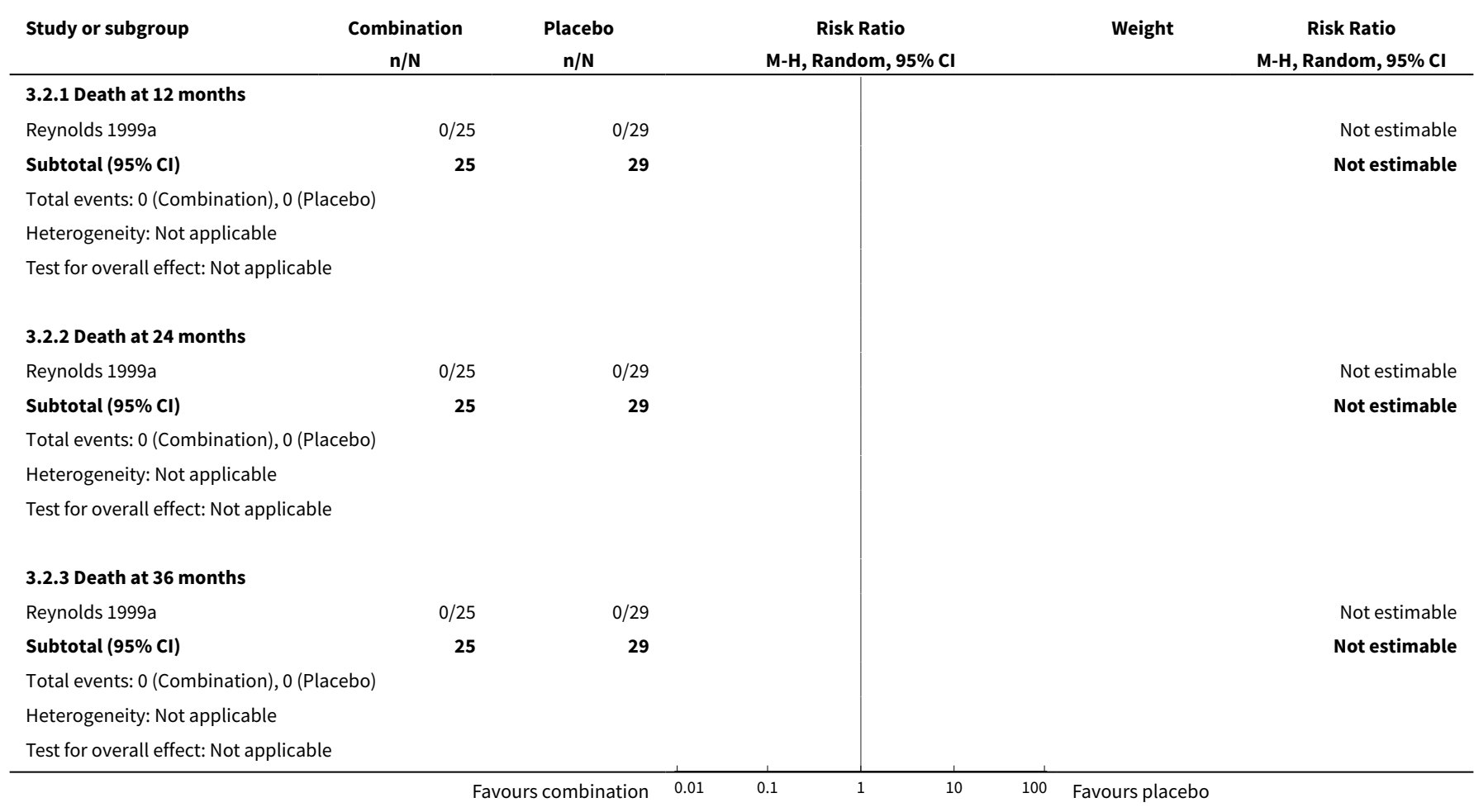




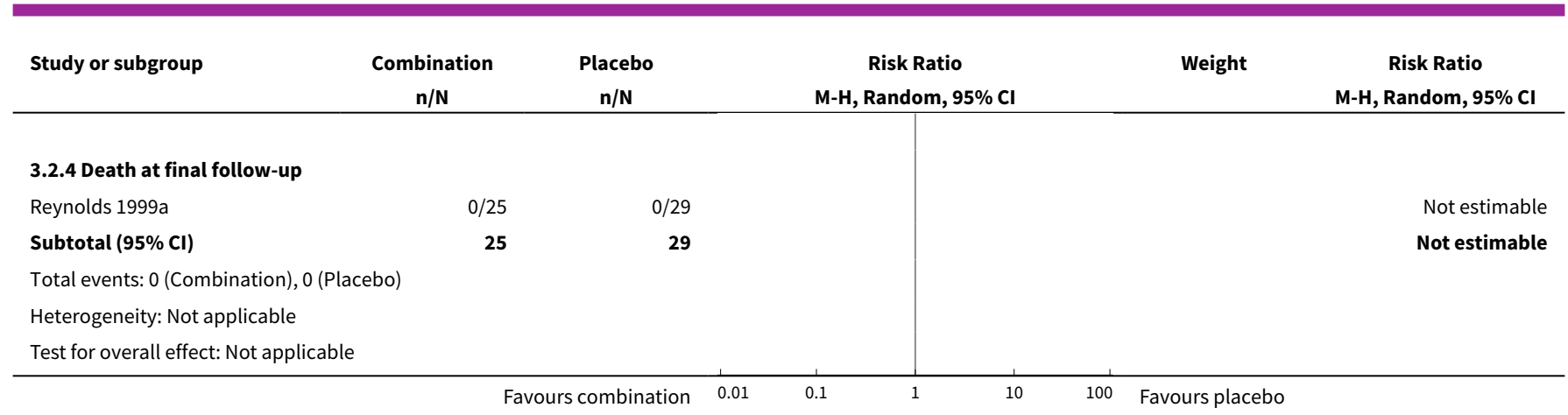

\section{Analysis 3.3. Comparison 3 Antidepressant/psychological therapies combination versus drug placebo, Outcome 3 Overall drop-out rates (excluding deaths).}

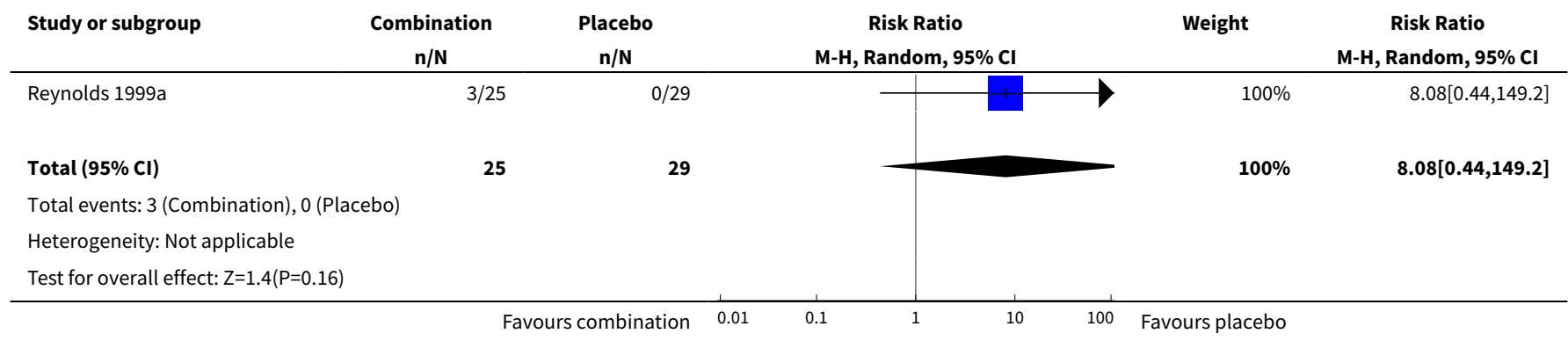

\section{Comparison 4. Antidepressant versus psychological therapies}

\begin{tabular}{|c|c|c|c|c|}
\hline Outcome or subgroup title & No. of studies & $\begin{array}{l}\text { No. of partici- } \\
\text { pants }\end{array}$ & Statistical method & Effect size \\
\hline 1 Recurrence & 1 & & Risk Ratio (M-H, Random, 95\% Cl) & Subtotals only \\
\hline 1.1 Recurrence at 12 months & 1 & 53 & Risk Ratio (M-H, Random, 95\% Cl) & $0.82[0.47,1.46]$ \\
\hline 1.2 Recurrence at 24 months & 1 & 53 & Risk Ratio (M-H, Random, 95\% Cl) & $0.71[0.49,1.04]$ \\
\hline 1.3 Recurrence at 36 months & 1 & 53 & Risk Ratio (M-H, Random, 95\% Cl) & $0.71[0.49,1.04]$ \\
\hline $\begin{array}{l}\text { 1.4 Recurrence at final fol- } \\
\text { low-up }\end{array}$ & 1 & 53 & Risk Ratio (M-H, Random, 95\% Cl) & $0.71[0.49,1.04]$ \\
\hline 2 Death & 1 & & Risk Ratio (M-H, Random, 95\% Cl) & Subtotals only \\
\hline 2.1 Deaths at 12 months & 1 & 53 & Risk Ratio (M-H, Random, 95\% Cl) & $0.0[0.0,0.0]$ \\
\hline 2.2 Deaths at 24 months & 1 & 53 & Risk Ratio (M-H, Random, 95\% Cl) & $0.0[0.0,0.0]$ \\
\hline 2.3 Deaths at 36 months & 1 & 53 & Risk Ratio (M-H, Random, 95\% Cl) & $0.0[0.0,0.0]$ \\
\hline 2.4 Deaths at final outcome & 1 & 53 & Risk Ratio (M-H, Random, 95\% Cl) & $0.0[0.0,0.0]$ \\
\hline
\end{tabular}




\begin{tabular}{lllll}
\hline Outcome or subgroup title & No. of studies & $\begin{array}{l}\text { No. of partici- } \\
\text { pants }\end{array}$ & Statistical method & Effect size \\
\hline $\begin{array}{l}\text { 3 Overall drop-out rates (ex- } \\
\text { cluding deaths) }\end{array}$ & 1 & 53 & Risk Ratio (M-H, Random, 95\% Cl) & $0.89[0.25,3.20]$ \\
\hline 3.1 Drop-outs at 36 months & 1 & 53 & Risk Ratio (M-H, Random, 95\% Cl) & $0.89[0.25,3.20]$ \\
\hline
\end{tabular}

\section{Analysis 4.1. Comparison 4 Antidepressant versus psychological therapies, Outcome 1 Recurrence.}

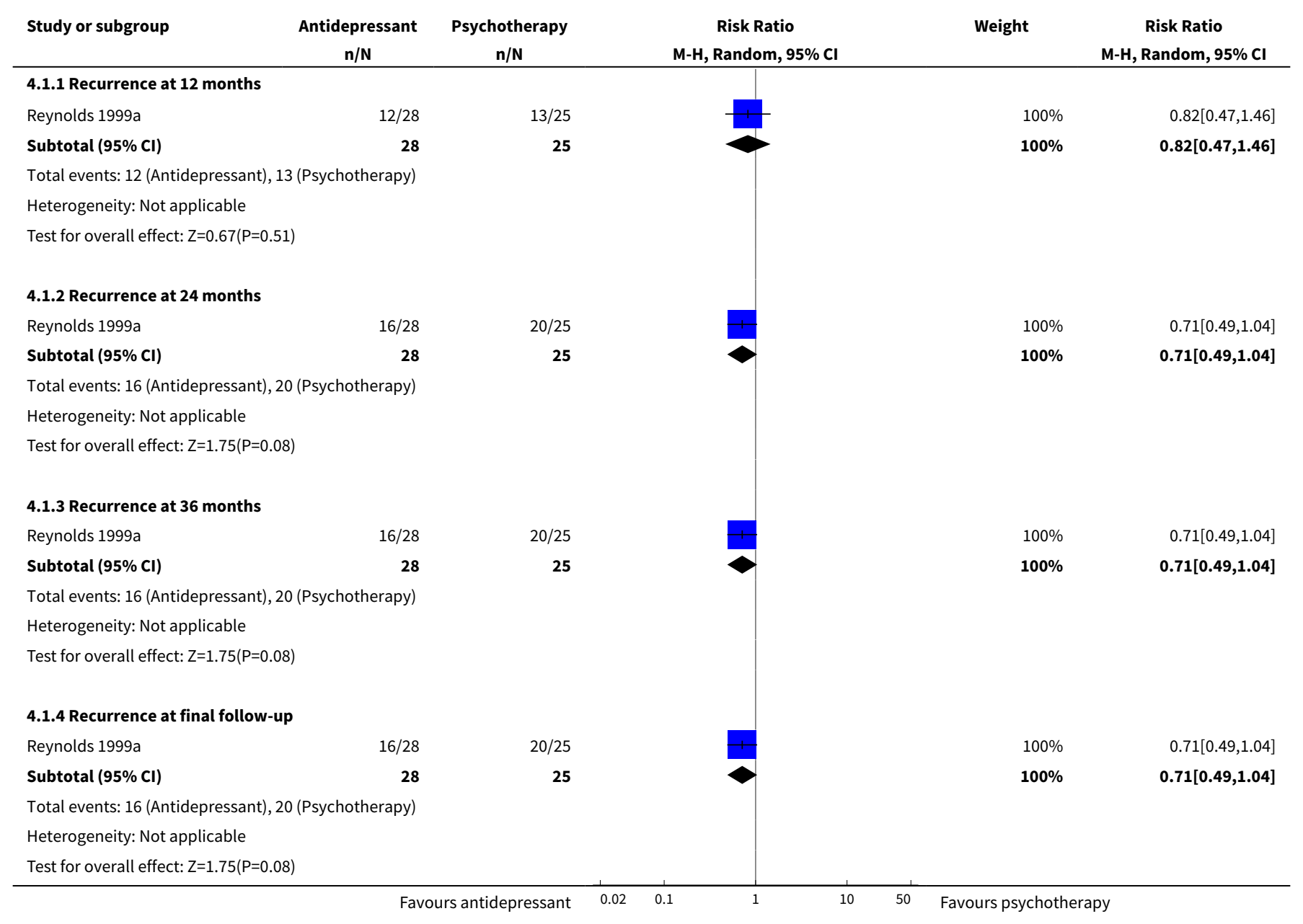

Analysis 4.2. Comparison 4 Antidepressant versus psychological therapies, Outcome 2 Death.

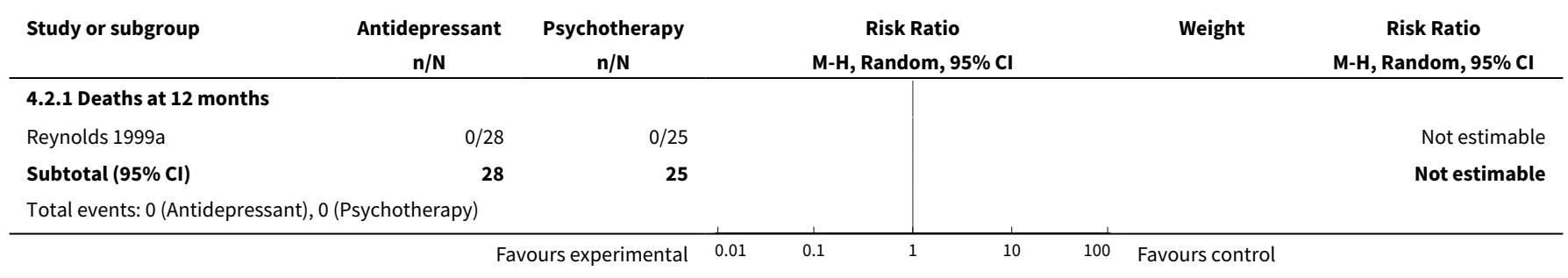




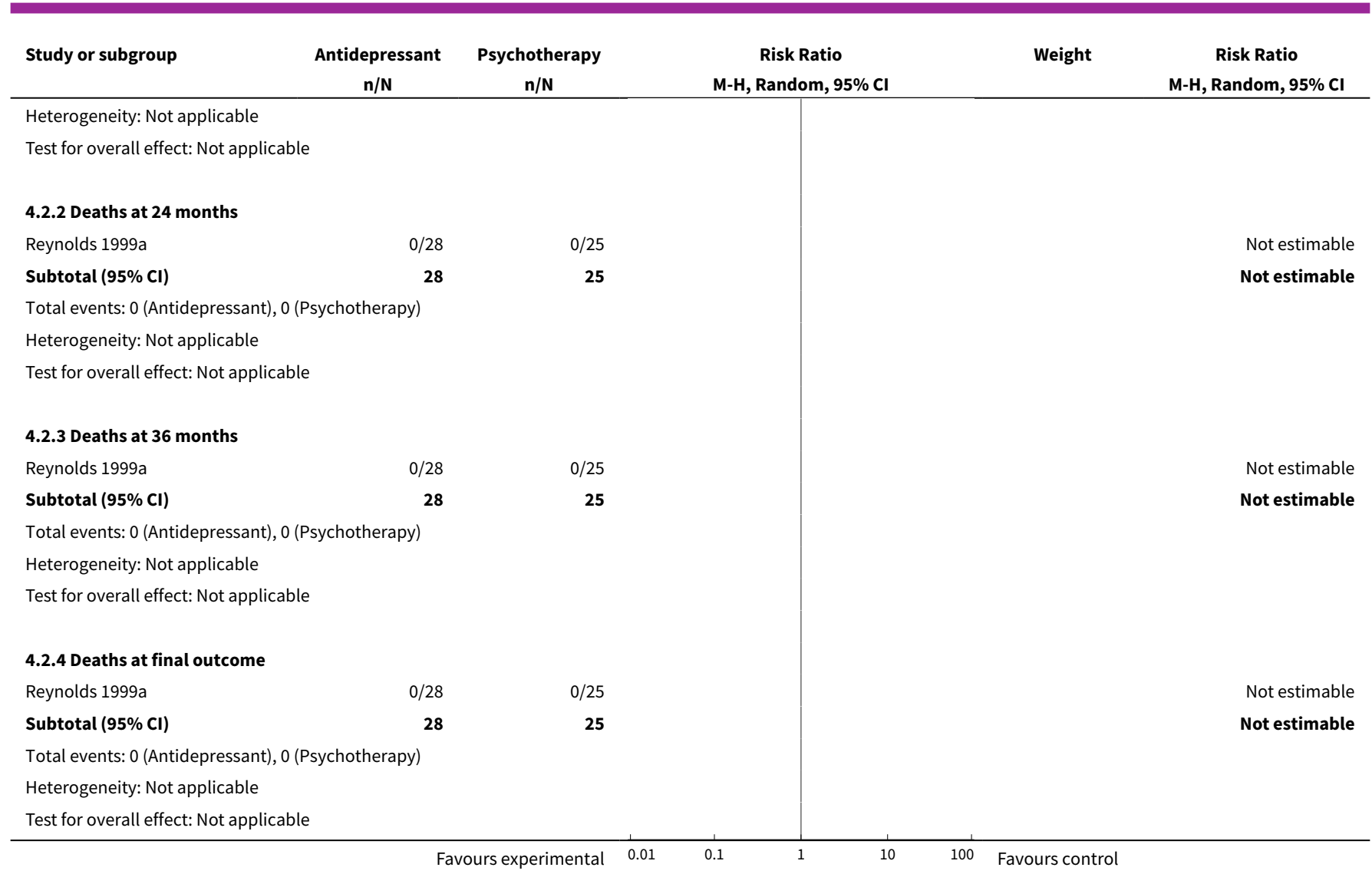

Analysis 4.3. Comparison 4 Antidepressant versus psychological therapies, Outcome 3 Overall drop-out rates (excluding deaths).

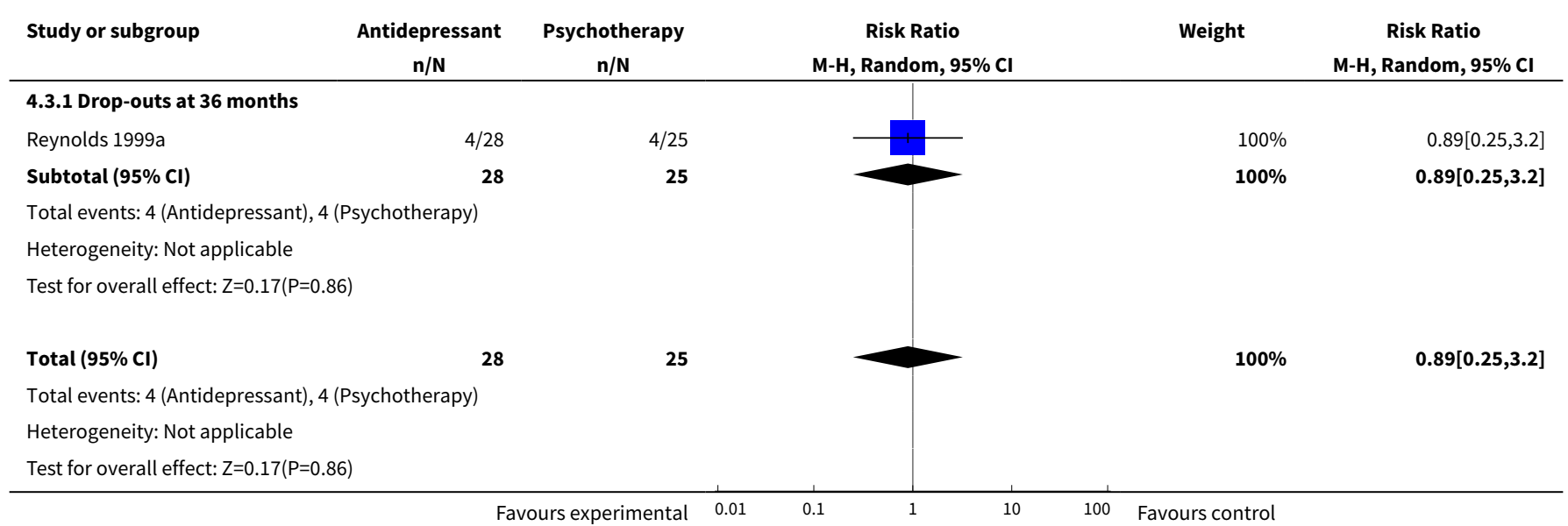


Comparison 5. Antidepressant/psychological therapies combination versus antidepressant alone

\begin{tabular}{|c|c|c|c|c|}
\hline Outcome or subgroup title & No. of studies & $\begin{array}{l}\text { No. of partici- } \\
\text { pants }\end{array}$ & Statistical method & Effect size \\
\hline 1 Recurrence & 2 & & Risk Ratio (M-H, Random, 95\% Cl) & Subtotals only \\
\hline 1.1 Recurrence at 6 months & 1 & 45 & Risk Ratio (M-H, Random, 95\% Cl) & $0.52[0.18,1.49]$ \\
\hline 1.2 Recurrence at 12 months & 2 & 98 & Risk Ratio (M-H, Random, 95\% Cl) & $0.61[0.36,1.03]$ \\
\hline 1.3 Recurrence at 24 months & 1 & 53 & Risk Ratio (M-H, Random, 95\% Cl) & $0.56[0.29,1.08]$ \\
\hline 1.4 Recurrence at 36 months & 1 & 53 & Risk Ratio (M-H, Random, 95\% Cl) & $0.56[0.29,1.08]$ \\
\hline $\begin{array}{l}\text { 1.5 Recurrence at final fol- } \\
\text { low-up }\end{array}$ & 2 & 98 & Risk Ratio (M-H, Random, 95\% Cl) & $0.56[0.34,0.94]$ \\
\hline 2 Death & 2 & & Risk Ratio (M-H, Random, 95\% Cl) & Subtotals only \\
\hline 2.1 Deaths at 6 months & 1 & 45 & Risk Ratio (M-H, Random, 95\% Cl) & $1.05[0.07,15.70]$ \\
\hline 2.2 Deaths at 12 months & 2 & 98 & Risk Ratio (M-H, Random, 95\% Cl) & $1.05[0.07,15.70]$ \\
\hline 2.3 Deaths at 24 months & 1 & 53 & Risk Ratio (M-H, Random, 95\% Cl) & $0.0[0.0,0.0]$ \\
\hline 2.4 Deaths at 36 months & 1 & 53 & Risk Ratio (M-H, Random, 95\% Cl) & $0.0[0.0,0.0]$ \\
\hline 2.5 Deaths at final outcome & 2 & 98 & Risk Ratio (M-H, Random, 95\% Cl) & $1.05[0.07,15.70]$ \\
\hline $\begin{array}{l}3 \text { Overall drop-out rates (ex- } \\
\text { cluding deaths) }\end{array}$ & 2 & & Risk Ratio (M-H, Random, 95\% Cl) & Subtotals only \\
\hline 3.1 Drop-outs at 6 months & 1 & 45 & Risk Ratio (M-H, Random, 95\% Cl) & $0.78[0.20,3.11]$ \\
\hline 3.2 Drop-outs at 12 months & 1 & 45 & Risk Ratio (M-H, Random, 95\% Cl) & $0.78[0.20,3.11]$ \\
\hline 3.3 Drop-outs at 36 months & 1 & 53 & Risk Ratio (M-H, Random, 95\% Cl) & $0.84[0.21,3.39]$ \\
\hline
\end{tabular}

Analysis 5.1. Comparison 5 Antidepressant/psychological therapies combination versus antidepressant alone, Outcome 1 Recurrence.

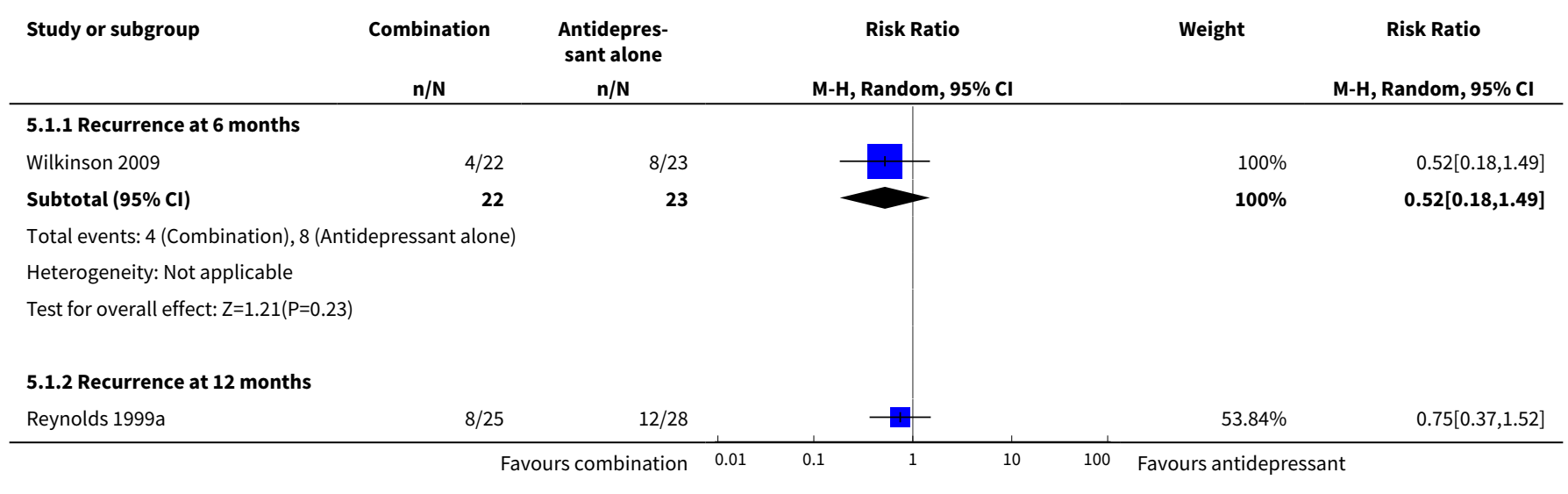




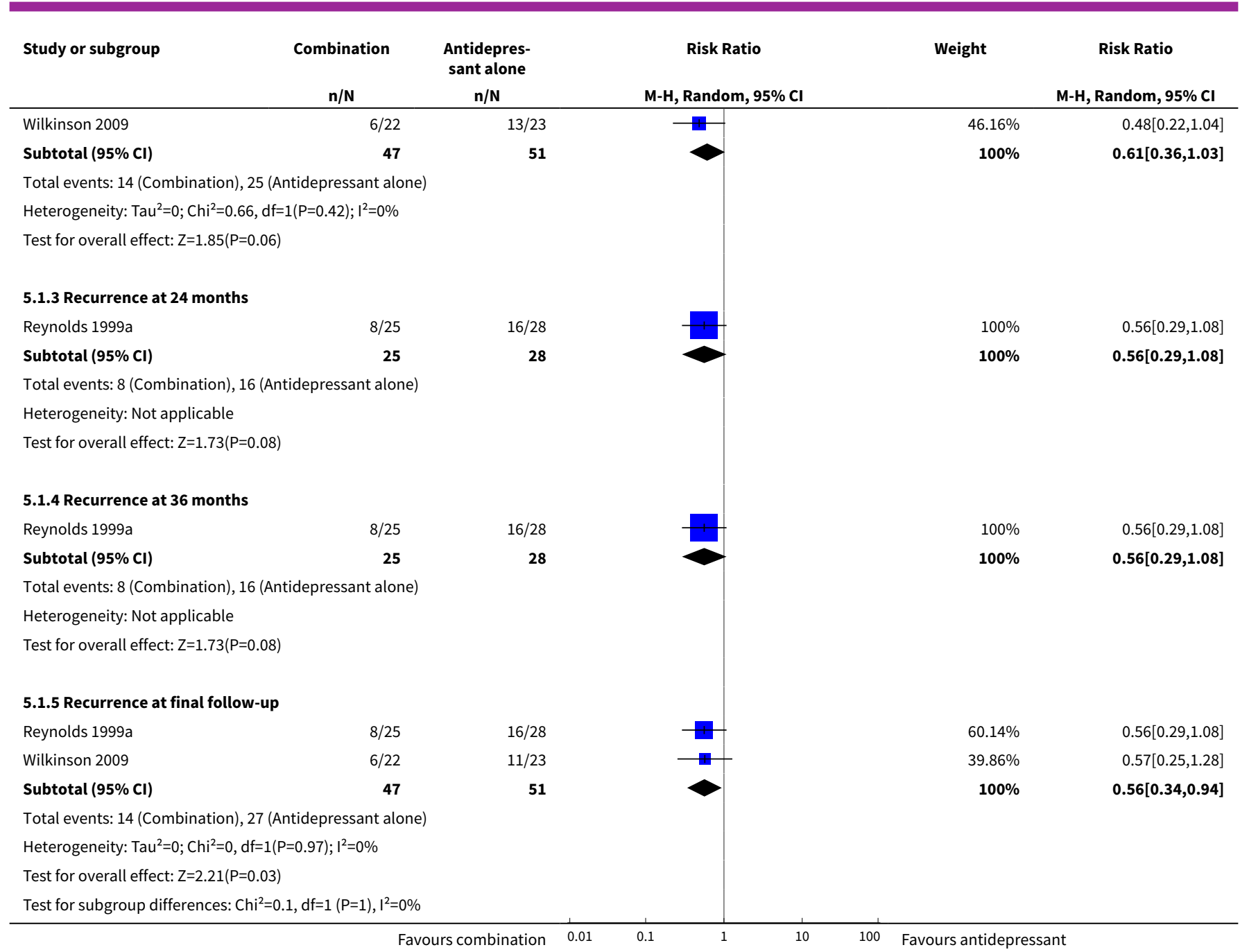

\section{Analysis 5.2. Comparison 5 Antidepressant/psychological therapies} combination versus antidepressant alone, Outcome 2 Death.

\begin{tabular}{|c|c|c|c|c|c|}
\hline \multirow[t]{2}{*}{ Study or subgroup } & Combination & $\begin{array}{l}\text { Antidepres- } \\
\text { sant alone }\end{array}$ & Risk Ratio & \multirow[t]{2}{*}{ Weight } & \multirow{2}{*}{$\begin{array}{c}\text { Risk Ratio } \\
\text { M-H, Random, } 95 \% \mathrm{Cl}\end{array}$} \\
\hline & $\mathrm{n} / \mathrm{N}$ & $\mathrm{n} / \mathrm{N}$ & M-H, Random, $95 \% \mathrm{Cl}$ & & \\
\hline \multicolumn{6}{|c|}{ 5.2.1 Deaths at 6 months } \\
\hline Wilkinson 2009 & $1 / 22$ & $1 / 23$ & & $100 \%$ & $1.05[0.07,15.7]$ \\
\hline Subtotal $(95 \% \mathrm{Cl})$ & 22 & 23 & & $100 \%$ & $1.05[0.07,15.7]$ \\
\hline \multicolumn{6}{|c|}{ Total events: 1 (Combination), 1 (Antidepressant alone) } \\
\hline \multicolumn{6}{|c|}{ Heterogeneity: Not applicable } \\
\hline \multicolumn{6}{|c|}{ Test for overall effect: $Z=0.03(P=0.97)$} \\
\hline \multicolumn{6}{|c|}{ 5.2.2 Deaths at 12 months } \\
\hline Reynolds 1999a & $0 / 25$ & $0 / 28$ & & & Not estimable \\
\hline Wilkinson 2009 & $1 / 22$ & $1 / 23$ & & $100 \%$ & $1.05[0.07,15.7]$ \\
\hline Subtotal $(95 \% \mathrm{CI})$ & 47 & 51 & & $100 \%$ & $1.05[0.07,15.7]$ \\
\hline \multicolumn{6}{|c|}{ Heterogeneity: Not applicable } \\
\hline
\end{tabular}




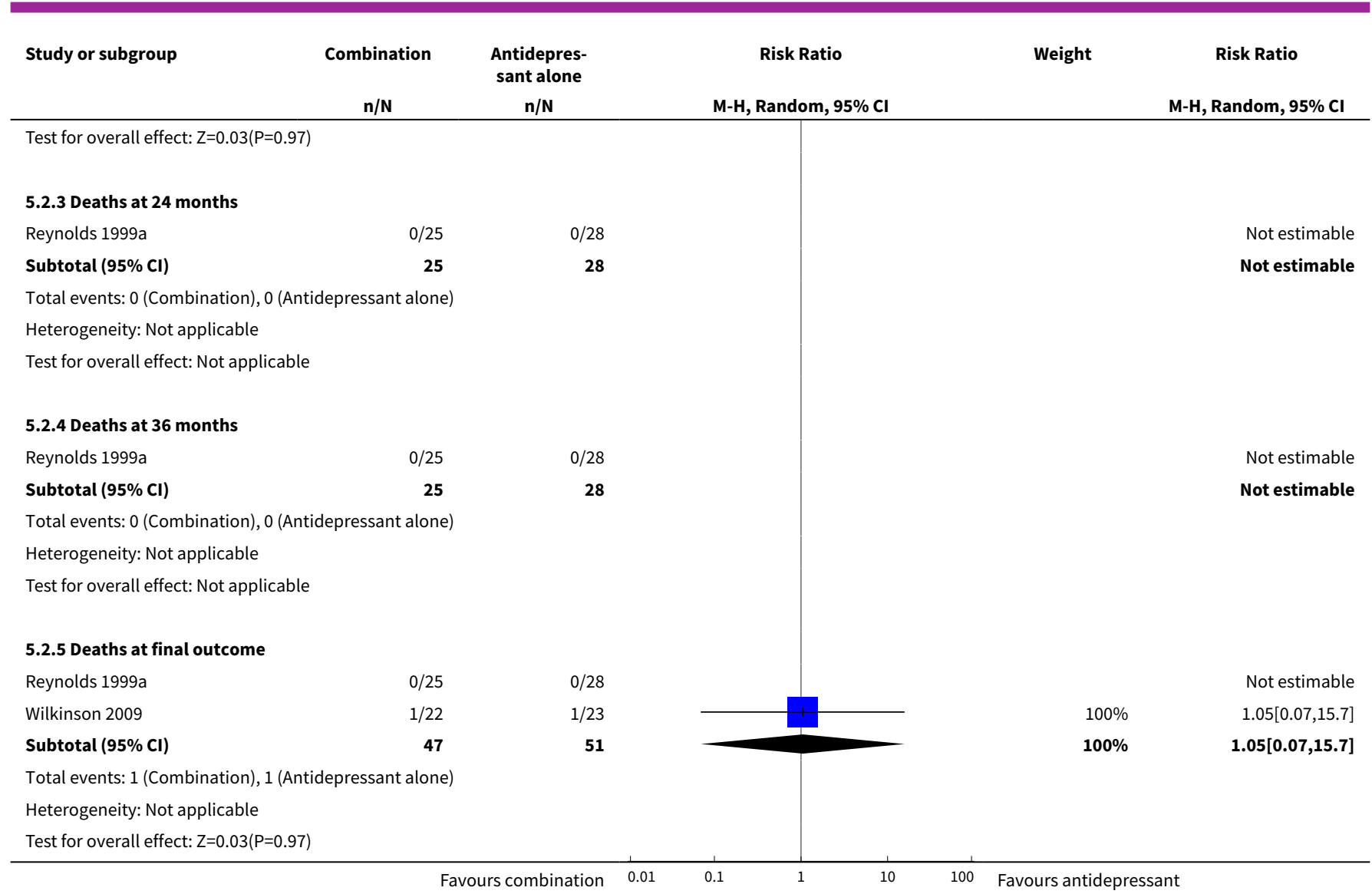

Analysis 5.3. Comparison 5 Antidepressant/psychological therapies combination versus antidepressant alone, Outcome 3 Overall drop-out rates (excluding deaths).

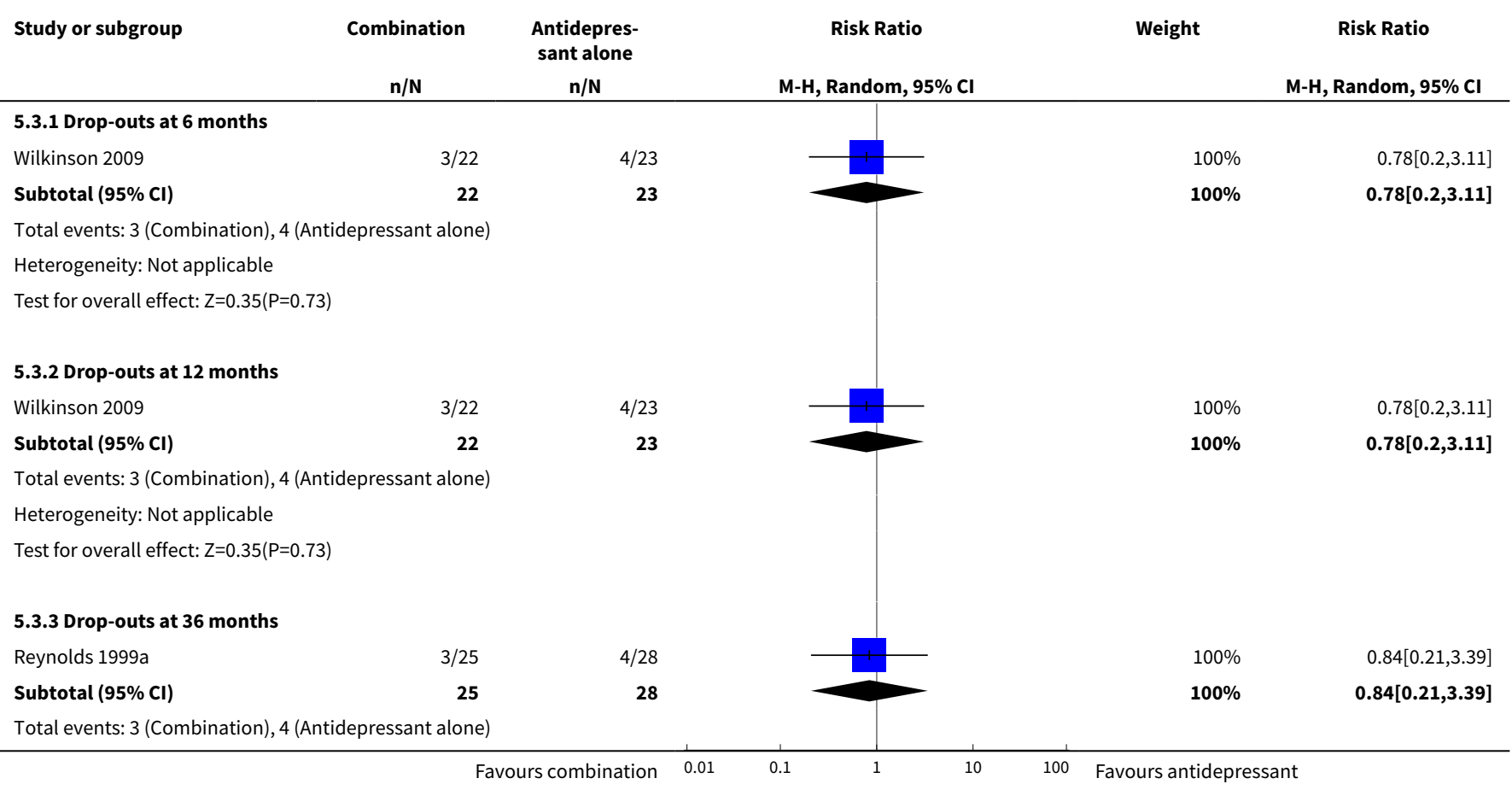




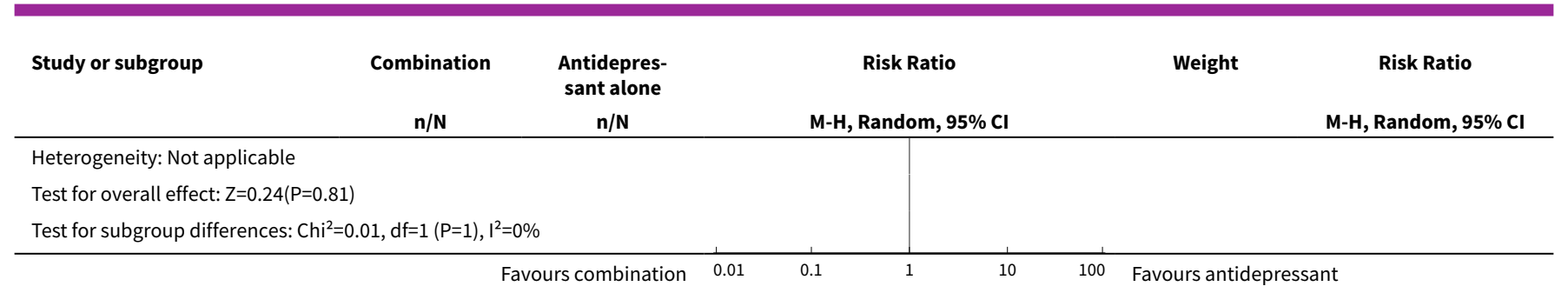

\section{Comparison 6. Antidepressant/psychological therapies combination versus psychological therapies alone}

\begin{tabular}{|c|c|c|c|c|}
\hline Outcome or subgroup title & No. of studies & $\begin{array}{l}\text { No. of partici- } \\
\text { pants }\end{array}$ & Statistical method & Effect size \\
\hline 1 Recurrence & 1 & & Risk Ratio (M-H, Random, 95\% Cl) & Subtotals only \\
\hline 1.1 Recurrence at 12 months & 1 & 50 & Risk Ratio (M-H, Random, 95\% Cl) & $0.62[0.31,1.22]$ \\
\hline 1.2 Recurrence at 24 months & 1 & 50 & Risk Ratio (M-H, Random, 95\% Cl) & $0.4[0.22,0.73]$ \\
\hline 1.3 Recurrence at 36 months & 1 & 50 & Risk Ratio (M-H, Random, 95\% Cl) & $0.4[0.22,0.73]$ \\
\hline $\begin{array}{l}\text { 1.4 Recurrence at final fol- } \\
\text { low-up }\end{array}$ & 1 & 50 & Risk Ratio (M-H, Random, 95\% Cl) & $0.4[0.22,0.73]$ \\
\hline 2 Deaths & 1 & & Risk Ratio (M-H, Random, 95\% Cl) & Subtotals only \\
\hline 2.1 Deaths at 12 months & 1 & 50 & Risk Ratio (M-H, Random, 95\% Cl) & $0.0[0.0,0.0]$ \\
\hline 2.2 Deaths at 24 months & 1 & 50 & Risk Ratio (M-H, Random, 95\% Cl) & $0.0[0.0,0.0]$ \\
\hline 2.3 Deaths at 36 months & 1 & 50 & Risk Ratio (M-H, Random, 95\% Cl) & $0.0[0.0,0.0]$ \\
\hline 2.4 Deaths at final outcome & 1 & 50 & Risk Ratio (M-H, Random, 95\% Cl) & $0.0[0.0,0.0]$ \\
\hline $\begin{array}{l}3 \text { Overall drop-out rates (ex- } \\
\text { cluding deaths) }\end{array}$ & 1 & 54 & Risk Ratio (M-H, Random, 95\% Cl) & $8.08[0.44,149.20]$ \\
\hline 3.1 Drop-outs at 36 months & 1 & 54 & Risk Ratio (M-H, Random, 95\% Cl) & $8.08[0.44,149.20]$ \\
\hline
\end{tabular}

Analysis 6.1. Comparison 6 Antidepressant/psychological therapies combination versus psychological therapies alone, Outcome 1 Recurrence.

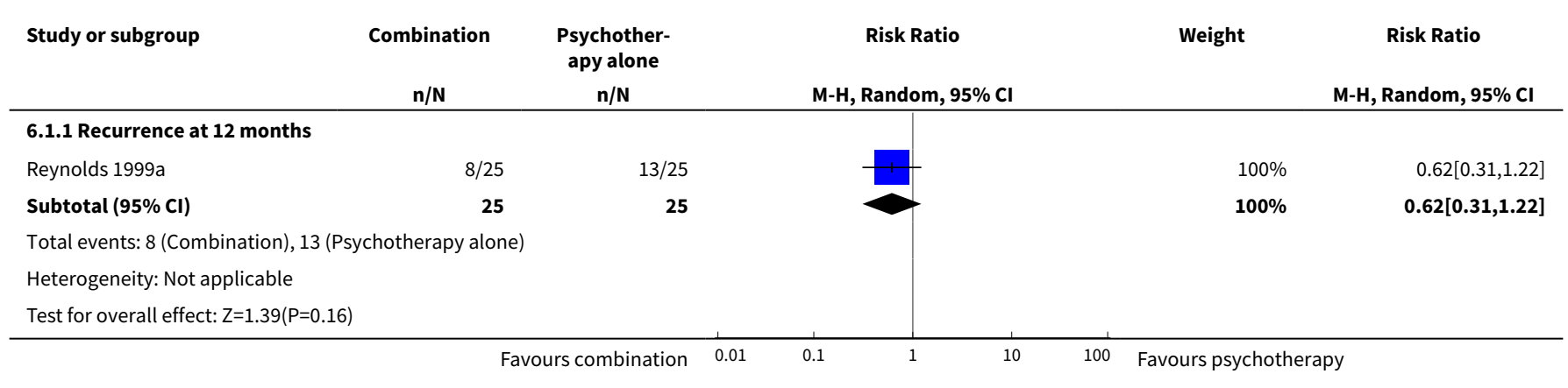




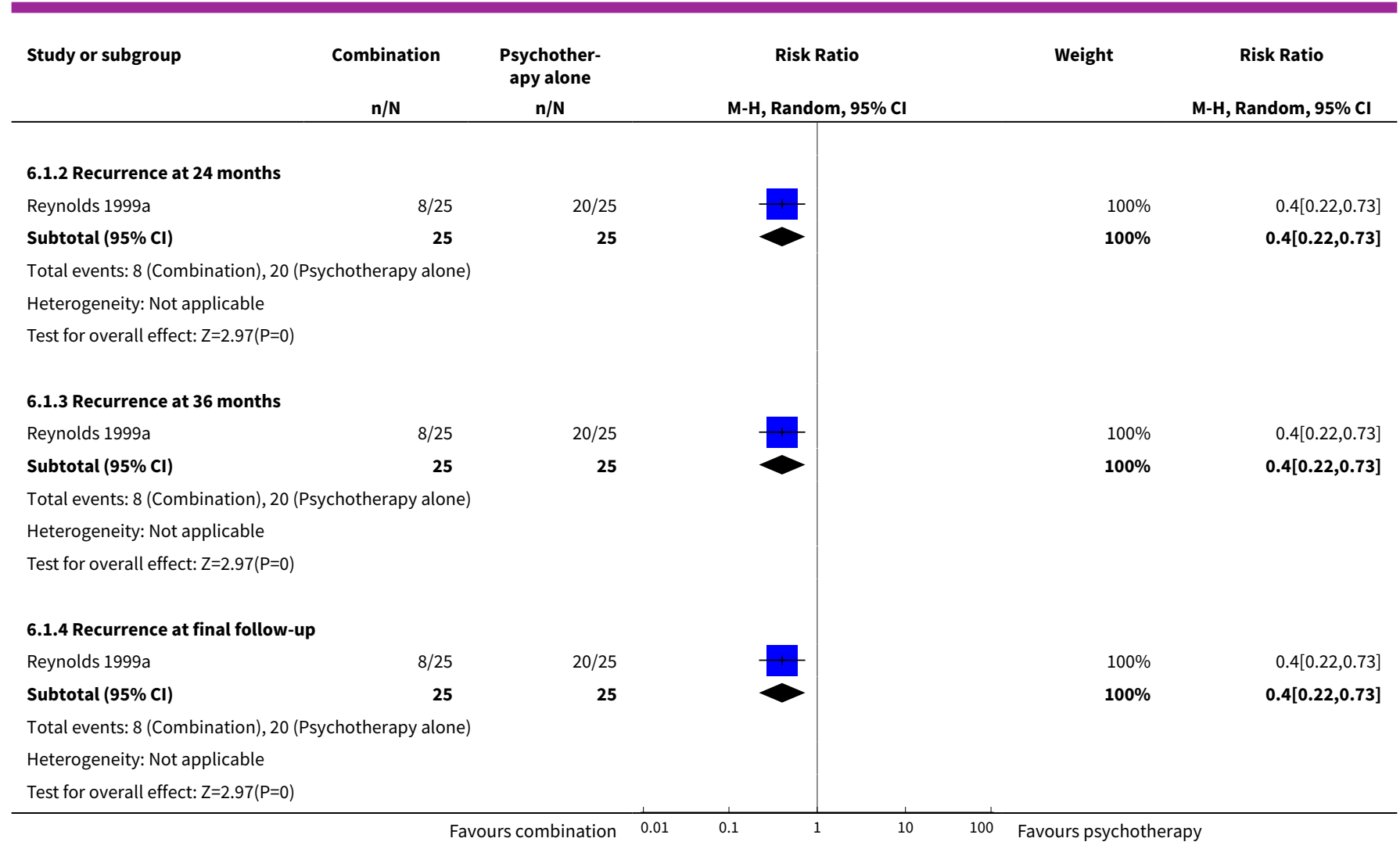

Analysis 6.2. Comparison 6 Antidepressant/psychological therapies combination versus psychological therapies alone, Outcome 2 Deaths.

\begin{tabular}{|c|c|c|c|c|c|}
\hline \multirow[t]{2}{*}{ Study or subgroup } & Combination & $\begin{array}{l}\text { Psychother- } \\
\text { apy alone }\end{array}$ & Risk Ratio & Weight & Risk Ratio \\
\hline & $n / N$ & $n / N$ & M-H, Random, $95 \% \mathrm{Cl}$ & & M-H, Random, 95\% Cl \\
\hline
\end{tabular}

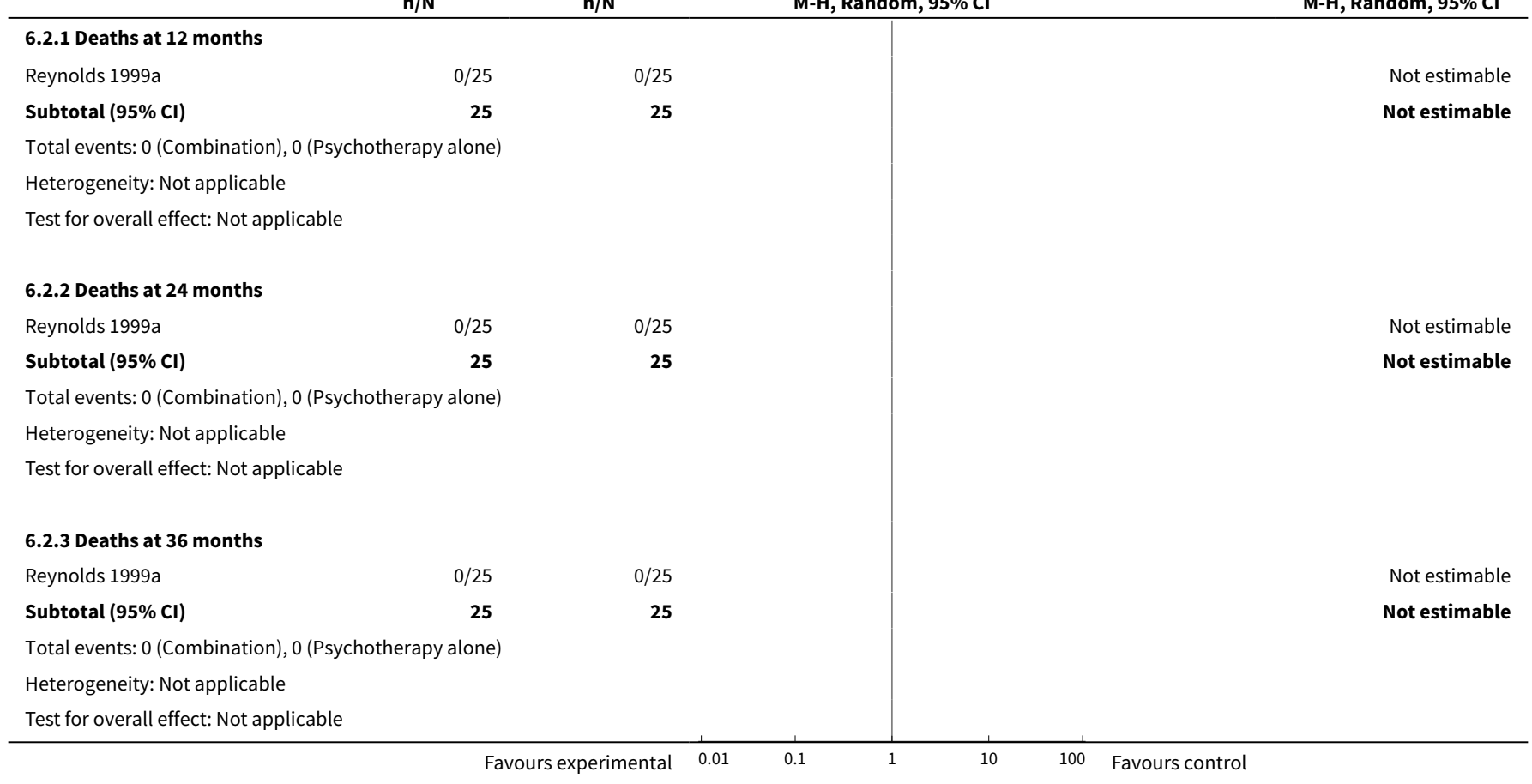




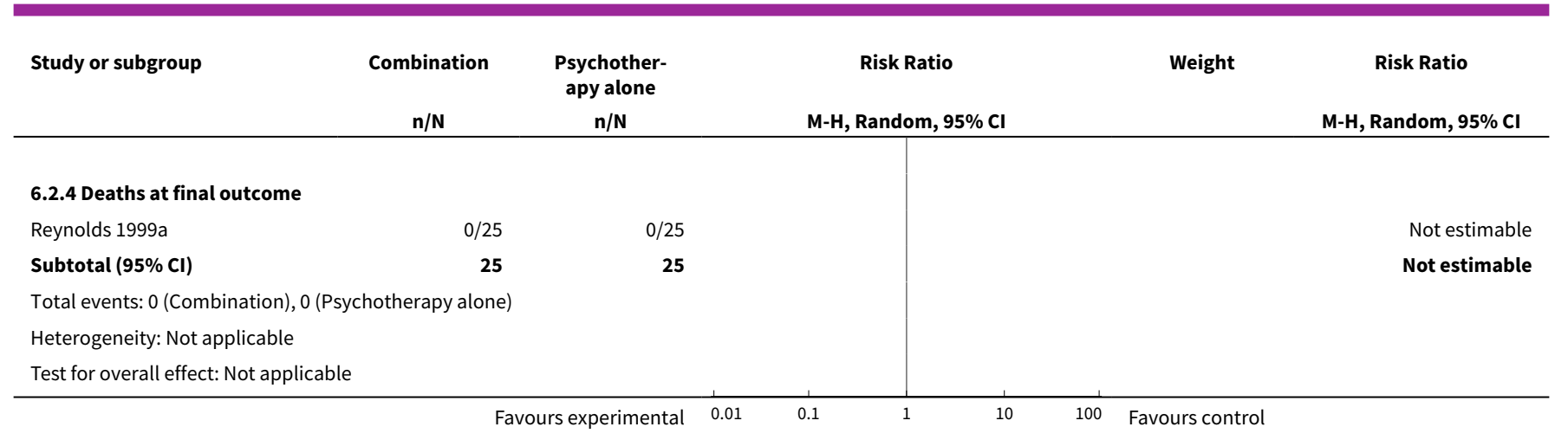

\section{Analysis 6.3. Comparison 6 Antidepressant/psychological therapies combination versus psychological therapies alone, Outcome 3 Overall drop-out rates (excluding deaths).}

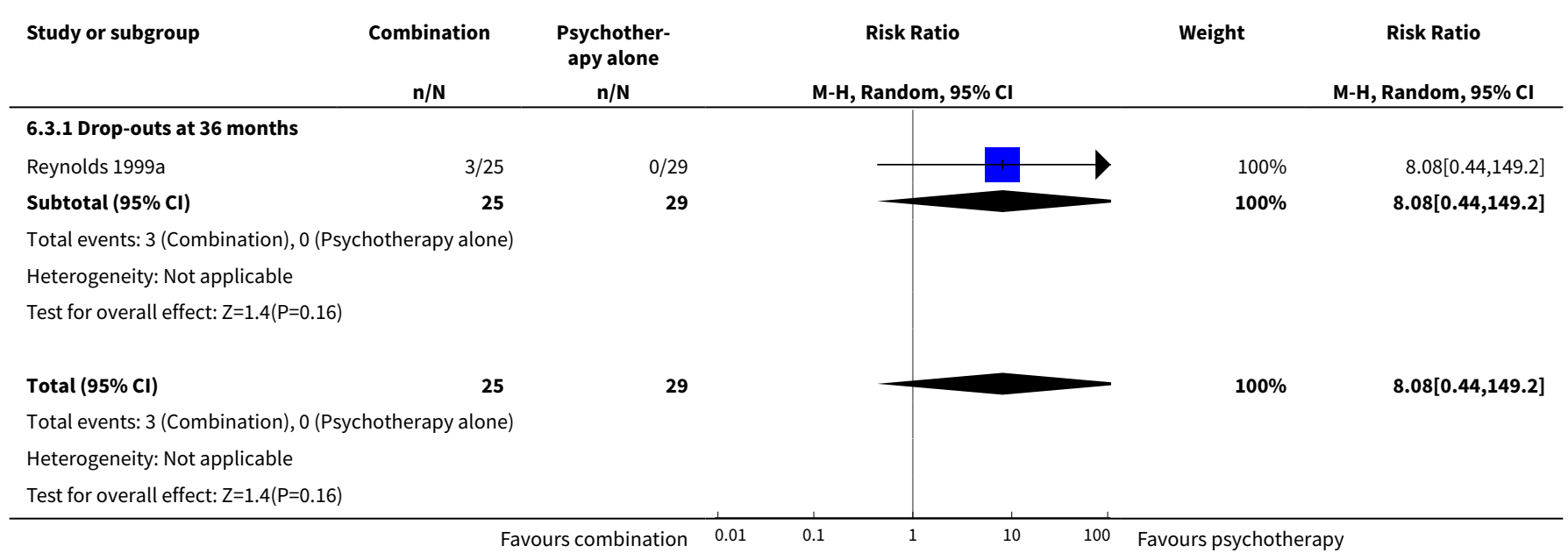

\section{APPENDICES}

\section{Appendix 1. Searches to June 2012}

The Specialised Register of the Cochrane Collaboration Depression, Anxiety and Neurosis Group (CCDAN) was searched using the following terms:

1. The CCDANCTR-Studies Register was searched up to 22 June 2012 using the following terms:

Condition $=\left(\right.$ Depress $^{\star}$ or Dysthymi ${ }^{\star}$ or Adjustment Disorder ${ }^{\star}$ or Mood Disorder ${ }^{\star}$ or "Affective Disorder " or "Affective Symptoms") AND Age Group $=$ Aged AND Free-text $=\left(\right.$ relaps $^{\star}$ or recurre ${ }^{\star}$ or reoccurre ${ }^{\star}$ or remission or prophyla* or ((continuation or maintenance) and (*therap ${ }^{\star}$ or treatment $\left.\left.{ }^{\star}\right)\right)$ or ((long-term or "long term") and (tolera* or treatment ${ }^{\star}$ or ${ }^{\star}$ therap $\left.\left.{ }^{\star}\right)\right)$ )

2. The CCDANCTR-References Register was searched up to 22 June 2012 using a more sensitive set of free-text terms to identify additional untagged/uncoded references:

(Depress* or Dysthymi* or Adjustment Disorder" or Mood Disorder ${ }^{\star}$ or "Affective Disorder*" or "Affective Symptoms") AND (relaps ${ }^{\star}$ or recurre ${ }^{\star}$ or reoccurre ${ }^{\star}$ or remission or prophyla* or ((continuation or maintenance) and ("therap* or treatment $\left.\left.{ }^{\star}\right)\right)$ or ((long-term or "long term") and (tolera* or treatment ${ }^{\star}$ or ${ }^{\star}$ therap $\left.\left.{ }^{\star}\right)\right)$ ) AND ((aging or ageing or elder ${ }^{\star}$ or frail or geriatric ${ }^{\star}$ or seniors or retired or late-life* or "late life" or "later life" or "late adulthood" or "old age" or "old people" or "older people" or "old person*" or "older person*" or "old citizen*" or "older citizen" or "old adult" or "older adult" or "old men" or "older men" or "old women" or "older women" or "old male*" or "older male*" or "old female*" or "older female*" or "old patient*" or "older patient*" or "old population*" or "older population*" or "old old" or old-old or "very old" or "senior citizen*" or pensioner* or retired or retirement or sedentary or "care home" or "nursing home*") or Keywords = (aged or "middle age*") or Abstract = ("60 years" or "65 years" or "70 years" or "75 years" or "80 years" or "85 years" or "90 
years" or "95 years" or "older than 60" or "older than 65" or "older than 70 " or "older than 75 " or "older than 80 " or "older than 85 " or "older than 90 " or "older than 95"))

N.B. The Group changed its name to 'Common Mental Disorders' in 2015 and this register is now known as the CCMDCTR.

\section{Appendix 2. Cochrane Specialised Register - core MEDLINE search strategy}

\section{Core search strategy used to inform the Cochrane Common Mental Disorders Group's specialised register: OVID Medline}

A weekly search alert based on condition + RCT filter only

1. [MeSH Headings]:

eating disorders/ or anorexia nervosa/ or binge-eating disorder/ or bulimia nervosa/ or female athlete triad syndrome/ or pica/ or hyperphagia/ or bulimia/ or self-injurious behavior/ or self mutilation/ or suicide/ or suicidal ideation/ or suicide, attempted/ or mood disorders/ or affective disorders, psychotic/ or bipolar disorder/ or cyclothymic disorder/ or depressive disorder/ or depression, postpartum/ or depressive disorder, major/ or depressive disorder, treatment-resistant/ or dysthymic disorder/ or seasonal affective disorder/ or neurotic disorders/ or depression/ or adjustment disorders/ or exp antidepressive agents/ or anxiety disorders/ or agoraphobia/ or neurocirculatory asthenia/ or obsessive-compulsive disorder/ or obsessive hoarding/ or panic disorder/ or phobic disorders/ or stress disorders, traumatic/ or combat disorders/ or stress disorders, post-traumatic/ or stress disorders, traumatic, acute/ or anxiety/ or anxiety, castration/ or koro/ or anxiety, separation/ or panic/or exp anti-anxiety agents/or somatoform disorders/or body dysmorphic disorders/ or conversion disorder/ or hypochondriasis/ or neurasthenia/ or hysteria/ or munchausen syndrome by proxy/ or munchausen syndrome/ or fatigue syndrome, chronic/ or obsessive behavior/ or compulsive behavior/ or behavior, addictive/ or impulse control disorders/ or firesetting behavior/ or gambling/ or trichotillomania/ or stress, psychological/ or burnout, professional/ or sexual dysfunctions, psychological/ or vaginismus/ or Anhedonia/ or Affective Symptoms/ or *Mental Disorders/

\section{2. [Title/Author Keywords]:}

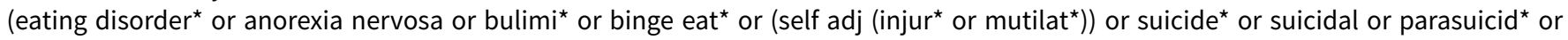
mood disorder ${ }^{\star}$ or affective disorder ${ }^{\star}$ or bipolar i or bipolar ii or (bipolar and (affective or disorder ${ }^{\star}$ )) or mania or manic or cyclothymic ${ }^{\star}$ or depression or depressive or dysthymi* or neurotic or neurosis or adjustment disorder ${ }^{\star}$ or antidepress ${ }^{\star}$ or anxiety disorder ${ }^{\star}$ or agoraphobia or obsess ${ }^{\star}$ or compulsi ${ }^{\star}$ or panic or phobi* or ptsd or posttrauma* or post trauma* or combat or somatoform or somati\#ation or medical* unexplained or body dysmorphi* or conversion disorder or hypochondria* or neurastheni* or hysteria or munchausen or chronic fatigue* or gambling or trichotillomania or vaginismus or anhedoni* or affective symptoms or mental disorder* or mental health).ti,kf.

\section{3. [RCT filter]:}

(controlled clinical trial.pt. or randomized controlled trial.pt. or (randomi\#ed or randomi\#ation).ab,ti. or randomly.ab. or (random* adj3 (administ* or allocat $^{\star}$ or assign* or class $^{\star}$ or control ${ }^{\star}$ or determine or divide $^{\star}$ or distribut ${ }^{\star}$ or expose or fashion or number $^{\star}$ or place $^{\star}$ or recruit* or subsitut ${ }^{\star}$ or treat $\left.{ }^{\star}\right)$ ).ab. or placebo ${ }^{\star}$.ab,ti. or drug therapy.fs. or trial.ab,ti. or groups.ab. or (control ${ }^{\star}$ adj3 (trial $^{\star}$ or study or $^{\star}$ studies)).ab,ti. or ((singl ${ }^{\star}$ or doubl ${ }^{\star}$ or tripl ${ }^{\star}$ or trebl $\left.l^{\star}\right)$ adj3 (blind ${ }^{\star}$ or mask ${ }^{\star}$ or dummy $\left.\left.{ }^{\star}\right)\right)$.mp. or clinical trial, phase ii/ or clinical trial, phase iii/ or clinical trial, phase iv/ or randomized controlled trial/ or pragmatic clinical trial/ or (quasi adj (experimental or random*)).ti,ab. or ((waitlist ${ }^{\star}$ or wait* list $^{\star}$ or treatment as usual or TAU) adj3 (control or group)).ab.)

\section{4. (1 and 2 and 3$)$}

Records are screened for reports of RCTs within the scope of the Cochrane Common Mental Disorders Group. Secondary reports of RCTs are tagged to the appropriate study record.

Similar weekly search alerts are also conducted on OVID EMBASE and PsycINFO, using relevant subject headings (controlled vocabularies) and search syntax, appropriate to each resource.

\section{FEE D B A C K}

\section{Feedback on original review (Continuation and maintenance treatments for depression in older people), 20 April 2015}

\section{Summary}

\section{Effects of interventions}

In this section, comparison of IPT+ADs versus IPT from Reynolds 1999 is missing [AD: antidepressant; IPT: interpersonal therapy].

\section{Comparison 2: Psychological therapies versus TAU [treatment as usual]/waiting list/placebo}

No such comparison exists in Reynolds article. All arms had an active component.

\section{Comparisons 3, 4, 5 (Figures 4, 5, 6)}

Figure 4: events for combination incorrect. Should be 5/25 (table 3 Reynolds).

Figure 5: numbers for recurrence at 12 months do not match Reynolds article (table 3). Numbers in article: 9/25 (IPT) and 8/28. 12 for AD is number of events after 3 years. It is unclear where 13 events for IPT comes from. Numbers for 24 months also do not match Reynolds article. 
Figure 6: Recurrence at 24 months does not match article. Numerator not provided. In article: 5/25 versus 12/28= RR 0.47. Recurrence at 12 months correct.

\section{Reply}

\section{Effects of interventions}

There is no forest plot for IPT+ADs versus IPT as we were asked to cut down the number of plots before publication and this is one that was cut. The findings for comparison 6 are presented in the text of the original review and a forest plot has been added to this update (Figure 9).

\section{Comparison 2: Psychological therapies versus TAU/waiting list/placebo}

We regarded placebo/medication clinic as placebo medication comparison for the purposes of the review and this was accepted by the referees and editors of the original review. This has been addressed in the update (see Potential biases in the review process).

\section{Comparisons 3, 4, 5 (Figures 4, 5, 6)}

The discrepancy between the numbers reported in the included study (Reynolds 1999a) and those reported in our review result from the different handling of drop-outs. The study authors used censoring of drop-outs for their survival analysis, whereas we used the more conservative intention-to-treat for our time-in-point analysis. This approach was discussed in referee feedback prior to publication of the review and is stated in the original review and in this update (see Quality of the evidence).

For the purposes of our review, we assumed all drop-outs to have occurred during year one of follow-up as the study authors were unable to provide us precise timings. See table.

\begin{tabular}{|c|c|c|c|c|c|c|}
\hline Event rate & $\begin{array}{l}\text { AD/IPT } \\
\text { combina- } \\
\text { tion } 12 \\
\text { months }\end{array}$ & $\begin{array}{l}\text { AD (and } \\
\text { MC) } 12 \\
\text { months }\end{array}$ & $\begin{array}{l}\text { IPT (and } \\
\text { placebo) } \\
12 \text { months }\end{array}$ & $\begin{array}{l}\text { AD (and } \\
\text { MC) } 24 \\
\text { months }\end{array}$ & $\begin{array}{l}\text { IPT (and } \\
\text { placebo) } \\
24 \text { months }\end{array}$ & $\begin{array}{l}\text { AD/IPT } \\
\text { combina- } \\
\text { tion } 24 \\
\text { months }\end{array}$ \\
\hline $\begin{array}{l}\text { Event rate from Reynolds et al. 1999a (tab. } \\
\text { 3) (recurrences only) }\end{array}$ & 5 & 8 & 9 & 12 & 16 & 5 \\
\hline $\begin{array}{l}\text { Event rate used in our review (recurrences } \\
+ \text { drop-outs) }\end{array}$ & $5+3$ & $8+4$ & $9+4$ & $12+4$ & $16+4$ & $5+3$ \\
\hline
\end{tabular}

AD: antidepressant; IPT: interpersonal therapy; MC: medication clinic.

For this update, we performed sensitivity analyses using only the study-defined recurrence rates (equivalent to a completer analysis) (see Effects of interventions).

\section{Contributors}

Feedback submitted by: Gerald Gartlehner.

Response submitted by: Philip Wilkinson.

\section{WHAT'S NEW}

\begin{tabular}{lll}
\hline Date & Event & Description \\
\hline 18 August 2016 & $\begin{array}{l}\text { New citation required but conclusions } \\
\text { have not changed }\end{array}$ & $\begin{array}{l}\text { Conclusions support those of the 2012 review (no new studies } \\
\text { added but the quality of the evidence was assessed using GRADE } \\
\text { criteira). }\end{array}$ \\
\hline 26 July 2016 & New search has been performed & $\begin{array}{l}\text { Methodology updated, Summary of Findings table added, new } \\
\text { search conducted (no new studies) }\end{array}$ \\
\hline
\end{tabular}




\section{H IS T O R Y}

Protocol first published: Issue 2, 2007

Review first published: Issue 11, 2012

\begin{tabular}{lll}
\hline Date & Event & Description \\
\hline 22 June 2015 & Feedback has been incorporated & $\begin{array}{l}\text { Feedback incorporated. An update of this review is now sched- } \\
\text { uled to start at the end of 2015. }\end{array}$ \\
\hline 31 October 2008 & Amended & Converted to new review format. \\
\hline
\end{tabular}

\section{CONTRIBUTIONS OFAUTHORS}

Philip Wilkinson conceived the review and provided a clinical perspective.

Philip Wilkinson and Zehanah Izmeth designed and revised the protocol.

Philip Wilkinson and Zehanah Izmeth wrote the review.

\section{DECLARATIONS OF INTEREST}

One author of this review (PW) was an investigator on one of the studies selected by this review. There was no financial implication.

\section{SOURCES OF SUPPORT}

\section{Internal sources}

- Oxford Health NHS Foundation Trust, UK.

- Department of Psychiatry, University of Oxford, UK.

- Oxford University Hospitals NHS Foundation Trust, UK.

\section{External sources}

- No sources of support supplied

\section{DIFFERENCES BETWEEN PROTOCOL AND REVIEW}

After the publication of the original protocol, the method for assessing trial quality in Cochrane reviews changed. Accordingly, contrary to the original protocol, trial quality was assessed using Cochrane's tool for assessing risk of bias (see Methods).

After the publication of the protocol, the use of $\mathrm{I}^{2}$ for assessing clinical heterogeneity changed from a simple threshold of $50 \%$ for significant heterogeneity to graded thresholds.

After publication, we amended the original protocol to included cluster-randomised and cross-over trials.

After the publication of the original protocol, we decided to perform a subgroup analysis of recurrence rates in trials of tricyclic antidepressants.

In line with revised Cochrane Handbook for Systematic Reviews of Interventions guidance, we made recurrence rate a primary outcome for benefit and overall drop-out rate at 12 months a primary outcome for harm. We made relapse and recurrence rates at other six monthly time points and final follow-up secondary outcomes.

\section{INDEX TERMS}

\section{Medical Subject Headings (MeSH)}

Antidepressive Agents [*therapeutic use]; Combined Modality Therapy [methods]; Depression [*therapy]; Maintenance Chemotherapy [methods]; Psychotherapy [ ${ }^{\star}$ methods]; Randomized Controlled Trials as Topic; Secondary Prevention 


\section{MeSH check words}

Aged; Female; Humans; Male; Middle Aged 